\title{
The Effect of Political Risk on Emerging and Developed Markets
}

by

Muhammad Tahir Suleman

\author{
A thesis \\ submitted to the Victoria University of Wellington \\ in fulfilment of the \\ requirements for the degree of \\ Doctor of Philosophy \\ in Finance. \\ Victoria University of Wellington \\ 2017
}





\section{Acknowledgments}

My Lord forgive and have mercy, for you are the best of those who show mercy! [Quran 23:118]

First of all, thanks to Almighty Allah, who gave me strength to complete my dissertation. I would like to convey my sincere gratitude to my supervisors Dr. John Randal and Dr. Martin Berka. I still remember my first day in New Zealand when John came to welcome me at Wellington Airport and my long journey began. I am really thankful to John for his continuous support and encouragement throughout my doctoral studies. He guided me in improving my programming, modelling and other professional skills. It would not have been possible for me to complete this research work without his dedicated invaluable time. I am very lucky to be one of the students of Dr. Martin Berka; he introduced and guided me to exchange rate dynamics. He always supported my thesis to ensure it was on right direction with his valuable feedback.

I am also grateful to Dr. Toby Daglish for his valuable suggestions regarding personal development skills. I learnt a lot while working with Toby on a joint research project, specifically new techniques and MatLab. I would also like to thank Dr. Brandon Chen for providing me with an opportunity to polish my teaching skills. I also owe special thanks to my co-authors of my other research paper for being patient and open to discussing my research ideas: Dr. Toby Daglish, Dr. Brandon Chen, Dr. Phoung, from Victoria University of Wellington, Professor Rodolfo Cermeno from CIDE, Mexico, and Dr. Hilal Butt from Hanken School of Economics, Finland.

I am very pleased to have amazing and outstanding friends and colleagues who supported and encouraged me throughout this journey. I would like to thank Dr. Jawad Mirza, Rio Yonson, Ha Nguyen, Mona Yaghoubi, Xanthia Bollen, Cyril Peter, Rob Nelson, Mick Jays and Dr. Yigit Salgam. I am also thankful to Victoria University of Wellington for awarding me with a Victoria Doctoral Scholarship and my supervisor Dr. John Randal for supporting my application. Sincere appreciation to the administrative staff at the School of Economics and Finance. Support from the library staff is also acknowledged.

I want to express my deepest gratitude though my words are insufficient, to my sweet, loving and great parents, Mr. \& Mrs. Muhammad Suleman, 
who taught me the first words to speak, the alphabet to write, and the first step to take, and by virtue of whose prayers I have been able to reach this position and whose hands are always raised for prayer, for my well being, even at this time. I am highly indebted to my brother Amir Suleman for his support and encouragement. A special thanks to my extended family, my in-laws, for their unconditional support and prayers. I acknowledge the cooperation and support of my wife Sumera Saeed Akhtar for her patience and courage during some stressful periods in this journey. Thank you so much for supporting me throughout this long journey and feeding me with delicious food. I have no words to explain your love, commitment and compromises. I dedicate my work to my daughter; she has brightened up my life with her smiles. 


\section{Abstract}

This thesis consists of three substantive chapters $(3,4,5)$ on the impact of political risk on equity and exchange rate returns and their volatilities.

Chapter 3 proposes a framework for predicting market returns and volatility using changes in the country's political risk. We identify the appropriate lag to to calculate changes over, and how the changes should be included in mean and volatility equations. The level of aggregation of political risk variable is also examined. Analysing 47 emerging and 21 developed markets, we find predictive power primarily for volatility of emerging markets, and recommended use of three political risk components which suitably capture important dimensions of political environment.

In the Chapter 4 we empirically examines the impact of political risk on returns and volatility of individual firms and industry portfolios from New Zealand and Pakistan. The data used in the study consist of 184 firms from New Zealand and 202 firms from Pakistan along with country-level political risk data from the ICRG. As in the, we find in Chapter 3 that the impact of political risk is more on volatility than the returns of firms in both markets. As we expect, the impact of political risk is more on Pakistani firms compared to those in New Zealand. Overall, results from the industry portfolios are according to the hypothesis that political risk impact is different across industries (volatility increase for some industries and decrease for few).

Chapter 5 examine the relationship between political risk variables on the nominal exchange rate return and its volatility. We again investigate developed versus developed markets, and also consider three different exchange rate regimes i.e. floating, managed floating and fixed. This is important to examine the link between political risk and exchange rate because there are two sources of political risk one on either side of the exchange rate. In our analysis, we use the political risk spread between the country of interest and the USA. Overall results reveal that emerging markets are more exposed to political risk compared to developed. Further, the impact of political risk variables is more on the floating exchange rate compared to managed floating and fixed exchange rate as might be expected, since intervention in the market will generally reduce to eliminate the influence of alternative factors. We also find strong evidence 
that volatility increases more during a period of high political risk and poor economic conditions for emerging markets. 


\section{Contents}

1 Introduction $\quad 1$

1.1 Political risk and financial markets . . . . . . . . . . . . 1

1.2 Contributions . . . . . . . . . . . . . . . . 3

1.3 Thesis outline . . . . . . . . . . . . . . 5

$\begin{array}{lll}2 & \text { Political risk: definition and properties } & \mathbf{7}\end{array}$

2.1 Introduction . . . . . . . . . . . . . . . . . 7

2.2 International country risk guide $(\mathrm{ICRG}) \quad \ldots \ldots . \ldots$

2.3 Empirical features of ICRG . . . . . . . . . . . . . . 10

2.3.1 Aggregate measure . . . . . . . . . . . . . . . . . . 10

2.3.2 Sub-components . . . . . . . . . . . . . . 20

2.4 Alternative to ICRG . . . . . . . . . . . . . . . . . . . . . . 24

2.4.1 Political events . . . . . . . . . . . . . . . 24

2.4.2 Alternative ratings . . . . . . . . . . . . . . . . 29

2.5 Conclusion . . . . . . . . . . . . . . . . . . . 32

3 Effect of political risk on stock market indices: a univariate analysis 33

3.1 Introduction . . . . . . . . . . . . . . . . . . . . 33

3.2 Literature review . . . . . . . . . . . . . . . . 36

3.3 Data . . . . . . . . . . . . . . . . . . . . 40

3.4 Description of Model . . . . . . . . . . . . . . . . . . . 43

3.5 Results . . . . . . . . . . . . . . . . 45

3.5.1 Appropriate model and lag . . . . . . . . . . . . 45

3.5.2 Political risk exposure from the mean equation . . . . . . 47

3.5.3 Political risk exposure from variance equation . . . . . . 53

3.6 Discussion . . . . . . . . . . . . . . . . . . 57

3.7 Conclusion . . . . . . . . . . . . . . . . . 58

4 Political risk, firm and industry volatility 61

4.1 Introduction . . . . . . . . . . . . . . . . . . 61

4.2 Literature review . . . . . . . . . . . . . . . . . 63

4.3 Data . . . . . . . . . . . . . . . 65 
4.4 Methodology . . . . . . . . . . . . . . . . . 67

4.5 Results . . . . . . . . . . . . . . . . 68

4.5.1 Political risk, firm returns and volatility . . . . . . . 68

4.5.2 Political risk, industry return and volatility . . . . . . . . 70

4.6 Conclusion . . . . . . . . . . . . . . . . . . . . . . 74

5 Effect of political risk on exchange rate return and volatility 77

5.1 Introduction . . . . . . . . . . . . . . . . . . . . 77

5.2 Literature review . . . . . . . . . . . . . . . . . . . . 79

5.3 Data . . . . . . . . . . . . . . . . . 87

5.4 Methodology . . . . . . . . . . . . . . . 90 90

5.4.1 Political risk, exchange rate volatility and economic conditions . . . . . . . . . . . . . . . . . 91

5.4.2 Political risk, economic conditions and risk premia . . . . 91

5.5 Results . . . . . . . . . . . . . . . . . 92

5.5.1 Political risk and exchange rate return . . . . . . . . 92

5.5.2 Political risk and exchange rate volatility . . . . . . . . . 94

5.5.3 Political risk, exchange rate volatility and economic conditions . . . . . . . . . . . . . . . 97

5.5.4 Political risk, economic conditions and risk premia . . . . 99

5.5.5 Robustness check . . . . . . . . . . . . . . . . 99

5.6 Conclusion . . . . . . . . . . . . . . . . 102

6 Conclusions 103

6.1 Conclusions . . . . . . . . . . . . . . . . . . 103

6.2 Future research directions . . . . . . . . . . . . . . 105

$\begin{array}{ll}\text { Appendices } & 107\end{array}$

$\begin{array}{ll}\text { A Model diagnostics } & 109\end{array}$

$\begin{array}{ll}\text { B Robustness checks } & 117\end{array}$

$\begin{array}{ll}\text { Bibliography } & 123\end{array}$ 


\section{1 \\ Introduction}

In this chapter, we briefly discuss the impact of political risk on the financial markets, along with the motivation, research question, and thesis contributions. At the end of the chapter an outline of the rest of the thesis is provided.

\subsection{Political risk and financial markets}

Over the past decades, researchers have identified numerous economic and political factors that can affect stock and foreign exchange markets. Economic factors include changes in interest rate, inflation, gross domestic product, and international trade etc, whereas political risk includes probability of change in the government, internal political conflicts, role of military in politics etc. Authors like Root (1972) consider political risk as an event that causes loss. Brewer (1983) explained political risk as an assortment of risks associated with doing business abroad. According to Fitzpatrick (1983), political risk focuses on adverse government actions but comprises inherent problems, and describes it as processes that change over time. Simon (1982) define political risk as government activities and political events.

In the literature, we find a longstanding relationship between politics and the financial markets. But does political risk, which is based on the uncertainty related to possible government actions and policies, have a direct effect on asset prices? On March 5, 2012, the Wall Street Journal published an article indicating that during presidential election years, the Dow Jones Industrial Average drops in the months preceding the election but is reinstated once the election is over. This would suggest that uncertainty over the outcome of the election has a negative effect on investment, but once it's over, investors start investing again. 
Political uncertainty, the uncertainty related to political events, decisions, and actions, is the result of changes in political policies and government leadership.

Broadly speaking, we find two strands in the literature regarding political risk and its impact on financial markets. The first links the political event with the movements in the prices of stock. Niederhoffer, Gibbs \& Bullock (1970) and Herbst \& Slinkman (1984) link political risk to price movement in stock markets. Empirical literature on stock exchange behaviour has focused on the link between stock prices and political risk (Chan \& John Wei (1996); Fong \& Koh (2002); Beaulieu, Cosset \& Essaddam (2006) ). A large amount of literature has linked political uncertainty with excess volatility in stock markets.

In the literature we have different points of view regarding the definition of political events. Researchers such as Robock (1971) and Kobrin (1979) concentrated on political risk as it changes the investment's overall profitability. Kim \& Mei (2001) examine the relationship between political factors and stock returns for the period of 1989-1993. Using an event-study technique they show that political developments have a significant impact on stock returns. They also show that adding a political variable to the regressions increases these models' explanatory power. Few researchers link the political news to trading activity (See. Chan, Chui \& Kwok (2001); Leblang \& Mukherjee (2005)).

On the other hand, research also associated the political events with the exchange rate movements. Bachman (1992) and Blomberg \& Hess (1997) argued that political events contain useful information for determining the exchange rate. Democratic politics affect the currency market equilibrium especially uncertainty about the electoral outcomes (Freeman, Hays \& Stix (2000); Hays, Freeman \& Nesseth (2003)). Block (2003) concluded that democracy reduced the likelihood of the currency crisis in the emerging markets. Political variables such as an election, also affect the return as well as volatility of exchange rate (Lobo \& Tufte (1998); Siokis \& Kapopoulos (2003); Cermeño, Grier \& Grier (2010)). Liu \& Pauwels (2012) link the exchange rate with the external political pressures and find a significant impact from the USA on the conditional volatility of Renminbi exchange rate.

It is questionable to think that the effect of political events on financial markets can be studied, using an event studies approach as it is not able to capture the effect of political risk on financial markets on a broader spectrum. In fact, event study approaches constrain the scope of the study to a number of political events only. Along with this, the chances of selection bias may also increase where certain political events are preferred over others. However, such methodology is simple and gives straightforward statistical results and the researcher may oversee other important political risk constituents that could equally stimulate equity returns. These drawbacks guide investigators to use different methods in quantifying the impact on the political risk of financial 
market.

The second strand of literature is related to the quantitative political risk measure used by the different rating agencies (e.g., ICRG, BERI, S \& P Rating, Moody's Investment Service and The Economist). These methods of political risk are more appropriate as they contain a continuous rating throughout the year. On the one hand few researchers also used political crisis as a measure of political risk. The initiative was taken by Berkman, Jacobsen \& Lee (2011) by analysing the impact of political crises on the stock market return and volatility. They used the crises data from International Crisis Behavior (ICB) for the period of 1918 to 2006. They found that volatility of the world market increased at the start of an international crisis. Frijns, Tourani-Rad \& Indriawan (2012) found a significant impact of political crisis on stock market integration. Other researchers, such as Huang, $\mathrm{Wu}, \mathrm{Yu} \&$ Zhang (2015a) found a positive and significant link between international political crisis and government bond yields. Huang, Wu, Yu \& Zhang (2015b) reported low dividend pay-outs during political crisis. Most recently researchers created policy uncertainty index based on the news articles and then used that index to analyse the impact on stock market return and volatility(see. Baker, Bloom \& Davis (2013); Brogaard \& Detzel (2015); Brogaard, Dai, Ngo \& Zhang (2015); Caldara \& Iacoviello (2016)).

Researchers such as Salisbury (1992),Howell \& Chaddick (1994) and Hoti \& McAleer (2005) analysed the country risk ratings provided by different organizations and found the International Country Risk Guide to be the most reliable.ll. Researchers used the risk ratings from the International Country Risk Guide (Political, Economic and Financial) analyzing the stock markets returns and found that these ratings have explanatory power to predict the stock market movements (See. Erb, Harvey \& Viskanta (1996); Cosset \& Suret (1995); Bekaert \& Harvey (1997), Bilson, Brailsford \& Hooper (2002);).

\subsection{Contributions}

Chapter 2 discusses what is political risk, how it is defined, the main sources of political risk and how we can quantify it. We also present the descriptive characteristics of political risk from ICRG along with its subcomponents. A brief literature on other measure of political risk is also presented and compared it with the data from ICRG. This is concluded that ICRG meets the needs mainly as it's available on a monthly basis for the majority of the countries and provide detailed variables for political risk.

In Chapter 3 we focuses on extending the current literature investigating which model to use when considering the data from the ICRG. Second, we have constructed three measure of political risk: government action, conflict, and quality of governance. We show that political risk as a composite is too coarse 
to find the impact of political risk at the country level. We also examine the effect of political risk on the volatility of the returns in the international equity markets as most of the previous research is only on returns. Data of forty seven emerging and twenty one developed markets used for the period of January 1984 to December 2013.

We start with the selection of the best model and the best lag for each country on the basis of AIC. We formulate four models, which include lagged political risk variables. We run all four models individually with five different lags $(1,3,6,12,24)$. Once the best model and best lag were identified, we used them to analyse the impact of political risk on the return and volatility of developed and emerging markets. The result revealed that model 4 with Lag 24 is best for the majority of emerging and developed markets. Further, we also conclude that the impact of risk components is more on emerging markets. Overall we find that impact of all the variables is more on volatility as compared to returns.

Chapter 4 empirically examines the impact of political risk on the returns and volatility of individual firms and industries in New Zealand and Pakistan. We extend the current research on the political risk and equity market returns on the firm level to examine which firms and industry are more exposed to political risk. The data used in the study consist of 184 firms in New Zealand and 202 firms in Pakistan. The political risk data is used from ICRG. We find that the impact of political risk is more on volatility than the returns in both markets. However, the impact of the political risk is more on Pakistani firms than those in New Zealand. Further, for the industry portfolios the results reveal that the impact of political risk varies across industries. Some industries are more expose political risk than others.

We examine the relationship between political risk components on the nominal exchange rate return and volatility in Chapter 5. We formulated three political risk components from the political risk index. Then we divided the data into developed and emerging markets to investigate which countries are affected most by political risk. The analysis is separately estimated for the three exchange rate regimes floating, managed floating, and fixed. Additionally, we also examined the relationship between political risk, volatility, and risk premium during bad economic conditions.

Data is used for over 100 emerging and developed markets for the period January 1984 to December 2013. We constructed three variables from exchange rate data exchange rate return, monthly volatility from daily returns and excess returns using one month forward exchange rates. Our results reveal that emerging markets are more exposed to political risk. Further impact of political risk components is more on the floating exchange rate compared to the managed floating and fixed exchange rate returns. One standard deviation increase in 
the political risk spread leads to a decrease in exchange rate returns by $9.7 \%$.

Turning towards the volatility dynamics, we find that both emerging and developed markets' volatility is influenced by all political risk components. However, the size of impact is more on emerging markets. Further, floating exchange rate volatility responds more to political risk components as compared to other two exchange rate regimes. Similar result was obtained when using the economic and financial data from ICRG. Further, we also find strong evidence that volatility increases more during a period of high political uncertainty and worse economic conditions mainly for emerging markets. A weak relationship found when exchange rate risk premium is used.

\subsection{Thesis outline}

The rest of the dissertation is organised as follows ${ }^{1}$ :

Chapter 2 discusses the political risk, and the different ways to quantify it. The empirical properties and statistical analysis of the political risk from international country risk guide is also reported.

Chapter 3 provides the detail about the model and lag selection to analyse the impact of political risk components and composite on the equity markets of the emerging and developed markets using the univariate volatility model.

Chapter 4 investigates the impact of political risk on return and volatility of firms and industry portfolios in Pakistan and New Zealand.

Chapter 5 focuses on the relationship between the political risk, nominal exchange rate and volatility of the exchange rate. Panel regression is used to analyse the impact of political risk on exchange rate return and volatility of over 100 emerging and developed markets.

Chapter 6 concludes the contributions of the thesis.

\footnotetext{
${ }^{1} \mathrm{~A}$ lot of feedback is included in this thesis from my supervisors, and seminar participants and further Chapters 3, 4 and 5 will be submitted for publications with my supervisor. That's why instead of using term "I" and "me", the term "we" and "our" is used throughout the thesis.
} 


\section{2 \\ Political risk: definition and properties}

This chapter discusses political risk, the main sources of political risk and how we can quantify it. We also present the descriptive characteristics of political risk as well as comments.

\subsection{Introduction}

In general, political risk refers to the possibility through which political instability could adversely affect the economic variables such as growth rate, unemployment and investment. Political instability has many dimensions. There are three philosophies related to political risk that have been explained by Hurwitz (1973) and Taylor \& Jodice (1983). The first philosophy links political stability with the level of democracy prevalent in the political system of a country. It is widely accepted that countries with non-democratic systems are more prone to political instability. The second philosophy considers the patterns of change in governments and the way these changes are brought about in countries. The third notion accounts for the extent to which civil and social unrest take place within a country. More specifically to the financial market, Errunza \& Losq (1987) indicate that political risk involves the explicit barriers to capital flows, taxes, expropriation and exchange control.

To the best of our knowledge, there are just three papers, two by Pastor and Veronesi $(2012,2013)$ that address the measurement of political uncertainty theoretically and one which is a theoretical as well as empirical paper on political uncertainty on option markets by Kelly, Pástor \& Veronesi (2016). In the first 
two papers, the authors develop a general equilibrium model of government policy using the price of political risk; however, the models differ in their use of homogenous and heterogenous government policies. In Pástor \& Veronesi (2012) paper, the authors use homogenous policies and find that the model indicates a decrease in stock prices after the announcement of a policy change. The magnitude of this decrease is large if the uncertainty about the government policy is large. Policy changes also increase the volatilities and correlations of stocks, and the jump risk premium, or the jump in stock prices on the date of the policy change announcement should be positive.

It is clear that both developed and emerging markets face political risk. Yet the difference between these two markets lies in the different degrees of severity that this risk poses on the stock markets and its impact on investment portfolios. From the investment perspective, political risk could arise from an unexpected political decision such as change in trade and investment policies by limiting cross-border capital mobility or controlling exchange rate movement. Such political movements can, therefore, create significant risk to an investment portfolio. According to Fitzpatrick (1983), political risk concerns adverse government actions. However, other authors such Simon (1982) point out that it's not only the adverse government action that creates political uncertainty in a country, but also internal, external and social sources. Bilson et al. (2002) describe political risk as the government actions and other domestic factors such as political conflicts, civil war etc which can threaten international as well as domestic investors. Arouri, Jawadi \& Nguyen (2010) conclude that results from every measurement technique deviate and they cannot be significantly extrapolate to other countries.

Risk rating agencies like Standard and Poor's, Moody's, Euromoney, Institutional Investor, Economist Intelligence Unit, and the ICRG analyze qualitative and quantitative information regarding alternative measures of political, economic and financial risk into associated composite risk ratings. These agencies provide ratings that reflect the risk inherent in a country and a reliable method of risk assessment. In the literature we find researchers (e.g., Erb, Harvey \& Viskanta (1995); Diamonte, Liew \& Stevens (1996); Bilson et al. (2002); Kabir Hassan, Maroney, Monir El-Sady \& Telfah (2003)) used these ratings as a proxy of political risk e.g., ICRG and IICCR (Institutional Investor Country Credit Rating). Others have used political news as a proxy of political risk (Kim \& Mei (2001); Fong \& Koh (2002); Beaulieu et al. (2006); Suleman (2012)). However, in this study, we use the political risk provided by the ICRG as it is the most popular quantitative measure of political risk in empirical studies and is the only risk rating agency providing consistent monthly data for a large number of countries.

There is quite a limited list of empirical studies that analyze the impact of 
political risk on equity investment by employing political risk ratings in a time series regression analysis. One of the important interests is the subjectivity of the ratings that are designated by the risk rating agencies. Despite this criticism, it is debatable that the political risk rating approach is able to capture a broader spectrum of political risk than an event studies approach since different risk factors are being studied in the previous approach. There has been a lack of ample research in the area of creating a link between political uncertainty and the financial markets using the political risk rating, particularly on volatility. In the next section, we discuss the features of political risk data from ICRG.

\subsection{International country risk guide (ICRG)}

Political risk is a qualitative measure and for analysing its contribution to financial data, we need to quantify it. A number of nstitutions such as the Bank of America, Business Environment Risk Intelligence, Economist Intelligence Unit, Euromoney, Institutional Investor, Standard and Poor's Rating Group, Political Risk Service Group, Coplin-O'Leary Ratings system and Moody's Investment Service offer country-by-country analysis of political risk. However, few of these agencies or institutes provide quantitative analysis and most of them are on a semi-annual or annual basis. Since January 1984, the ICRG has been compiling economic, financial, political and composite risk ratings for over 90 countries on a monthly basis. As of December 2014, these four risk ratings were available for a total of 140 countries. This study employs political risk indices developed by the ICRG and compiled by the PRGS Group ${ }^{1}$.

According to the ICRG, their risk ratings have been cited by experts at the IMF, World Bank, United Nations, and other international institutions as a standard against which other ratings can be measured. The ICRG has been acclaimed by publications such as Barron's and The Wall Street Journal for the strength of its analysis and rating system. For example, Howell \& Chaddick (1994) find that ICRG indices are more reliable and are able to predict risk better than other major political risk information providers. Hoti (2005) examined the qualitative comparison of the country risk rating system used by seven leading agencies and found that ICRG is the best one to forecast the political, financial and economic risk. Bekaert, Harvey, Lundblad \& Siegel (2014) found that risk ratings from ICRG predict the political events well and that political risk ratings provided by ICRG can be used as an alternative to political events.

We used the data from ICRG in this study for the period of January 1984 to December 2013 depending on the availability of the financial and political

\footnotetext{
${ }^{1}$ The PRS Group, Inc in East Syracuse, New York has published its International Country Risk Guide which has provided financial, political and economic risk ratings for 140 countries since 1984 .
} 
data of the selected countries. ICRG provide four types of indices including political risk index (political risk onwards), economic risk index (economic risk onwards), financial risk index (financial risk onwards) and composite risk index (composite risk onwards). The composite risk is the weighted average of all the three risks (political, economic and financial risk).

Political risk compounds the degree of political uncertainty in a given country and consists of twelve components, whereas financial and economic risk consist of five subcomponents each. The details about components and the weights of each component are presented in Table 2.1. The maximum number of 100 reflect the lowest risk, and a score of zero is the highest risk. However for the better understanding of these ratings we subtract the actual index from 100, so that higher values of the index correspond to higher political risk.

\subsection{Empirical features of ICRG}

\subsubsection{Aggregate measure}

Researchers use the political risk rating from ICRG in diverse ways. Erb et al. (1995), Erb et al. (1996) and Diamonte et al. (1996) classify the rating into four risk categories, very high (0.0-49.5), high (50.0-59.5), moderate (60.0-69.5), low (70-84.5) and very low (85.0-100). However, Cosset \& Suret (1995) classified the countries on a scale from $\mathrm{A}+$ for the least risky to $\mathrm{D}$ - for the most risky. Few used the political risk rating as the monthly change in the political risk index for the selected countries at time $t$. (See Bilson et al. (2002) and Kabir Hassan et al. (2003)). Hoti \& McAleer (2005) and Hoti (2005) consider the ICRG risk ratings as an index and calculate the monthly percentage change in the respective risk ratings. Further, they also computed the volatility for ratings and by the squared deviation of each observation from the respective sample mean.

Figure 2.1 presents the map of average political risk over the period of January 1984 to December 2013 for over 100 countries. Red denotes countries with high political risk (ranging between 40 and 60 on average), yellow with medium political risk (ranging between 25 and 39.5) and green with low political risk (ranging between 7 and 24.5). The countries for which data is not included for empirical analysis are denoted with grey. For the African region the highest political risk countries are Congo, Sudan and Uganda, for Asia Bangladesh, Indonesia and Pakistan, for the Americas Bolivia, Colombia, and Ecuador, and for Europe Russia and Serbia. Most of the developed countries are in green establishing less political risky countries. 
Table 2.1: ICRG indices and their components

\begin{tabular}{|c|c|c|c|}
\hline Component & Points(max) & $\%$ of index & $\%$ of composite risk \\
\hline \multicolumn{4}{|l|}{ Political risk } \\
\hline Government stability & 12 & 12 & 6 \\
\hline Socioeconomic conditions & 12 & 12 & 6 \\
\hline Investment profile & 12 & 12 & 6 \\
\hline Internal conflict & 12 & 12 & 6 \\
\hline External conflict & 12 & 12 & 6 \\
\hline Religious tensions & 6 & 6 & 3 \\
\hline Ethnic tensions & 6 & 6 & 3 \\
\hline Corruption & 6 & 6 & 3 \\
\hline Military in politics & 6 & 6 & 3 \\
\hline Law and order & 6 & 6 & 3 \\
\hline Democratic accountability & 6 & 6 & 3 \\
\hline Bureaucracy quality & 4 & 4 & 2 \\
\hline Total political points & 100 & 100 & 50 \\
\hline \multicolumn{4}{|l|}{ Economic risk } \\
\hline GDP per head & 5 & 10 & 2.5 \\
\hline Real GDP growth & 10 & 20 & 5 \\
\hline Inflation & 10 & 20 & 5 \\
\hline Budget balance as a $\%$ of GDP & 10 & 20 & 5 \\
\hline Current account as a \% of GDP & 15 & 30 & 7.5 \\
\hline Total economic points & 50 & 100 & 25 \\
\hline \multicolumn{4}{|l|}{ Financial risk } \\
\hline Foreign debt as s $\%$ of GDP & 10 & 20 & 5 \\
\hline $\begin{array}{l}\text { Foreign debt service as a } \% \text { of } \\
\text { exports of goods and services }\end{array}$ & 10 & 20 & 5 \\
\hline $\begin{array}{l}\text { Current account as a \% of } \\
\text { exports of goods and services }\end{array}$ & 15 & 30 & 7.5 \\
\hline $\begin{array}{l}\text { Net international liquidity as } \\
\text { months of import cover }\end{array}$ & 5 & 10 & 2.5 \\
\hline Exchange rate stability & 10 & 20 & 5 \\
\hline Total financial points & 50 & 100 & 25 \\
\hline
\end{tabular}




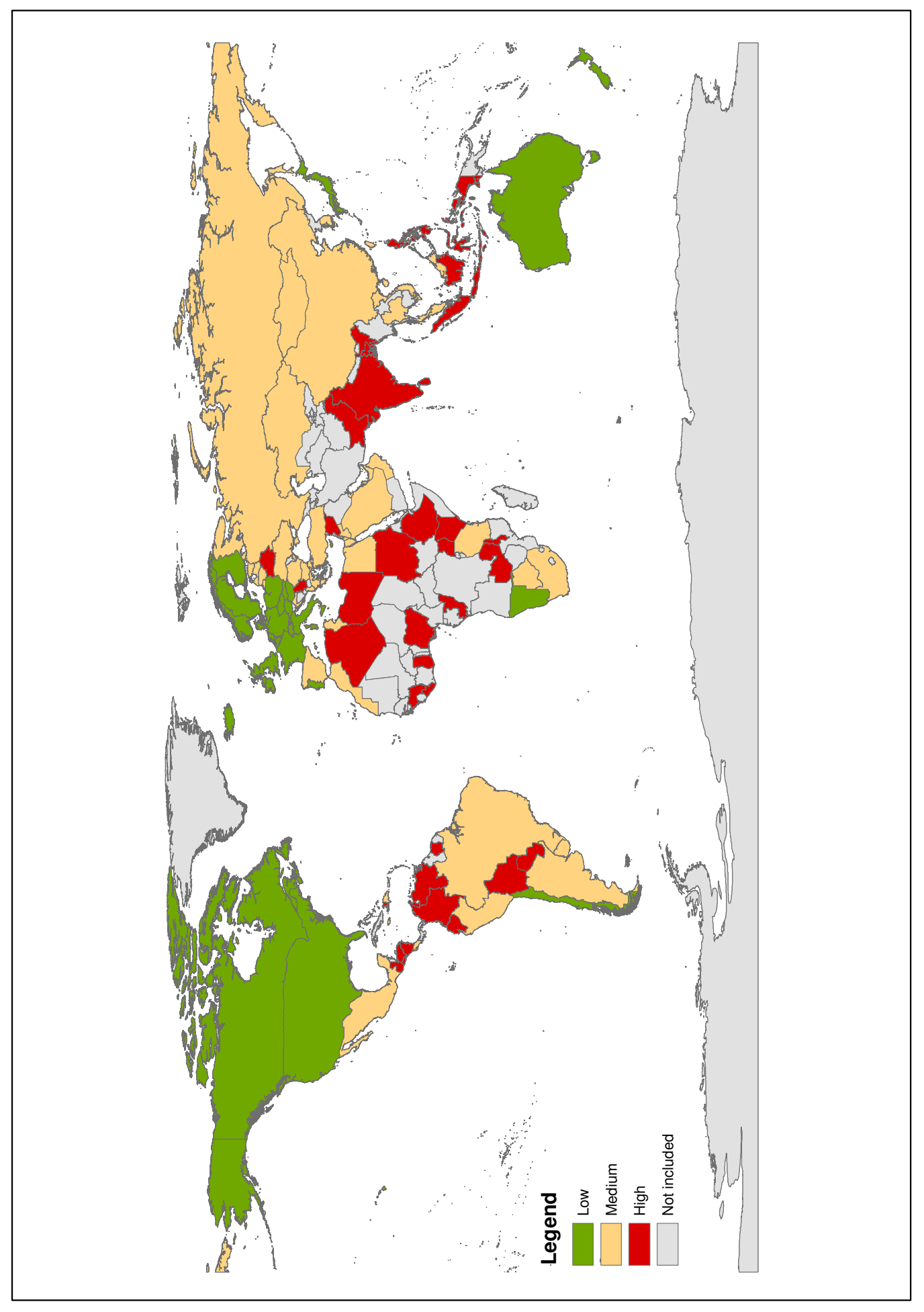

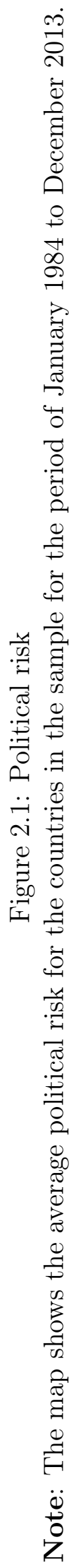


Figures 2.2 to 2.4 present the time series graph for the level of political risk for developed and emerging markets. The higher values correspond to the higher risk in the country and the maximum value for each country is 100 . The graphs show that there is a good sign of variation in the index for the majority of the countries in the sample. However, the developed markets present low variation compared to emerging markets. Only Hong Kong exhibits higher political risk among all the developed markets. As for the emerging markets, on average there is high political risk for the majority of countries such as Bangladesh, Egypt, Indonesia, Nigeria, and Pakistan.

The graphs of monthly change in political risk for the developed and emerging markets are presented in Figures 2.5 to 2.7. We can clearly observe that there are quite a few changes in political risk for the developed markets, even the risk is low for these countries. For many of the emerging markets, the changes are quite big and occur often. This establishes that the emerging markets are more volatile regarding political risk compared to the developed markets.

The preliminary analysis of the monthly change in political risk shows that the emerging markets become less politically risk than the developed markets. The descriptive statistics of monthly political risk for the developed markets are presented in Table 2.2. The average change in the political risk of the developed markets is 0.011 , establishing a minor increase in the political risk in the developed markets. The highest political risk is for Hong Kong of 26 with the standard deviation of 7.6. Finland is the least risky country among the developed markets with an average political risk of 10 and a standard deviation of 4.1. The difference between minimum and maximum of the developed markets is not large except for Hong Kong which is 32, as compared to the emerging markets like Jordan with 42 points. The average political risk for developed markets (16) seems quite low compared to emerging markets where the average is 32. Regarding the variation in political risk, the average standard deviation is 5.2 for emerging markets. However, for the developed it is 4.39.

Table 2.3 presents the statistical properties of political risk from the emerging markets. The average change in political risk is positive (riskier) for four out 

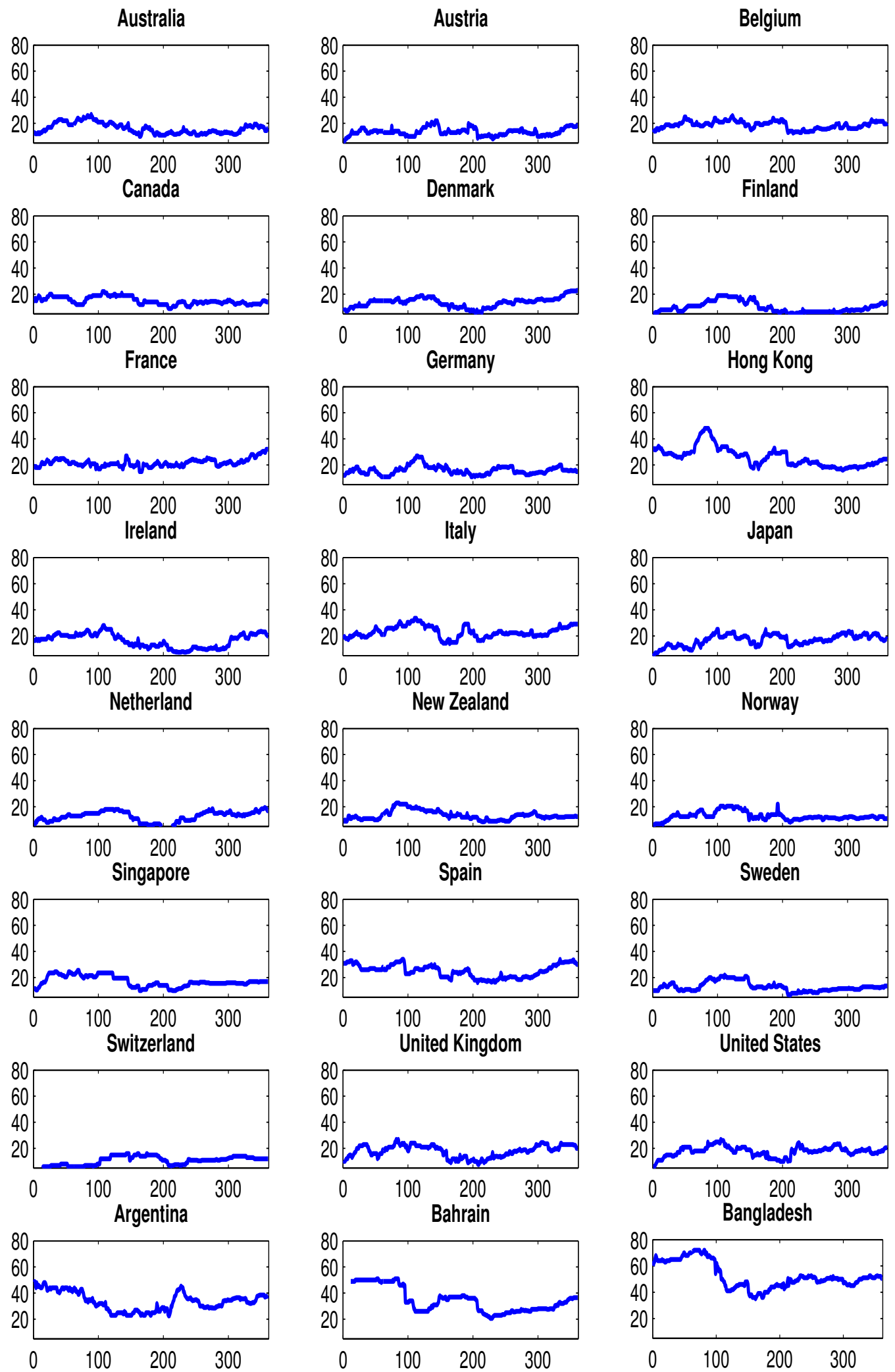

Figure 2.2: Political Risk (Level)

Note: The political risk is on level and varies between 0 and 100, where higher values correspond to higher risk in the country. 

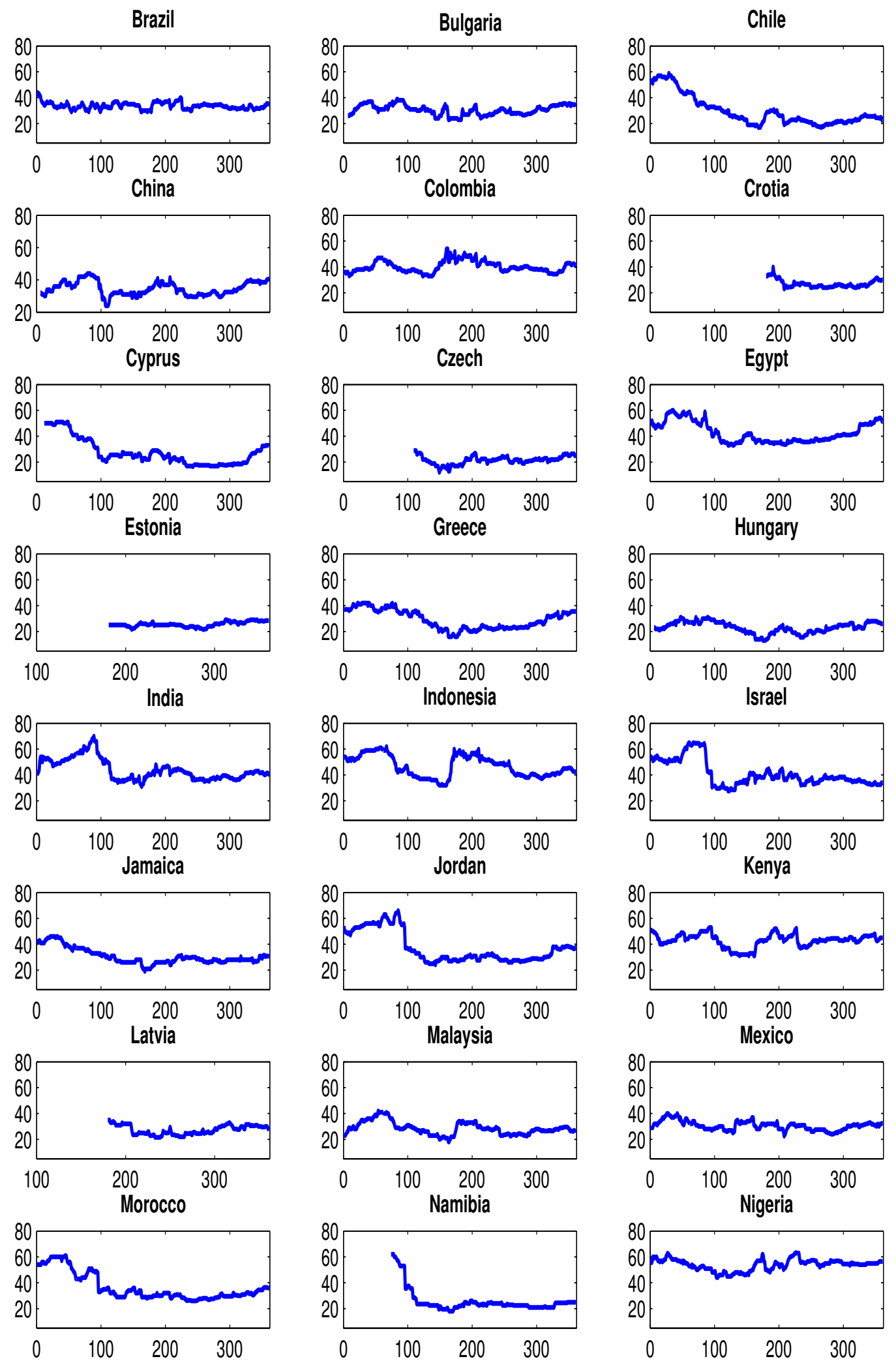

Figure 2.3: Political Risk (Level)

Note: The political risk is on level and varies between 0 and 100, where higher values correspond to higher risk in the country. 

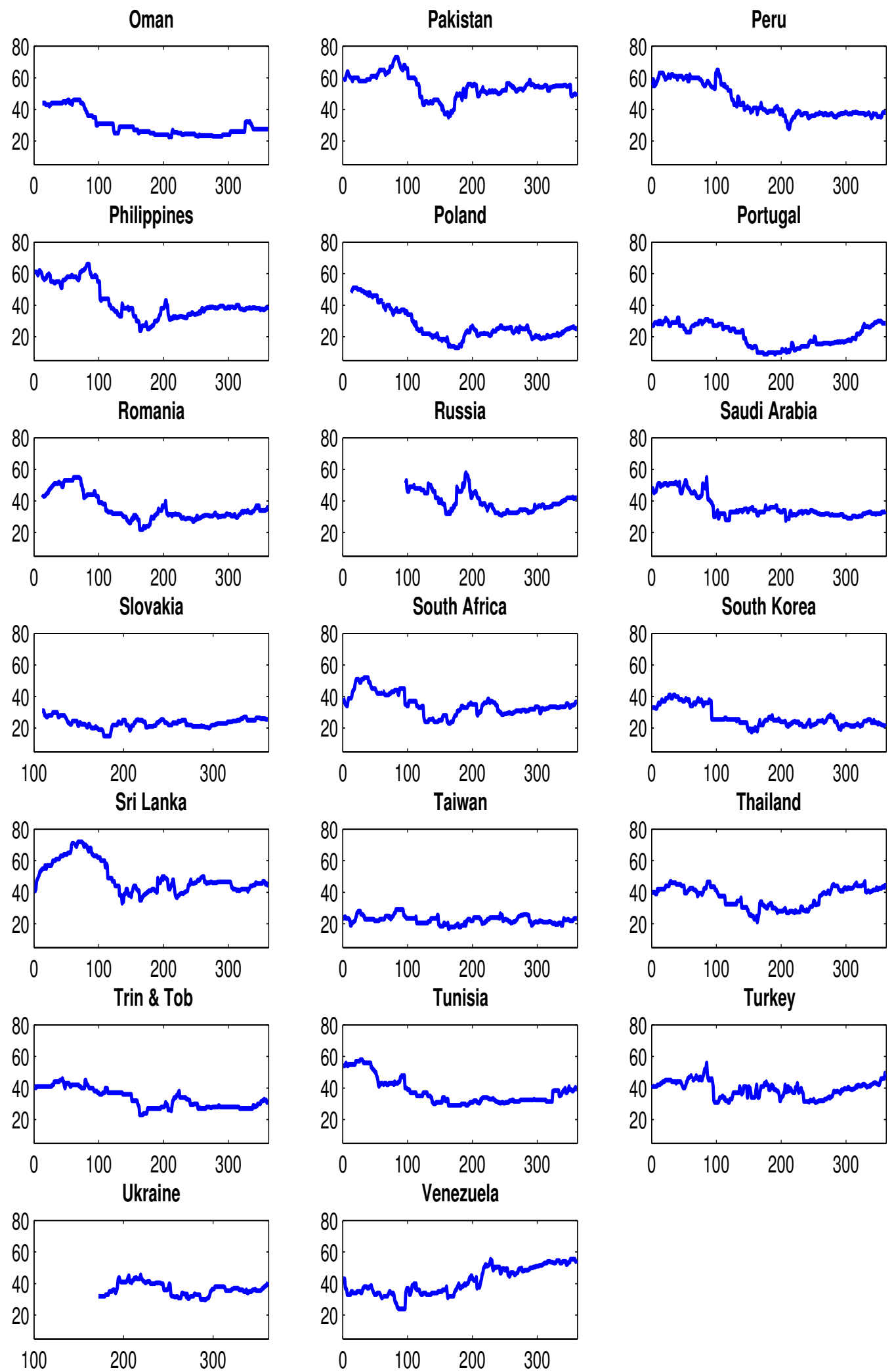

Figure 2.4: Political Risk (Level)

Note: The political risk is on level and varies between 0 and 100, where higher values correspond to higher risk in the country. 

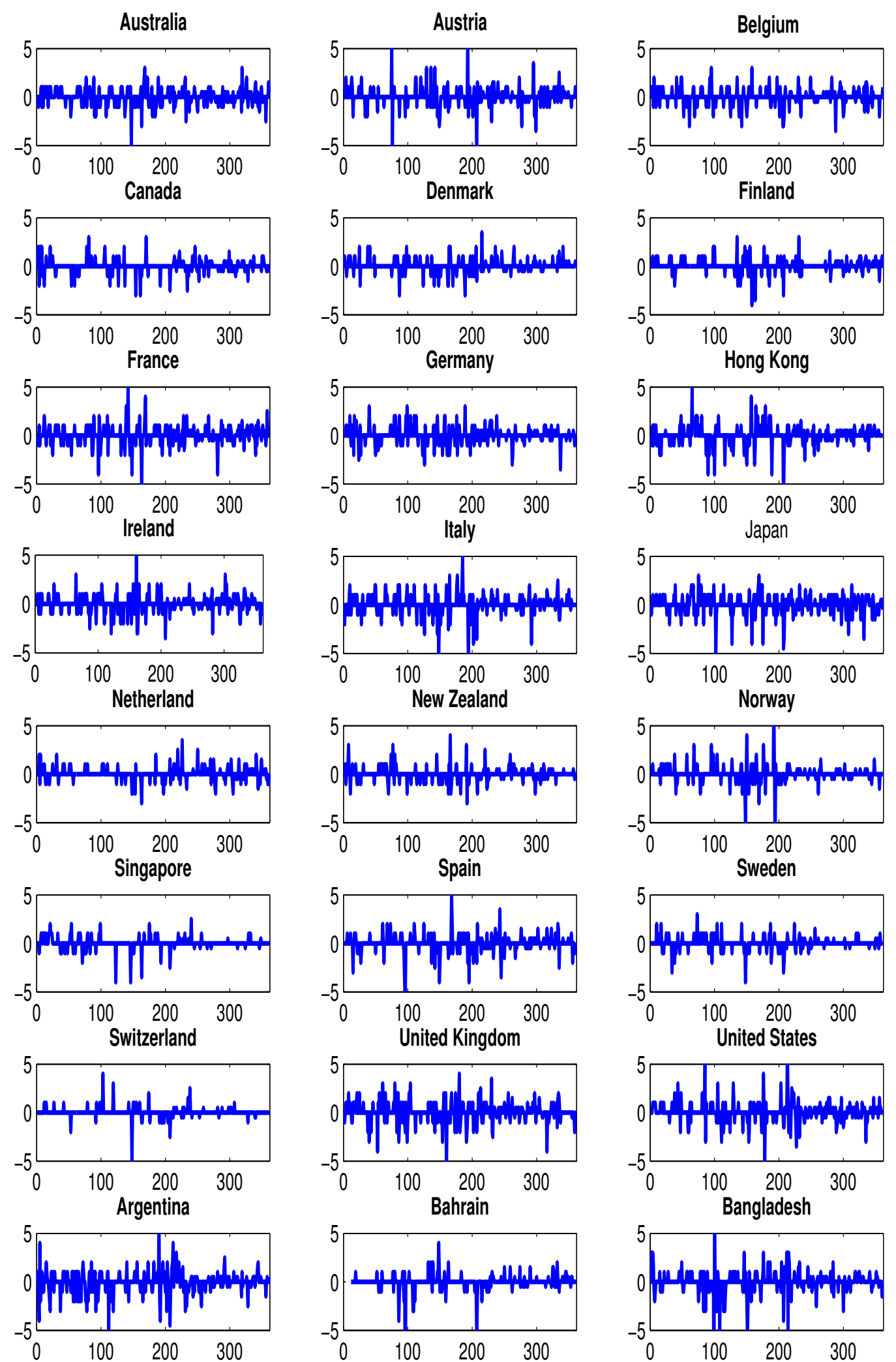

Figure 2.5: Political Risk (Change)

Note: The graphs shows monthly change in political risk. We scale all countries between 5 and -5 ; however, there are countries with greater changes than the scale. 

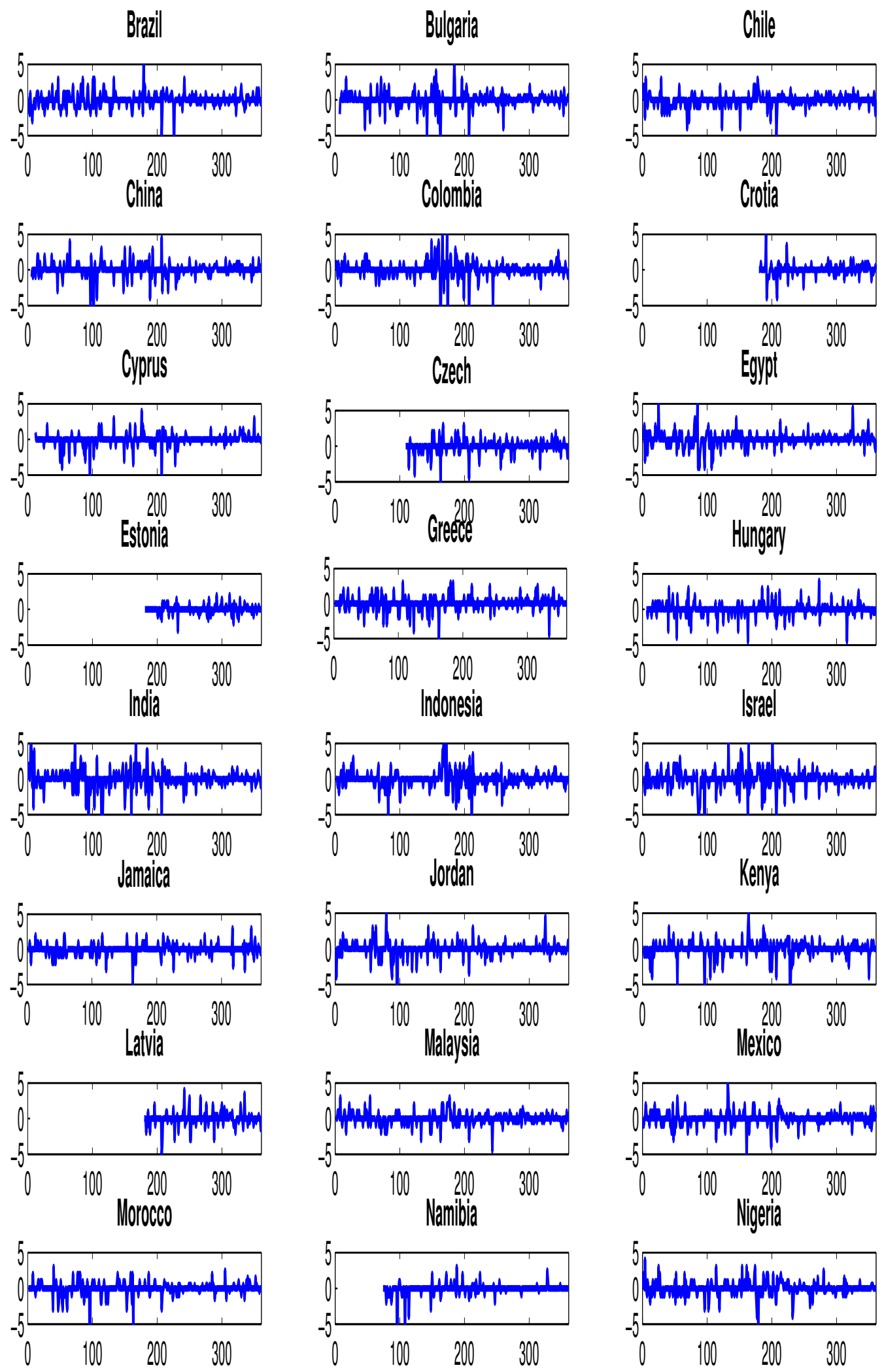

Figure 2.6: Political Risk (Change)

Note: The graphs shows monthly change in political risk. We scale all countries between 5 and -5 ; however, there are countries with greater changes than the scale. 


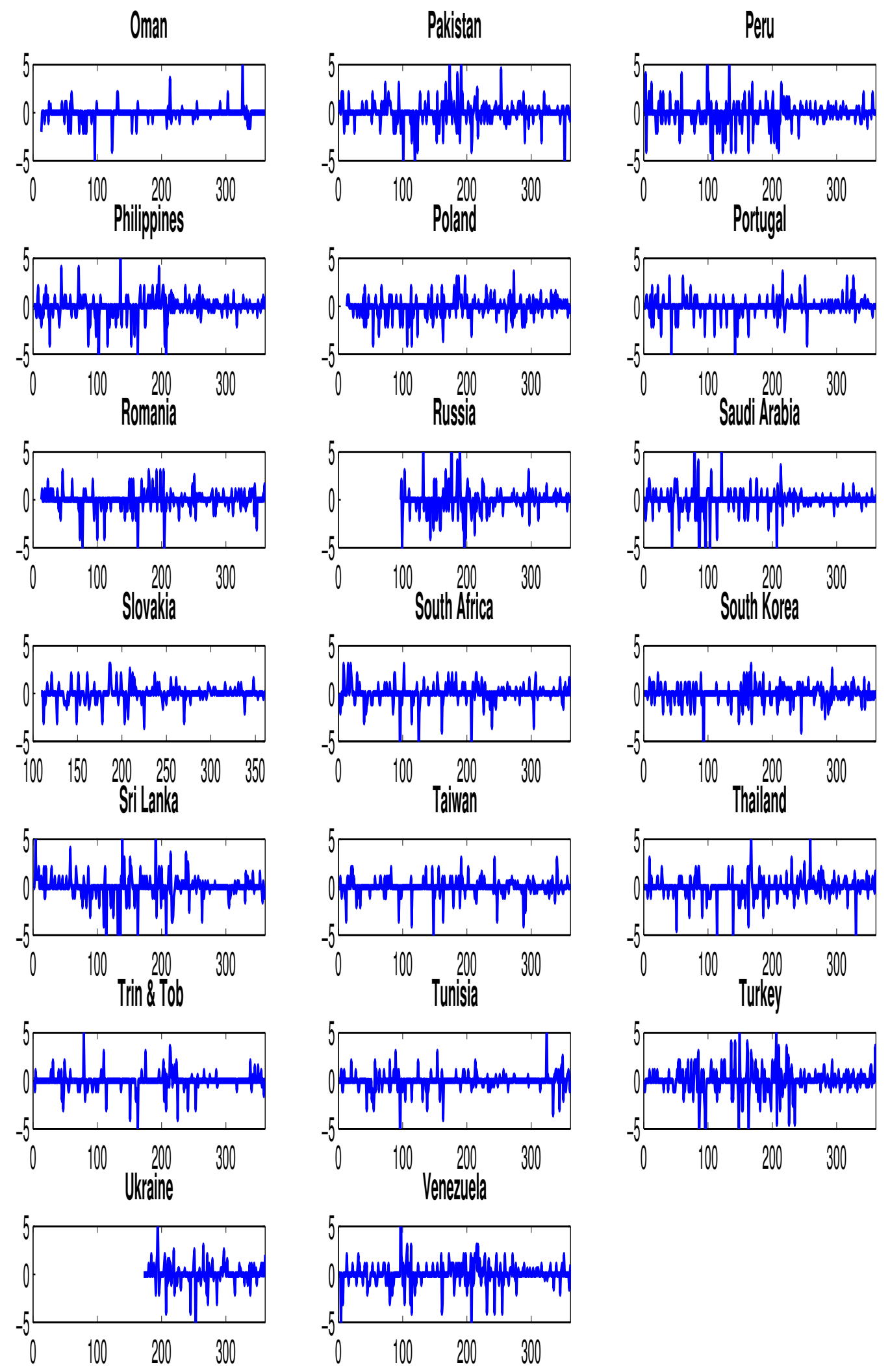

Figure 2.7: Political Risk (Change)

Note: The graphs shows monthly change in political risk. We scale all countries between 5 and -5 ; however, there are countries with greater changes than the scale. 
Table 2.2: Descriptive Statistics for Political Risk Index (Developed Markets)

\begin{tabular}{|c|c|c|c|c|c|c|c|c|c|}
\hline & Beginning Date & Mean & Std. Dev. & $\begin{array}{l}\text { Average } \\
\text { Change }\end{array}$ & $\begin{array}{l}\text { Std.Dev } \\
\text { of Change }\end{array}$ & $\begin{array}{l}\text { Positive } \\
\text { Change }\end{array}$ & $\begin{array}{l}\text { Negative } \\
\text { Change }\end{array}$ & Min & Max \\
\hline Australia & $31 / 01 / 1985$ & 16.14 & 4.07 & 0.01 & 0.82 & 87 & 74 & 10 & 27 \\
\hline Austria & $31 / 01 / 1985$ & 13.45 & 2.90 & 0.03 & 1.02 & 70 & 57 & 7 & 22 \\
\hline Belgium & $31 / 01 / 1985$ & 18.69 & 2.99 & 0.02 & 0.81 & 72 & 54 & 13 & 26 \\
\hline Canada & $31 / 01 / 1985$ & 15.10 & 2.91 & -0.01 & 0.68 & 53 & 51 & 9 & 22 \\
\hline Denmark & $31 / 01 / 1985$ & 13.77 & 2.91 & 0.04 & 0.66 & 54 & 42 & 6 & 23 \\
\hline Finland & $31 / 01 / 1985$ & 10.01 & 4.08 & 0.02 & 0.66 & 57 & 41 & 4 & 19 \\
\hline France & $31 / 01 / 1985$ & 21.73 & 3.01 & 0.04 & 0.98 & 94 & 72 & 15 & 32 \\
\hline Germany & $31 / 01 / 1985$ & 15.91 & 3.28 & 0.01 & 0.83 & 70 & 65 & 11 & 27 \\
\hline Hong Kong & $31 / 01 / 1985$ & 26.09 & 7.38 & -0.02 & 0.99 & 76 & 63 & 16 & 48 \\
\hline Ireland & $29 / 01 / 1988$ & 16.37 & 5.31 & 0.01 & 0.87 & 76 & 63 & 8 & 28 \\
\hline Italy & $31 / 01 / 1985$ & 23.07 & 4.39 & 0.02 & 1.02 & 79 & 59 & 14 & 34 \\
\hline Japan & $31 / 01 / 1985$ & 16.92 & 4.23 & 0.03 & 0.99 & 109 & 71 & 6 & 25 \\
\hline Netherlands & $31 / 01 / 1985$ & 12.52 & 4.07 & 0.02 & 0.65 & 55 & 43 & 3 & 20 \\
\hline New Zealand & $31 / 01 / 1985$ & 13.47 & 3.51 & 0.01 & 0.69 & 52 & 53 & 8.5 & 23 \\
\hline Norway & $31 / 01 / 1985$ & 12.87 & 3.25 & 0.01 & 0.94 & 53 & 48 & 6 & 22 \\
\hline Singapore & $31 / 01 / 1985$ & 17.14 & 4.08 & 0.02 & 0.61 & 42 & 31 & 10 & 25 \\
\hline Spain & $31 / 01 / 1985$ & 25.06 & 4.08 & -0.01 & 0.91 & 72 & 52 & 16 & 34 \\
\hline Sweden & $31 / 01 / 1985$ & 13.03 & 3.61 & 0.00 & 0.63 & 47 & 41 & 6.5 & 22 \\
\hline Switzerland & $31 / 01 / 1985$ & 10.51 & 3.45 & 0.02 & 0.53 & 30 & 22 & 3 & 16 \\
\hline United Kingdom & $31 / 01 / 1985$ & 17.83 & 4.62 & 0.02 & 1.07 & 92 & 71 & 8 & 27 \\
\hline United States & $31 / 01 / 1985$ & 17.69 & 3.94 & 0.04 & 1.02 & 86 & 64 & 6 & 27 \\
\hline
\end{tabular}

of seven African emerging markets and eight out of fourteen European emerging markets. However, the average change in political risk is negative for twelve out of seventeen and seven out of nine Asian and American emerging markets respectively. In emerging markets the average political risk is 32 and the standard deviation is 5.2. Nigeria and Pakistan have the highest political risk rating of 54.5 and 53.4 respectively with a standard deviation of 3.7 and 7.7 respectively. This is due to the large values in government stability, internal as well as external conflicts, high level of corruption and involvement of the military in politics. Further, the maximum value of the index is also for Pakistan, establishing it as the most risky country out of all the selected countries. The least risky country among the emerging markets is Portugal with and an average political risk of 19; however, the variation is much higher (6.7). Further, the difference between the minimum and maximum political risk is large for the majority of the emerging and a few developed markets, which concludes the presence of volatility in these markets and may be useful as a predictor variable.

\subsubsection{Sub-components}

Bekaert et al. (2014) and Bekaert, Harvey \& Lundblad (2005) grouped the twelve components into four sub-indices which they named: Government Actions, Conflict, Quality of Institutions, and Democratic Tendencies. Following them, we reorganize these components into three groups on the basis of their contents and also how these components are correlated. We find that the group 


\section{Table 2.3: Descriptive Statistics for Political Risk Index (Emerging Markets)}

We used the countries listed on the emerging market data base (EMBD). EMBD classifies emerging markets into two categories, major markets and frontier markets. Further, these emerging markets are divided into four regions. The Index is between 0 and 100, where a higher value represents a higher political risk in a country. The table includes mean which is the average political risk, Std. Dev. standard deviation of political risk, Average change stands for the monthly average change in political risk, Std.Dev of Change for standard deviation of the monthly change in political risk, Min and Max stands for minimum and maximum values of political risk. Positive and negative change represents the number of the changes $(+/-)$ throughout the sample period.

\begin{tabular}{|c|c|c|c|c|c|c|c|c|c|}
\hline & Beginning Date & Mean & Std. Dev. & $\begin{array}{l}\text { Average } \\
\text { Change }\end{array}$ & $\begin{array}{l}\text { Std.Dev } \\
\text { of Change }\end{array}$ & $\begin{array}{l}\text { Positive } \\
\text { Change }\end{array}$ & $\begin{array}{c}\text { Negative } \\
\text { Change }\end{array}$ & Min & $\operatorname{Max}$ \\
\hline \multicolumn{10}{|l|}{ Africa } \\
\hline Egypt & $26 / 02 / 1993$ & 39.18 & 5.43 & 0.05 & 0.73 & 82 & 71 & 33 & 54 \\
\hline Kenya & $28 / 02 / 1990$ & 42.55 & 5.38 & -0.01 & 1.14 & 83 & 53 & 31 & 53 \\
\hline Morocco & $29 / 01 / 1988$ & 33.27 & 6.89 & -0.07 & 1.16 & 63 & 47 & 26 & 56 \\
\hline Namibia & $29 / 02 / 2000$ & 23.12 & 1.47 & 0.01 & 0.43 & 21 & 34 & 21 & 26 \\
\hline Nigeria & $31 / 07 / 1995$ & 54.64 & 3.59 & 0.04 & 0.97 & 70 & 65 & 46 & 64 \\
\hline South Africa & $31 / 01 / 1985$ & 34.83 & 6.97 & -0.01 & 1.09 & 69 & 51 & 23 & 52 \\
\hline Tunisia & $30 / 01 / 1998$ & 32.87 & 2.98 & 0.05 & 0.73 & 48 & 48 & 29 & 41 \\
\hline \multicolumn{10}{|l|}{ Americas } \\
\hline Argentina & $30 / 11 / 1989$ & 31.33 & 5.59 & -0.03 & 1.09 & 93 & 81 & 23 & 46 \\
\hline Brazil & $31 / 01 / 1990$ & 33.54 & 2.29 & -0.003 & 1.02 & 82 & 92 & 29 & 40 \\
\hline Chile & $28 / 02 / 1990$ & 24.39 & 4.82 & -0.04 & 0.78 & 64 & 76 & 17 & 36 \\
\hline Colombia & $28 / 02 / 1992$ & 40.43 & 4.65 & 0.02 & 1.45 & 80 & 70 & 33 & 54 \\
\hline Jamaica & $31 / 07 / 1987$ & 28.9 & 4.08 & -0.03 & 0.78 & 51 & 56 & 19 & 41 \\
\hline Mexico & $29 / 02 / 1988$ & 29.84 & 2.83 & -0.01 & 0.91 & 78 & 62 & 23 & 37 \\
\hline Peru & $31 / 05 / 1993$ & 38.66 & 4.35 & -0.07 & 1.08 & 72 & 79 & 28 & 56 \\
\hline Trin\& Tobago & $28 / 02 / 1991$ & 30.83 & 4.42 & -0.03 & 0.82 & 37 & 42 & 23 & 40 \\
\hline Venezuela & $30 / 01 / 1990$ & 43.05 & 8.87 & 0.06 & 1.27 & 8 & 59 & 24 & 56 \\
\hline \multicolumn{10}{|l|}{ Asia } \\
\hline Bahrain & $28 / 02 / 2003$ & 28.11 & 4.03 & 0.12 & 0.46 & 46 & 40 & 21 & 37 \\
\hline Bangladesh & $31 / 01 / 1996$ & 47.17 & 4.66 & 0.02 & 1.05 & 78 & 65 & 35 & 53 \\
\hline China & $31 / 05 / 1991$ & 33.75 & 3.91 & -0.01 & 1.03 & 72 & 50 & 24 & 43 \\
\hline India & $31 / 01 / 1985$ & 43.82 & 8.17 & -0.03 & 1.32 & 88 & 78 & 31 & 70 \\
\hline Indonesia & $31 / 01 / 1985$ & 46.54 & 8.31 & -0.03 & 1.23 & 76 & 83 & 32 & 62 \\
\hline Israel & $29 / 05 / 1987$ & 39.59 & 9.55 & -0.05 & 1.50 & 91 & 80 & 28 & 65 \\
\hline Jordan & $30 / 12 / 1988$ & 33.92 & 10.19 & -0.06 & 1.31 & 61 & 52 & 24 & 66 \\
\hline Korea & $31 / 03 / 1986$ & 26.29 & 5.98 & -0.05 & 1.04 & 83 & 75 & 17.5 & 41 \\
\hline Malaysia & $31 / 01 / 1985$ & 28.57 & 4.99 & -0.00 & 0.79 & 74 & 69 & 18 & 42 \\
\hline Oman & $29 / 11 / 1996$ & 25.33 & 2.11 & -0.01 & 0.63 & 22 & 35 & 22 & 33 \\
\hline Pakistan & $31 / 01 / 1989$ & 53.34 & 7.54 & -0.05 & 1.32 & 81 & 70 & 35 & 73 \\
\hline Philippines & $28 / 02 / 1986$ & 40.91 & 10.17 & -0.05 & 1.26 & 72 & 72 & 24 & 66 \\
\hline Saudi Arabia & $30 / 11 / 1998$ & 32.11 & 1.77 & -0.01 & 0.74 & 64 & 56 & 28 & 37 \\
\hline Sri Lanka & $31 / 07 / 1987$ & 48.54 & 5.98 & -0.05 & 1.04 & 81 & 59 & 33 & 72 \\
\hline Taiwan & $31 / 01 / 1985$ & 22.49 & 2.51 & 0.001 & 0.86 & 65 & 49 & 17 & 29 \\
\hline Thailand & $29 / 09 / 1995$ & 35.12 & 6.98 & 0.06 & 1.09 & 76 & 64 & 21 & 47 \\
\hline Turkey & $29 / 02 / 1988$ & 38.78 & 5.03 & 0.03 & 1.51 & 100 & 81 & 31 & 56 \\
\hline \multicolumn{10}{|l|}{ Europe } \\
\hline Bulgaria & $30 / 11 / 2000$ & 30.27 & 3.19 & 0.03 & 0.79 & 81 & 53 & 24 & 35 \\
\hline Croatia & $31 / 01 / 2000$ & 26.45 & 2.41 & -0.06 & 0.80 & 37 & 34 & 23 & 36 \\
\hline Cyprus & $29 / 01 / 1993$ & 22.59 & 4.55 & 0.04 & 0.86 & 46 & 44 & 17 & 33 \\
\hline Czech & $31 / 05 / 1994$ & 21.15 & 2.91 & 0.01 & 0.92 & 55 & 43 & 12 & 27 \\
\hline Estonia & $31 / 01 / 2000$ & 25.57 & 1.97 & 0.02 & 0.61 & 34 & 25 & 22 & 29 \\
\hline Greece & $31 / 10 / 1988$ & 27.32 & 6.48 & -0.01 & 0.96 & 72 & 58 & 16 & 42 \\
\hline Hungary & $31 / 07 / 1991$ & 22.13 & 4.14 & -0.02 & 0.87 & 61 & 53 & 13 & 31 \\
\hline Latvia & $31 / 01 / 2000$ & 26.95 & 3.38 & -0.02 & 1.04 & 34 & 36 & 22 & 33 \\
\hline Poland & $31 / 05 / 1994$ & 21.67 & 3.44 & 0.01 & 0.87 & 71 & 73 & 13 & 27 \\
\hline Portugal & $29 / 01 / 1993$ & 17.76 & 6.22 & 0.02 & 0.83 & 63 & 44 & 9 & 30 \\
\hline Romania & $31 / 10 / 1997$ & 30.99 & 3.12 & 0.07 & 0.89 & 67 & 54 & 22 & 40 \\
\hline Russia & $31 / 10 / 1994$ & 38.63 & 5.82 & -0.01 & 1.44 & 51 & 51 & 31 & 58 \\
\hline Slovakia & $31 / 01 / 1994$ & 23.13 & 2.82 & -0.01 & 0.84 & 40 & 41 & 15 & 30 \\
\hline Ukraine & $30 / 04 / 1999$ & 36.73 & 3.83 & 0.04 & 1.19 & 45 & 31 & 30 & 46 \\
\hline
\end{tabular}


Table 2.4: Correlation twelve variables of political risk

\begin{tabular}{|c|c|c|c|c|c|c|c|c|c|c|c|c|}
\hline & GOV & $\mathrm{SOC}$ & INV & INT & $\mathrm{EXT}$ & COR & MIL & REL & LAW & ETH & DEM & BUR \\
\hline GOV & 1 & 0.27 & 0.08 & 0.43 & 0.29 & 0.12 & 0.24 & 0.11 & 0.38 & 0.29 & 0.08 & 0.27 \\
\hline $\mathrm{SOC}$ & 0.07 & 1 & 0.59 & 0.49 & 0.28 & 0.51 & 0.55 & 0.25 & 0.59 & 0.29 & 0.33 & 0.66 \\
\hline INV & 0.09 & 0.13 & 1 & 0.46 & 0.32 & 0.238 & 0.51 & 0.22 & 0.46 & 0.25 & 0.30 & 0.52 \\
\hline INT & 0.13 & 0.06 & 0.09 & 1 & 0.59 & 0.463 & 0.65 & 0.48 & 0.69 & 0.58 & 0.43 & 0.54 \\
\hline $\mathrm{EXT}$ & 0.07 & 0.05 & 0.12 & 0.17 & 1 & 0.308 & 0.48 & 0.37 & 0.43 & 0.40 & 0.38 & 0.38 \\
\hline COR & 0.06 & 0.01 & -0.01 & 0.05 & 0.02 & 1 & 0.59 & 0.37 & 0.64 & 0.34 & 0.52 & 0.69 \\
\hline MIL & 0.07 & 0.03 & 0.04 & 0.12 & 0.10 & 0.026 & 1 & 0.46 & 0.66 & 0.43 & 0.58 & 0.67 \\
\hline REL & 0.03 & 0.02 & 0.03 & 0.13 & 0.11 & 0.024 & 0.10 & 1 & 0.36 & 0.45 & 0.37 & 0.29 \\
\hline LAW & 0.07 & 0.05 & 0.04 & 0.19 & 0.12 & 0.075 & 0.15 & 0.15 & 1 & 0.49 & 0.43 & 0.68 \\
\hline ETH & 0.06 & 0.03 & 0.01 & 0.19 & 0.11 & 0.035 & 0.11 & 0.14 & 0.18 & 1 & 0.23 & 0.32 \\
\hline DEM & 0.05 & 0.02 & 0.04 & 0.07 & 0.04 & 0.053 & 0.06 & 0.03 & 0.03 & 0.00 & 1 & 0.32 \\
\hline BUR & 0.02 & 0.01 & 0.01 & 0.04 & 0.03 & 0.049 & 0.06 & 0.05 & 0.06 & 0.03 & 0.00 & 1 \\
\hline
\end{tabular}

"Democratic Tendencies", which consists of two components, Military in Politics and Democratic Accountability does not change over time for the majority of the developed markets. So we merged these two components into "Quality of Institutions" and named it as "Quality of Governance" 2 .

Table 2.4 details the correlations of the twelve risk components. The average correlation across all countries of the twelve variables by level is presented in the upper part of the matrix and in the bottom triangle of the matrix is the correlation of monthly change. We can clearly observe a higher correlation by levels for the majority of the twelve components. The highest correlation is for the internal conflicts and law and order, bureaucracy and corruption, Bureaucracy and military in politics. However, the correlation for the monthly changes in the levels is very low.

The first group is named "Government Actions" and consists of three subcomponents. The first, government stability, assesses unity, legislative strength and popularity among the journal public. The second is socioeconomic conditions which is related to actions of the government towards unemployment, poverty and increase in consumer confidence. The third is investment profile

\footnotetext{
${ }^{2}$ As we are using the monthly change in the political risk data, to incorporate it properly in our model there should be time variation in the political risk index. Our analysis shows that there is no change in the "Democratic Tendencies" group for the following developed countries: Australia, Austria, Belgium, Canada, Denmark, Finland, France, Germany, Hong Kong, Ireland, Italy, the Netherlands, New Zealand, Norway, Sweden, Switzerland, United Kingdom and United States. For the emerging markets the following countries have an average of zero change in the index: Argentina, Bahrain, Bulgaria, Estonia, Jamaica, Latvia, Oman, Saudi Arabia, Tunisia, Turkey and Ukraine. To account for consistency between all countries across all the subgroups, we merged the two subgroups Quality of Institutions and Democratic Tendencies into one group and named it Quality of Governance. Results for this can be provided on request.
} 
Table 2.5: ICRG indices and their components

\begin{tabular}{lccr}
\hline Component & Government Action & Conflict & Quality of Governance \\
\hline Political risk & & \\
Government stability & $\checkmark$ & & \\
Socioeconomic conditions & $\checkmark$ & & \\
Investment profile & $\checkmark$ & $\checkmark$ & \\
Internal conflict & & $\checkmark$ & \\
External conflict & $\checkmark$ & $\checkmark$ \\
Religious tensions & & $\checkmark$ \\
Ethnic tensions & & $\checkmark$ \\
Corruption & & $\checkmark$ \\
Military in politics & & \\
Law and order & & \\
Democratic accountability & & \\
Bureaucracy quality & & & \\
\hline
\end{tabular}

which covers the risk of contract viability, changes in the taxation, and repatriation.

The next group is labeled as "Conflict" and consists of four subcomponents concerning the risk associated with political unrest, cross border tension, war etc. The four variables are included in this group are internal conflicts, external conflicts, religious tensions, and ethnic tensions.

The final group is "Quality of Governance" which includes the components reflect governance of institutions by elected governments of a country, such as corruption, military in politics, law and order, democratic accountability and bureaucracy quality. If the government is not properly governing the institutions then the there will be higher uncertainty related to this group.

As these three sub groups of political risk are going to be used for the analysis, the next question arises as to whether they are correlated with each other or not? If these are correlated then there is an issue of multicollinearity. For this purpose we test the correlation for all three variables, i.e., Government Actions and Conflict, Government Actions and Quality of Governance, and Conflict and Quality of Governance. The results of correlation among these variables are presented in figure 2.8. We find that there is a correlation among these variables by level, see figure 2.8, a, b and c. However, there is quite a low correlation among these three variables after monthly change and volatility of the change. There are few outliers in the graphs that show a higher correlation for a few countries. The next step, to eliminate the doubt about multicollinearity among three groups, a variance inflation factor (VIF) test was conducted for all the countries in the sample ${ }^{3}$. We find a low values for all the countries; on

\footnotetext{
${ }^{3}$ Variance inflation factor works in two steps. In the first step, we run OLS regression among three subgroups. The second step is to calculate the VIF with the following formula; $V I F=\frac{1}{1-R^{2}}$. A low value of the VIF exhibits low correlation.
} 
average VIF is less than five.

We also use economic risk which is a measure of assessing a country's current economic strengths and weaknesses. The economic risk consists of five components which include per capita GDP, the real GDP growth rate, inflation,and fiscal and current account balances expressed as a percentage of GDP. The rating of economic risk is between 0 and 50 and a high rating indicates sound economic conditions whereas a low rating demonstrates weak economic conditions in the country.

The overall aim of the financial risk is to provide a measure of a country's ability to finance its official, commercial, and trade debt obligations. This also consists of five subcomponents like economic risk which is external debt as a percentage of GDP, foreign debt as percentage of export of goods and services, current accounts as a percentage of goods and services, net liquidity in a month, and exchange rate stability against the US dollar. The financial risk fluctuates between 0 and 50, a high rating display a low level of external exposure and vice versa. We also subtracted both economic risk and financial risk for each country from 50, so that a higher value in this index shows higher risk in the country for economic and financial risk. The weights for each component of ER and and FR are explained in Table 2.1.

\subsection{Alternative to ICRG}

\subsubsection{Political events}

It is often difficult to identify the exposure of political risk to financial markets specifically working with developing and emerging markets, that are facing quite a different type of political risk. The researcher defined (time) dummy variables to account for political risk (political events), to estimate its effect on financial markets. Bittlingmayer (1998) conducted a study on Germany's stock market for the period 1880 to 1940 and founded that stock prices and stock volatility were significantly affected by major political events such as World War I and World War II. Kim \& Mei (2001) examined the Hong Kong stock market and documented that political news announcements and political development affect the market returns and volatility. They found that bad news, as compared to good news, and major political news largely affect the stock market volatility. Suleman (2012) found similar results for the Pakistani stock market and confirm that bad news increases the volatility more than good news.

Further Vuchelen (2003), found that the stock prices in Belgium were significantly determined by political events such as general elections, new government formation and changes in coalitions parties. Chen, Bin \& Chen (2005) documented that prices of the Taiwanese market perform abnormally due to 


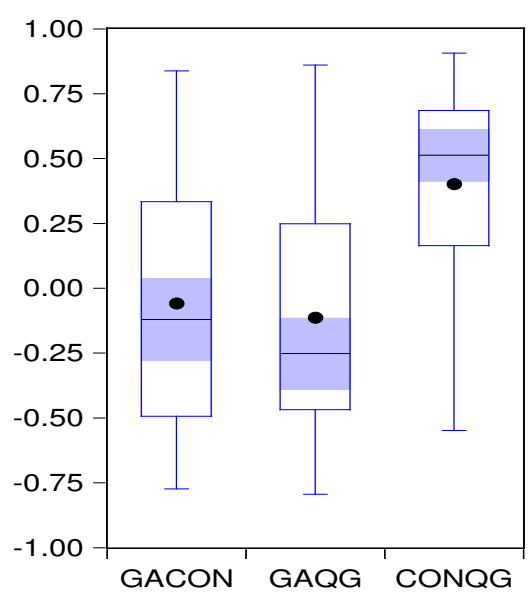

((a)) All markets(Level)

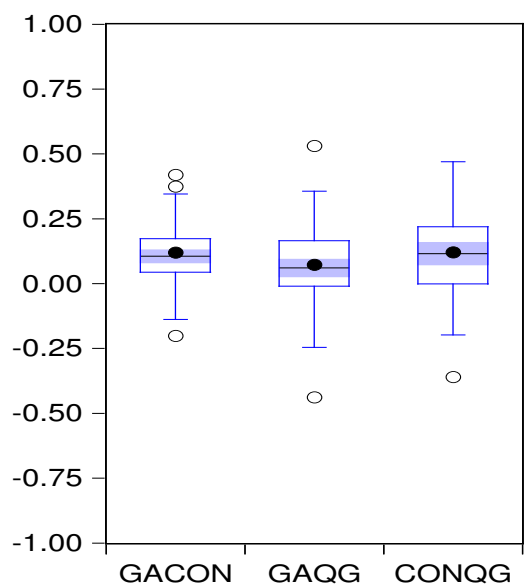

((d)) All markets(Change)

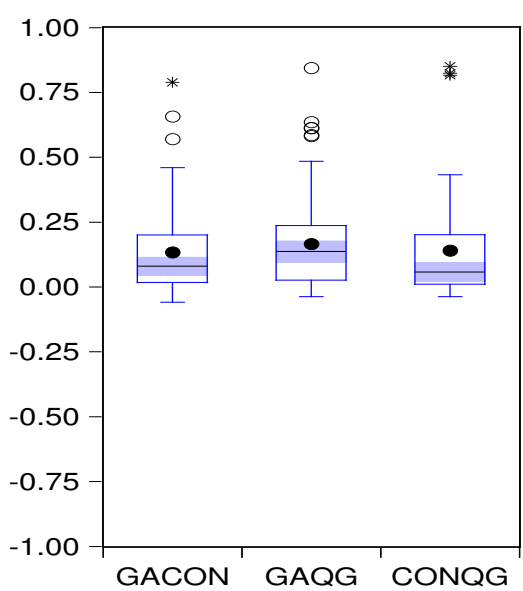

((g)) All markets(Volatility)

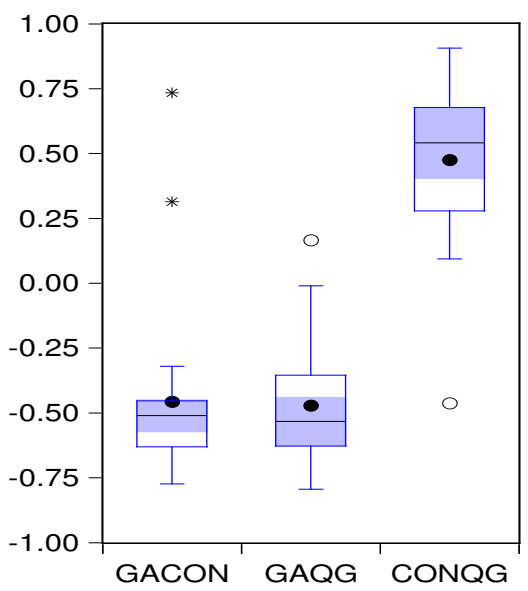

((b)) Developed markets(Level)

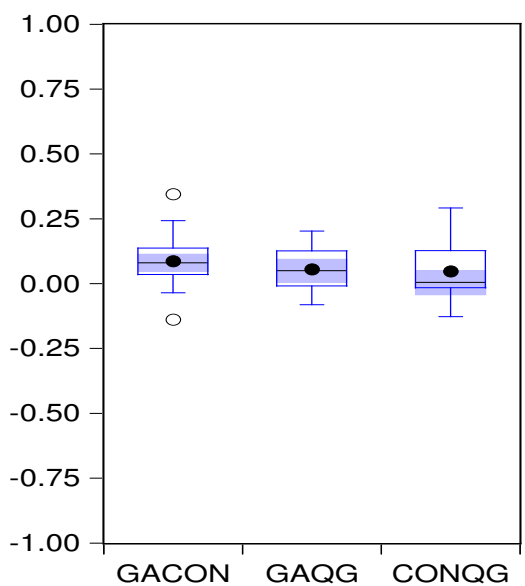

((e)) Developed markets(Change)

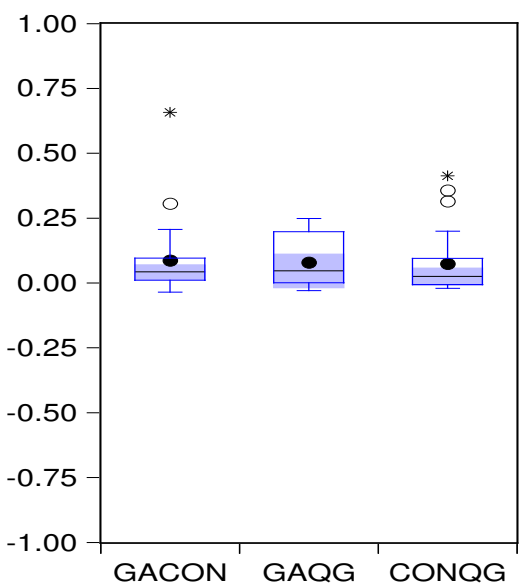

((h)) Developed markets(Volatility)

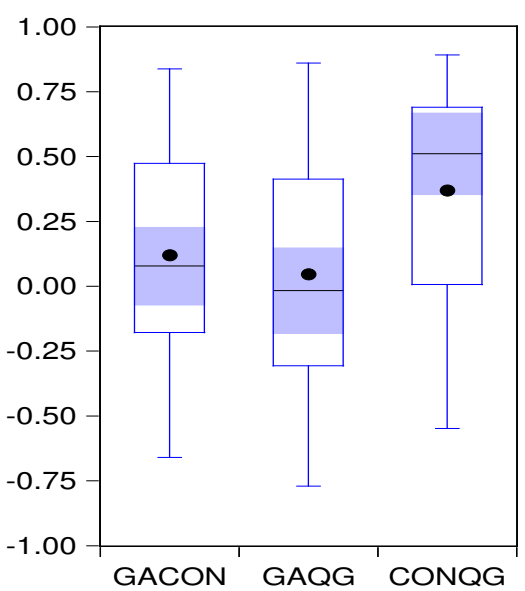

((c)) Emerging markets(Level)

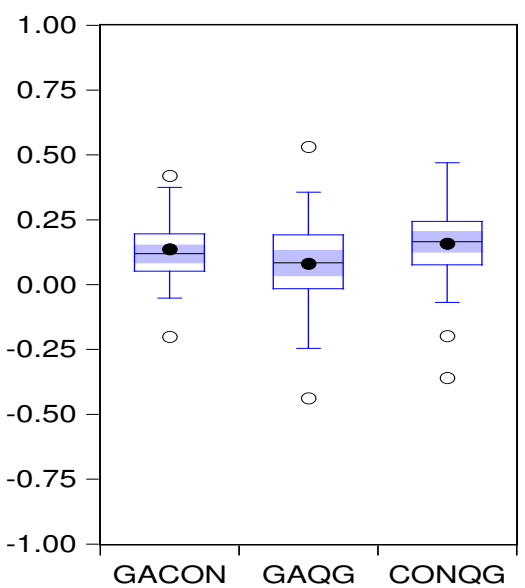

((f)) Emerging markets(Change)

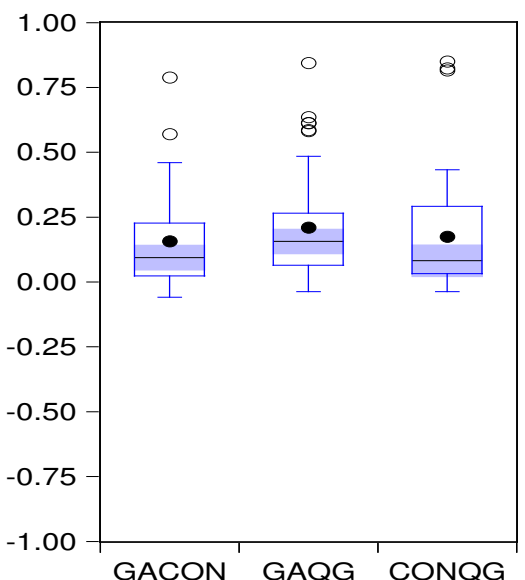

((i)) Emerging markets(Volatility)

Figure 2.8: Box plot of correlation among subgroups

Note: GA stands for government action, CON for Conflict, and QG for quality of governance. 
political events. Mehdian, Nas \& Perry (2008) indicated that due to the unexpected political events, the stock prices of the Turkish market were adjusted systematically below their fundamental values. Arouri et al. (2010) suggest that outcomes from every measurement technique deviate and they cannot be significantly extrapolated to other countries. To overcome such a problem, a large number of studies opt to enquire about the impact of political risk on stock prices by applying an event study approach.

Brooks, Davidson \& Faff (1997) gathered daily data on three South African indices (the All Share Index (ALSI), the Industrials Index (IND) and the Gold Index (GOLD) over the period 20 March 1986 to 23 February 1996. By studying the possible ARCH-related effects associated with the political changes occurring in South Africa, they presented an opportunity of examining the 'emergence' of a sophisticated and developed capital market which was isolated from the international community. They found that, with the exception of GOLD returns, more complex volatility models can be supported by the data in the postannouncement period. As these more complex models are typically supported by $\mathrm{ARCH}$ studies in other stock markets, this suggests greater international integration of the Johannesburg Stock Exchange in the post-1990's period.

Chan \& John Wei (1996) studied the impact of political news on the stock market volatility in Hong Kong using daily data for the period January 1, 1990 to May 31, 1993. They separated the period into two sub-periods : (1) January l, 1990 to July 8, 1992, the pre-Patten period, and (2) July 9, 1992 to May 31, 1993, the Patten period. Two indices were used for the empirical analysis: bluechip shares are proxied by the Hang Seng Index, and China-related stocks are proxied by the Red-Chip Index. As for the political risk, they first identified the days on which political news regarding Sino-British confrontation or cooperation was released. They searched for the news on the front page of one of the major newspaper in Hong Kong, the South China Morning Post, every day. If there was a major title regarding political issues, as defined above, that day was considered as an event day, otherwise it was a non-event day. They modified GARCH-M assuming that good and bad political news had a different impact on the return and volatility.

$$
\begin{gathered}
R_{t}=\alpha_{0}+\alpha_{1} h_{t}+\alpha_{3} D N_{t}+\alpha_{4} D N_{t} \times D P_{t}+\epsilon_{t}, \quad \epsilon_{t} \mid I_{t-1} \sim N\left(0, h_{t}\right) \\
h_{t}=\beta_{0}+\beta_{1} \epsilon_{t-1}^{2}+\beta_{2} h_{t-1}+\beta_{3} D E_{t}+\beta_{4} D E_{t} \times D P_{t}
\end{gathered}
$$

where $D N$ is the news dummy which is equal to the positive one for favorable political news, the negative one to unfavorable news and equal to zero for no news. Correspondingly, $D E$ is the event dummy equal to one otherwise zero and $D P$ is the Patten administration dummy equal to one after Patten arrived and zero before Patten arrived. Results provide strong evidence of the impact 
of political news on stock market volatility. The GARCH-M regression results further show that favorable (unfavorable) political news causes positive (negative) returns for the index. At the same time, they also found that the volatility, but not the returns of red-chip stocks, is affected by political shocks. They suggest that this may be due to the combined market wide and substitution effects caused by accompanying political news.

Aggarwal, Inclan \& Leal (1999) investigated whether global or local events are more important in causing major changes in emerging market volatility. First, they identified movements in volatility of the data and then the events that took place around that time period. They used daily data from 16 emerging and developed stock markets for the period 1985 to 1995 to examine the impact of political events. For the empirical investigation, they first detected the change points and then introduced dummy variables into the variance equation of the GARCH model to account for the sudden change in variance. They used the following GARCH $(1,1)$ model with dummy variables:

$$
h_{t}=\omega+d_{1} D_{1}+\cdots+d_{n} D_{n}+\alpha \epsilon_{t-1}^{2}+\beta h_{t-1}
$$

Where $D_{1}, \ldots . ., D_{n}$ represents the dummy, variables take a value of one from each point of sudden change of the variance onwards, otherwise zero. The results strongly support key political events thats tend to be associated with sudden change in the volatility such as the Marcos-Aquino conflict in the Philippines.

Mei \& Guo (2004) studied the impact of political risk on the financial crisis by analyzing the political election cycle. First, countries were segregated according to the form of election such as the presidential or parliamentary system. All the countries in the sample were divided into two periods: first, the time leading up to an election and the time of government transaction after the election, and second, the time after the transaction was completed and the start of the next election season. The following model was used in this study:

$$
Y_{i}=\alpha+\beta_{0} X_{i}+\beta_{1} D_{i}+\epsilon_{i}
$$

Here $Y_{i}$ denotes the financial crisis in a country which is equal to 1 if the crisis occurs otherwise $0 . X_{i}$ is a vector of economic and financial variables and $D_{i}$ represents a dummy variable of a political election cycle. These results divulge a significant relationship between political uncertainty and financial crisis. They also found that eight out of nine financial crises suggested that political uncertainty could be a major source of financial crisis. Further, the finding suggests that market volatility increases during a political election and transition period.

Lin \& Wang (2005) investigated the response of the Nikkei 225 stock market to transition of the ruling party in Japan. Employing the univariate asymmetric 
GARCH model, they utilized stock return volatility as an indicator to measure the impact of transition of the ruling party and to explore the dynamic relationship between financial market reaction and political behavior in Japan. Second, given the prime minister must be responsible for the performance of the cabinet, and thestock market will reflect his ruling performance, by applying the theory of organizational effectiveness, which focuses on the succession of leaders, they seek to answer whether the succession of prime minister affects the performance of the capital market. Nikkei 225 daily stock data for the period November 9, 1979 to April 5, 2005 were used for the analysis. The political data about the Japanese Congress electing nineteen Prime Ministers to form a cabinet during the sample periods were obtained from official records of Prime Ministers of Japan that contained term of office, party membership of prime minister and the member of previous cabinet. They used the following model for the analysis:

$$
\begin{array}{r}
R_{t}=\alpha_{0}+\alpha_{1} D_{1}+\alpha_{2} D_{2}+\alpha_{3} R_{t-1}+\epsilon_{t}, \quad \epsilon_{t} \mid I_{t-1} \sim N\left(0, h_{t}\right) \\
\ln h_{t}=\tau_{0}+\tau_{1} D_{1}+\tau_{1} D_{2}+\alpha\left|\mu_{t-1}\right|-E\left|\mu_{t-1}\right|+\theta \mu_{t-1}+\beta \ln h_{t-1}
\end{array}
$$

where $D_{1}$ denotes the dummy which takes the value of one with the transaction of the ruling party otherwise zero. The other dummy variable, $D_{2}$, is equal to one during the post-1987 crash, otherwise zero. Their investigation found that Nikkei 225 returns and volatilities are insignificantly related at $5 \%$ significant level for transition of the ruling party. However, the effect of the 1987 crash on Nikkei 225 stock returns is significantly negative at the $1 \%$ level and is significantly increased at the $5 \%$ level of volatilities.

Specifically addressing the effect of democratization in Taiwan,Wang \& Lin (2009) investigated the response of the stock market to political uncertainty during congressional sessions (Legislative Yuan) in Taiwan. Employing the univariate asymmetric GARCH model, they utilized stock return volatility as measures of the impact of political uncertainty during the congressional period to explore the dynamic relationship between financial markets' reaction and political behavior in Legislative Yuan. Daily data on the Taiwan Stock Exchange Value Weighted Index were used for the period February 24, 1984 to January 31, 2004. Dates when the legislative assembly was in session and in recess during the sample period were obtained from official records that contained about 46 sessions and 45 recesses during the sample period. They compared the performance of the EGARCH and the GJR model fitted to daily Taiwan stock returns. Additionally, the dummies were embedded in the EGARCH $(1,1)$ and GJR GARCH $(1,1)$ to detect the effect of congressional sessions and transition of the ruling party. They found that the congressional session had a negative effect on stock returns but volatility is not significant. However, the democratic effect on stock returns was negative and also increased the volatility. Moreover, 
the congressional effect on stock market returns following democratization significantly exceeded that before democratization, but had no significant effect for the volatility in the same circumstances.

It can be concluded that political events are a good proxy for political risk as these respond to actual events. However, these come with some drawback such as hard to collect news when analysing large numbers of countries, and they are labor intensive, and time consuming. There are chances of selection bias where specific political events are being chosen over others. Such unexpected difficulties lead researchers to use substitute methods in determining the effect of risk on stock returns.

\subsubsection{Alternative ratings}

Political risk is considered a non-business risk which is linked to political forces. Specifically, multinational corporations have recognized political risk as an element that may influence the outcome of their international investments (Shanmugam (1990)). Ghose (1988) refers to political risk as analogous to sovereign risk and linked within the overall country risk. Political risk arises from events such as wars, internal and external conflicts, territorial disputes, revolutions leading to changes of government, and terrorist attacks around the world. Social factors include civil unrest due to ideological differences, unequal income distribution, and religious clashes. Shanmugam (1990) introduces external reasons as a further political aspect of country risk. For instance, if the borrowing nation is situated alongside a country that is at war, the country risk level of the prospective borrower will be higher than if its neighbour were at peace. Although the borrowing nation may not be directly involved in the conflict, the chances of a spillover effect may exist. Additionally, the inflow of refugees from the war would affect the economic conditions in the borrowing nation. In practical terms, political risk relates to the possibility that the sovereign government may impose foreign exchange and capital controls, additional taxes, and asset freezes or expropriations.

Since the Third World debt crisis in the early 1980s, commercial agencies such as Moody's, Standard and Poor's, Euromoney, Institutional Investor, Economist Intelligence Unit, ICRG, and Political Risk Services have compiled sovereign indexes or ratings as measures of credit risk associated with sovereign countries. Risk rating agencies provide qualitative and quantitative country risk ratings, combining information about alternative measures of economic, financial and political risk ratings to obtain a composite risk rating. Table 2.6 presents the list of risk rating agencies used in the majority of the literature: Institutional Investor, Euromoney, Moody's Standard and Poor's, ICRG, Economist Intelligence Unit, and Political Risk Services. These agencies are the 
Table 2.6: Risk Rating Agencies

\begin{tabular}{lccr}
\hline Rating Agencies & Frequency & components & Countries \\
\hline Institutional Investor & semi-annual & - & 135 \\
Euromoney & semi-annual & 9 & 187 \\
Moody's & - & - & 100 \\
Standard and Poor's & weekly & 7 & 77 \\
Political Risk Services & annual & - & 100 \\
Economist Intelligence Unit & quarterly & 7 & 100 \\
International Country Risk Guide & monthly & 22 & 140 \\
\hline
\end{tabular}

leading commercial analysts of country risk. A detailed analysis and discussion of the ratings provided by the ICRG is presented in the section 2.3. Here we discuss briefly the rating system of other rating agencies ${ }^{4}$.

The ratings provided by the institutional investors consist of semi-annual surveys of over 135 countries. These ratings are provided by 75 to 100 bankers on a scale of 0 to 100 , where 100 present less chance of default for a country. The names of the respondents of the survey by the bankers are kept strictly confidential (Howell (2001)). The survey is published in the March and September issues of the monthly magazine by the institutional investors. Institutional investor country risk rating is also known as the banker's judgment.

Euromoney provides semi-annual risk ratings for 187 countries. Countries are scored on the basis of nine components. To obtain an overall country rating, a weighting is assigned to each of the nine categories (Economic outlook 25\%; Political risk 25\%; Debt indicators 10\%; Debt in default or rescheduled $10 \%$; Credit ratings 10\%; Access to bank finance 5\%; Access to short term finance 5\%; Access to international bond markets 5\%; and discount on forfeiting $5 \%$ ). The final score is calculated from the following formula: finalscore $=$ weighting $\div$ (maximumscore - minimumscore $) \times($ minimumscore $)$. The best underlying value per category achieves the full weighting, while the worst scores zero. Euromoney publish their survey in March and September issues.

Standard and Poor's (S\&P's) provides weekly updates on the credit ratings of 77 countries and territories. These ratings are not country ratings as they address the credit risks of national governments, not the credit risk of other issuers. However, sovereign ratings set the benchmark for the ratings assigned to other issuers in the country. S\&P's provides short- and long-term ratings, as well as a qualitative outlook on the sovereign's domestic and foreign currency reserves. Ratings are provided for seven major areas, namely long term debt, commercial paper, preferred stock, certificates of deposit, money market funds, mutual bond funds, and the claims-paying ability of insurance companies. For-

\footnotetext{
${ }^{4}$ The information regarding the other rating institutes is obtained from the websites of the relative rating agency.
} 
eign currency issuer ratings are also distinguished from local currency issuer ratings to identify those instances where sovereign risk makes them different for the same issuer. The ratings range from $\mathrm{C}$ (lowest) to AAA (highest). The rating outlook assesses the potential direction of a long-term credit rating over the intermediate to longer term. In determining a rating outlook, consideration is given to any changes in the economic and/or fundamental business conditions.

Moody's provides sovereign credit risk analysis for more than 100 nations, virtually every one of which participates in the world's capital markets. For each nation, Moody's publishes several different types of ratings to capture divergent risks, including country ratings for both short- and long-term foreign currency securities. In establishing country risk, Moody's analysts assess both political and economic variables to derive country risk ratings, which act as sovereign ceilings or caps on ratings of foreign currency securities of any entity that falls under the political control of a sovereign state (Howell (2001)). Country risk ratings account for foreign currency transfer risk and systemic risk in the nation. Using Moody's Aaa to C rating scale, foreign currency long-term government bonds and domestic currency long-term government bonds are rated. Local currency guideline ratings, which indicate the highest rating level likely for debt issues denominated in local currency, are also provided.

Political Risk Services (PRS) provides reports for 100 countries. Each report assesses potential economic, financial and political risks to business investments and trade. Country reports are the only source for risk forecasts and analysis based on the PRS rating system, which assesses different political scenarios. PRS provides a political risk model with three industry forecasts at the micro level, namely financial transfers (banking and lending), foreign direct investment (such as retail, manufacturing, and mining), and exports to the host country market. The 100 reports are revised on a quarterly basis ${ }^{5}$.

Economist Intelligence Unit (EIU) publishes country risk reports that are available quarterly with monthly updates. These reports summarise the risk ratings for all 100 key emerging and highly indebted countries that are monitored by the Country Risk Service (CRS). The CRS risk rating methodology examines two different types of risk: (1) country risk, as determined by (with weights in parentheses) political (22\%), economic policy (28\%), economic structure $(27 \%)$, and liquidity (23\%) factors; and (2) specific investment risk. Three different types of specific investment risk are currency risk (associated with accepting foreign exchange exposure against the US dollar), sovereign debt risk (associated with foreign currency loans to sovereign states), and banking sector risk (associated with foreign currency loans to banks). These specific investment risk ratings are also determined by the same four factors, with different weights.

\footnotetext{
${ }^{5}$ For details about the methodology please see: http://www.prsgroup.com/ commonhtml/methods.html
} 
For currency risk, economic policy is the most heavily weighted factor at $65 \%$, with economic structure, political, and liquidity factors having weights of $17 \%$, $14 \%$, and $4 \%$, respectively. In the case of sovereign debt risk, liquidity has the highest weight at $31 \%$, with economic policy and economic structure each being weighted at $27 \%$, and the political factor at $15 \%$. Finally, for banking sector risk, economic structure is the most heavily weighted at $44 \%$, with economic policy, liquidity, and political factors weighted at $35 \%, 15 \%$, and $6 \%$, respectively ${ }^{6}$. Details about how these ratings have been used in financial market literature is explained in each chapter's literature review.

\subsection{Conclusion}

It is concluded that ICRG meets the needs mainly as it's available on a monthly basis for the majority of the countries. ICRG provide detailed variables for political risk as elaborated in Section 2.3.

\footnotetext{
${ }^{6}$ for detailed information please see the following web page: http://store.eiu.com
} 


\section{. \\ . \\ Effect of political risk on stock market indices: a univariate analysis}

In this chapter, we compare different lags and models to identify the best model and lag on the basis of Akaike information criterion (AIC). We also examine the optimal level of aggregation among political risk components, political risk and composite risk. Later on, the best model and lag are used to analyse the impact of political risk on the equity indices of emerging and developed markets ${ }^{1}$.

\subsection{Introduction}

Political changes arising from the collapse of communism, and the execution of market-oriented economic and financial reforms have resulted in a huge amount of external capital flowing into the emerging markets of Eastern Europe, Latin America, Asia, and Africa (Ramcharran 2003). These events have alarmed international investors about the reality that globalisation of world trade and open capital markets is risky which can result in financial crisis that can spread rapidly and can prove to be a destabilizing factor for the international financial sector (Hayes 1998). Political risk emanates from the uncertainty related to exercise of power by governments and its consequences. Non-government actors in a country can also trigger political risk.

\footnotetext{
${ }^{1}$ This chapter was circulated and presented with a title of "Dynamics of Political Risk Rating and Stock Market Volatility". We are thankful to the valuable comments and suggestions of the participants at the 54th New Zealand Association of Economists Annual Conference 2013, PhD Symposium New Zealand Finance Colloquium, 2014.
} 
There are other factors that can increase political risk in a country. These risks are baseless political decisions, other events (political conflicts, military interference in politics etc) and conditions that disturb the prevalent business conditions and ultimately result in losses to investors, exporters and creditors. It has been witnessed that financial markets respond readily to news flows related to a country's politics. Ross (1976) introduced the arbitrage pricing theory which suggests that expected return of an asset is dependent on the sensitivity of that asset relative to risk factors (one or more risk factors). However this theory does not specify the risk factors that influence the expected returns. The basic model is as follow,

$$
P_{t}=\sum_{\tau=1}^{\infty} \frac{E_{t}\left(D_{t+\tau}\right)}{\left(1+r_{t}, \tau\right)^{\tau}}
$$

In the spirit of Fama \& French (1993) and Fama \& French (215), many variables (firm specific, economic, financial, political) potentially affect future dividend distributions and/or the discount rates, and therefore prices and returns. No theory that says how these factors influence prices or returns. For e.g. in CAPM: $E\left(R_{i t}\right)=r_{f}+\left(E\left(R_{m t}\right)-r_{f}\right) \beta_{i}$, a country's political risk may affect $r_{f}, E\left(R_{m t}\right), \beta_{i}$ but no indication how. We choose to fit statistical model in changes of political risk to model the stationary returns. The political risk we use, will reflect anticipated political risk to some extent, i.e. the measure is compiled by experts in political science.

Recent examples highlights the effect of political events on market returns include Brexit and Russian military action in Crimea. For example, the investors were expecting Britain to vote to stay in the EU, and unexpected outcome results in repricing across asset classes. This results in a huge fall in European equity markets as investor feared that vote in favour of Brexit could destabilize other members of European Union. The FTSE 100 index drop by 8.7\%, and FTSE 250 index, considered a better measure for the British economy fell $12 \%$. In the Europe German stock index DAX fell by $7 \%$, France's CAC index fallen $8.6 \%$, and IBEX index of Spanish stock exchange was down by $11 \%$. The USA stock market also fall in respond to Brexit news as Dow Jones industrial average fell 3.4\%, S\&P 500 by 3.64\%, and NAZDAQ composite fell 4.1\%.Similarly, Russia's invasion of the Crimea on 23 March 2014 lead the Russian stock market index (RTS) to drop by almost $13 \%$, and, in the exchange rate market the Russian Ruble dropped to an all-time low against both the Dollar and the Euro (by $2.5 \%$ and $1.5 \%$ respectively). European stocks lost about $3 \%$ of their value after the Russian parliament approved a request to deploy forces to the Ukraine. Another example is the European politicians announcement to cut Greece's debt in half (on 27 October 2011), US stocks increased by 3\%, and French and German by $5 \%$. 
Pantzalis, Stangeland \& Turtle (2000) and Li \& Born (2006) report abnormally high stock market returns in the weeks prior to major elections, especially for elections with an element of uncertainty about them. This evidence is consistent with a positive relationship between the equity premium and political uncertainty. Erb et al. (1996) find an insignificant relationship between political risk by using ICRG, and future stock returns. Other related asset pricing studies include Belo, Gala \& Li (2011), who link the cross-section of stock returns to the firm's exposure to the government sector, and Boutchkova, Doshi, Durnev \& Molchanov (2012), who related political uncertainty to stock volatility. Over the past decades as there has been a great increase in foreign direct investment in the emerging markets, researchers are more interested to forecasting the political and economical risk. Political risk is important for both emerging and developed markets, as the average change in political risk decreased in emerging markets and the difference in the average change of the political risk is only 2.5\% (Diamonte et al. (1996)).

The purpose of this chapter is to examine how political risk affects the first and second moment of the returns. In particular, this chapter focuses on whether stock market data seem to be affected by political risk as quantified by the ICRG (see Chapter 2 for details about ICRG data). We seek to bridge the gap in the political risk literature by analyzing the following questions. First, which model and lag is best to use when considering the data from the ICRG as there is no set standard to use the lag of political risk data from the ICRG. Second, is the political risk priced in emerging as well as in developed markets. Third, is the effect of political risk on the first as well as the second moment. Fourth, how do change and squared change of the political risk components i.e., government action, conflicts and quality of governance, political risk, and composite risk influence stock returns and volatility across emerging and developed markets. Monthly data from 47 emerging and 21 developed stock markets and political risk from the ICRG are used to study the impact of political risk on returns and volatility.

Empirical findings confirm that Model 4, which includes both variables (change and squared change) in both mean and variance equations perform best for majority of the emerging and developed markets. The results also confirm that political risk is priced in emerging as well as in some developed markets. We find a significant and predictable sign for majority of the emerging and few developed markets i.e., as political risk increases, the stock returns decrease and the volatility increase. The impact of the political components on the variance equation supports that political risk has a positive effect on the variance of the majority of emerging but few developed markets. The conflict risk measure is more significant for emerging markets as compared to developed markets. Further, we also study the impact of country risk (composite risk) on the return 
and volatility of these markets and find it's important for both markets.

The rest of the chapter is organized as follows. Section 2 describes the literature review. Data and the motivation for the model used in this paper are presented in Section 3. Section 4 discuss the methodology and section 5 provides empirical analysis. Section 6 is the conclusion.

\subsection{Literature review}

Erb et al. (1996) explored five measures of country risk: Political risk, economic risk, financial risk and composite risk from ICRG, and a fifth measure from Institutional Investors' (II) country credit rating. They investigated whether the risk indices contain information about future expected returns. They formed two portfolio strategies: upgrade and downgrade on the basis of the ICRG political risk measure. The portfolios are rebalanced every six months, and if the rating does not change, the country stays in its respective portfolio. On the basis of portfolios based on previous rating changes and held for six months, their results show that the composite-risk measure has considerable power to identify high and low-return portfolios. They used the following fixed-effect model:

$$
R_{i, t}=\omega_{i}+\beta \mathrm{RM}_{i, t-1}+\epsilon_{i, t} \quad i=1, \ldots N \quad t=1, \ldots T
$$

where $R_{i, t}$ is a six month return from July 1984 to June 1995 and $\mathrm{RM}_{i, t-1}$ is each of the five risk measures lagged and matched with the country in the sample. The full sample for all countries consists of 884 observations, 441 from developed and 443 from emerging equity markets. They found that the coefficient $\beta$ is significantly different from zero when the risk components are tested separately. Further, higher expected returns are associated with higher risk components. On the other, hand when the effect of the risk measure is estimated jointly, only the financial risk variable comes with significant coefficient. They found that political risk has some explanatory power only for emerging markets, whereas economic and financial measures are significant for the developed markets.

Bekaert \& Harvey (1997) explored the changing influence of world factors on the volatility of emerging markets. Monthly data from the International Finance Corporation(IFC) of the World Bank were used for the period of January 1976 to December 1992. They used economic, financial and country risk variables such as asset concentration, market capitalisation to GDP, size of trade sector, cross-sectional volatility of individual securities within each country, foreign exchange variability and national credit ratings to investigate differentiation in volatility across emerging markets. They estimated the following pooled time series cross-sectional regression: 


$$
\ln \left(\sigma_{i}^{2}\right)=\omega_{i}+\beta_{i} \mathrm{PR}_{i}+\theta \mathrm{X}_{i}+\epsilon_{i} \quad i=1, \ldots N .
$$

There are $N$ countries, $\sigma_{i}^{2}$ is $T_{i} \times 1$ vector of pre-estimated conditional variance (GARCH Model) where $T_{i}$ is the number of observations of country $i, \mathrm{X}_{i}$ is a matrix of $L$ explanatory variables for country $i$, including lagged exchange rate, and dividend yield. They found weak negative relationship exist between country credit rating and volatility. Lower quality ratings are generally associated with higher volatility and higher ratings with lower volatility. They also concluded that political risk explains a large amount of variation in volatility of returns.

Cosset \& Suret (1995) evaluate the benefits of international portfolio diversification in politically risky countries. They used a conventional mean-variance optimization procedure to access the impact of political risk on the risk and return of an internationally diversified portfolio. They used monthly data on political risk ratings and stock returns for a sample of 36 countries. Their findings suggest that diversification among politically risky countries improves the risk return characteristics of optimal portfolios. They also found that including politically risky countries in an international portfolio gives a reduction in overall portfolio risk.

Further Bilson et al. (2002) extended the political risk literature in two ways. First, they presented a model of return variation that incorporates political risk after taking into account both the global and local influence on returns. Second, they tested the impact of political risk at both individual and aggregated portfolio levels. Monthly data were used from 17 emerging and 18 developed markets for the period 1985-1997. The following model estimated to test the impact of political risk on stock returns:

$$
r_{i, t}=\omega_{i}+\beta \Delta \mathrm{PR}_{i, t}+\theta \mathrm{X}_{i, t}+\epsilon_{i t} \quad i=1, \ldots N \quad t=1, \ldots T .
$$

where $r_{i, t}$ is the residual for country $i$ at time $t$ obtained from the following regression $R_{i, t}=\omega_{i}+\gamma_{i} R_{w, t}+r_{i, t} . \mathrm{X}_{i, t}$ which is a vector of explanatory variable such as monthly percentage change in exchange rate, monthly percentage change in dividend yield and the variance of monthly local market returns for country $i$ at time $t . \Delta \mathrm{PR}_{i, t}$ is the monthly change in the political risk index for country $i$ at time $t$ from the ICRG. They found that political risk is important in explaining return variation in the individual emerging markets, particularly in the Pacific Basin, but not in the developed markets. The coefficient estimate of the political risk variable is significant and a negative sign in five emerging markets suggesting that returns decrease as political risk increases. However, only one developed market has similar results, so they concluded that political risk is more prominent in emerging markets compared developed markets. 
Ramcharran (2003) extended this literature by using the data from European Credit Ratings to estimate the effect of political, economic and credit risk on equity returns, dividend yield, price-to-earnings ratio and price-to-book ratios from 21 emerging equity markets. For analysis purposes a panel model was used to estimate over a shorter period from 1992 to 1999 and concluded that political risk has a significant impact on emerging market returns.

Further, Girard \& Omran (2007) studied the effect of political risk on five emerging markets (Egypt, Jordan, Morocco, Saudi Arabia, and Tunisia) for the period 1997 to 2001. They used the composite risk rating provided by the ICRG to measure the impact of political risk on stock returns in addition to the company's fundamental valuation such as price-to-earnings ratio, dividend yield and price-to-book ratio. Data related to political, financial and economic risk were obtained from the ICRG. They found that the company's fundamental and country risk rating factors help to explain the returns in selected markets. They also suggest despite financial, political and economic reforms, there is still an impediment for investors due to political risk in these emerging markets.

The above literature focuses on the impact of political risk on the mean returns. However, analysis of the connection between political risk and volatility is less common. Kabir Hassan et al. (2003) used the data from the ICRG of political risk services. They examined the effect of local factors by utilizing the country's political, financial and economic risk on the stock market volatility in the context of ten emerging markets in the Middle East and Africa (MEAF). They used the GARCH-M model by allowing the political shocks (difference between rating at $t$ and its mean) in local factors to affect conditional variance. They used the following model;

$$
\begin{gathered}
R_{i, t}=\omega_{i}+\beta_{i} \mathrm{PR}_{i, t}+\theta_{i} \mathrm{X}_{i, t}+\epsilon_{i t} \\
h_{i, t}=\omega_{i}+\alpha_{i} \epsilon_{i, t-1}^{2}+\gamma_{i} h_{i, t-1} \quad i=1, \ldots N \quad t=1, \ldots T .
\end{gathered}
$$

where $R_{i, t}$ is the stock return for market $i$ at time $t, \mathrm{PR}_{i, t}$ is the difference between the risk rating at $t$-period and its conditional mean. $\mathrm{X}_{i, t}$ is a vector including economic, financial and the trade-off between the risk and the expected returns. They found that the shocks in the political, economic and financial risk rating transfer the volatility constraints in the MEAF emerging markets. Further, only three out of ten markets significantly determine stock market volatility using political risk. However, five out of ten countries have only three years of data, which might raise questions on the findings.

Lam \& Zhang (2014) investigated the impact of policy uncertainty on stock returns in 49 developed and emerging markets during the period 1995-2006 by constructing two global policy uncertainty measures. Government stability and bureaucracy quality data were obtained from the ICRG to construct these two 
measures. They used the zero investment strategy for the country level portfolios from their policy uncertainty measures. They sorted the countries monthly according to low minus high government stability and bureaucracy quality respectively. Through this they have two types of stock returns according to policy uncertainty. Their results confirm policy uncertainty measures significantly affect the returns. They found one standard deviation increase in the bureaucracy quality increase the returns of $27 \%$ per year whereas for the government stability it is $7.8 \%$.

Lehkonen \& Heimonen (2015) investigated the effect of political risk and democracy on the 49 emerging markets using the annual data for the period 2000 to 2012. They used two measures of democracy: first, democratic accountability (it's a subcomponent of political risk) from the ICRG, and second, the polity variable from Polity IV. They also used the composite political risk from the ICRG. They used the following model for the estimation:

$$
\begin{aligned}
R_{i, t}= & \omega_{0}+\beta_{1} \operatorname{dem}_{i, t}+\beta_{2} \operatorname{dem}_{i, t}^{2}+\beta_{3} \mathrm{PR}_{i, t}+\beta_{4} \operatorname{dem}_{i, t} \times \mathrm{PR}_{i, t} \\
& +\beta_{5} \mathrm{dem}_{i, t}^{2} \times \mathrm{PR}_{i, t}+\beta_{6} R_{i, t-1}+\beta_{7} \mathrm{X}_{i, t}+\epsilon_{i}
\end{aligned}
$$

In the above equation, $R_{i, t}$ is the returns of market $i$ at time $t$, dem refers to democracy variable from Polity IV, where as PR refers to different political risk measures from the ICRG. X is a vector consisting of variables such as inflation, industrial production, term spread and interest rates etc. Country fixed effect was also included in the estimation of the model. Lagged variables were used to capture the persistence of the left hand side variable. Overall, their results suggest that both political risk and democracy increase the returns of emerging markets. However, the political risk variable from ICRG does so for all cases, whereas democracy is only three out of six.

Dimic, Orlov \& Piljak (2015) examined the impact of political risk and subcomponents from the ICRG on the stock returns of developed, emerging and frontier markets. They used the unbalanced data with annual observations from 1990 to 2013 for 64 countries divided into developed, emerging and frontier. They estimated the following fixed effect panel model:

$$
R_{i, t}=\omega_{0}+\beta_{1} \mathrm{QI}_{i, t}+\beta_{2} \operatorname{Con}_{i, t}+\beta_{3} \operatorname{Dem}_{i, t}+\beta_{4} \operatorname{Gov}_{i, t}+\beta_{5} \mathrm{X}_{i, t}+\epsilon_{i}
$$

where QI, Con, Dem, Gov denotes the four subgroups named as Quality of Institutions, Conflict, Democratic Tendencies and Government Actions from the ICRG. $X_{i, t}$ is a vector of annual GDP growth rate, Inflation, VIX index and return on the world index. They also estimated the above model only using the composite political risk from the ICRG. Their finding suggest that a decrease in political risk leads to an increase in all three markets' stock returns. However, the results for the subgroups differ across these three markets. For example the 
conflict variable shows significant negative effect on stock returns for emerging and frontier markets but no significant effect on developed markets.

Clearly there is no consensus in the literature about how to the model the link between political risk and return and volatility of returns. Most recently, Pástor \& Veronesi (2013) develop a complex theoretical model. On the basis of this they made several important quantitative predictions e.g., political uncertainty increase the stock market volatility. We use these as a basis of an augmented EGARCH model whereby changes in political risk are allowed to affect both the return and volatility of returns. Precisely how this is done is described in section 3.4.

It can be concluded from the literature review that most of the research is conducted by using the composite risk and the main focus was on its implication of the returns and no consistent modelling approach. However, our study differed from theirs in two main ways. First, we have constructed three measures of political risk from the ICRG as explained in Chapter 2. We hypothesise that political risk as a composite is too coarse to find the impact of political risk at the country level. We also extended the existing literature by investigating the effect of political risk on the volatility of the returns in the international equity markets. Further, we also extended the literature by investigating which model and lag are best to use when considering the data from the ICRG as there is no set standard to use the lag of political risk data from the ICRG.

\subsection{Data}

We used data from emerging and developed markets for empirical analysis. The data from the 21 developed markets were used: Australia, Austria, Belgium, Canada, Denmark, Finland, France, Germany, Hong Kong, Ireland, Italy, Japan, the Netherlands, New Zealand, Norway, Singapore, Spain, Sweden, Switzerland, United Kingdom, and the United States of America. The stock market data were downloaded from DataStream for both emerging and developed markets for January 1984 to December 2013. All returns are measured in local currency to analyse the impact of political risk on the returns and volatility. For emerging markets we used the countries listed on the emerging market data base (EMBD). EMBD classify emerging markets into two categories, major markets consisting of 35 markets and frontier markets consisting of 20 markets. Due to the data availability for both political and financial markets, at the end the sample consisted of 47 emerging markets. Further, we broke down the emerging markets into four regions, Africa, Americas, Asia, and Europe. African countries include Egypt, Kenya, Morocco, Namibia, Nigeria, South Africa, and Tunisia. Americas countries are Argentina, Brazil, Chile, Colombia, Jamaica, Mexico, Peru, Trinidad \& Tobago, and Venezuela. The countries in the Asian region are 
Table 3.1: Descriptive Statistics of Monthly Returns (Developed Markets)

\begin{tabular}{|c|c|c|c|c|c|c|c|c|c|}
\hline & Mean & Std. Dev. & Skewness & Kurtosis & Min & Max & $A C$ & $A C^{2}$ & ARCH LM \\
\hline Australia & 0.61 & 5.07 & -3.69 & 40.05 & -54.09 & 13.85 & 0.071 & 0.112 & 0.021 \\
\hline Austria & 0.37 & 7.17 & -0.79 & 7.01 & -36.51 & 24.96 & 0.104 & 0.253 & 0.312 \\
\hline Belgium & 0.49 & 5.73 & -1.49 & 10.49 & -35.27 & 22.79 & 0.137 & 0.306 & 0.242 \\
\hline Canada & 0.55 & 4.51 & -1.22 & 7.71 & -24.62 & 11.95 & 0.078 & 0.159 & 0.055 \\
\hline Denmark & 0.82 & 5.41 & -0.48 & 4.03 & -19.62 & 16.99 & 0.078 & 0.137 & 0.133 \\
\hline Finland & 0.74 & 8.64 & -0.33 & 4.77 & -37.12 & 27.76 & 0.096 & 0.316 & 0.199 \\
\hline France & 0.59 & 5.74 & -0.55 & 4.12 & -24.89 & 19.98 & 0.089 & 0.232 & 0.165 \\
\hline Germany & 0.53 & 6.38 & -0.95 & 5.53 & -28.68 & 17.95 & 0.124 & 0.140 & 0.139 \\
\hline Hong Kong & 0.81 & 7.95 & -1.38 & 12.33 & -58.03 & 28.34 & 0.132 & 0.212 & 0.011 \\
\hline Ireland & 0.22 & 6.36 & -0.70 & 4.59 & -25.75 & 19.47 & 0.119 & 0.136 & 0.145 \\
\hline Italy & 0.41 & 6.71 & 0.08 & 3.51 & -17.30 & 23.01 & 0.107 & 0.168 & 0.042 \\
\hline Japan & 0.10 & 5.79 & -0.33 & 4.28 & -23.65 & 18.85 & 0.081 & 0.108 & 0.198 \\
\hline Netherlands & 0.49 & 5.30 & -1.15 & 6.07 & -26.07 & 13.111 & 0.103 & 0.114 & 0.180 \\
\hline New Zealand & 0.19 & 6.03 & -0.75 & 8.53 & -38.52 & 22.61 & 0.178 & 0.197 & 0.145 \\
\hline Norway & 0.57 & 7.03 & -1.22 & 6.62 & -35.38 & 14.98 & 0.086 & 0.151 & 0.151 \\
\hline Singapore & 0.35 & 7.21 & -1.64 & 13.94 & -55.09 & 20.71 & 0.075 & 0.079 & 0.016 \\
\hline Spain & 0.68 & 6.65 & -0.56 & 5.07 & -29.65 & 21.70 & 0.079 & 0.180 & 0.088 \\
\hline Sweden & 0.91 & 6.81 & -0.46 & 4.96 & -24.74 & 19.13 & 0.079 & 0.147 & 0.141 \\
\hline Switzerland & 0.63 & 4.93 & -0.98 & 6.41 & -26.68 & 13.92 & 0.125 & 0.173 & 0.123 \\
\hline UK & 0.49 & 4.63 & -1.14 & 8.22 & -30.27 & 13.73 & 0.115 & 0.163 & 0.103 \\
\hline USA & 0.69 & 4.51 & -1.06 & 6.33 & -24.16 & 12.21 & 0.057 & 0.181 & 0.141 \\
\hline
\end{tabular}

Bahrain, Bangladesh, China, India, Indonesia, Israel, Jordan, Malaysia, Oman, Pakistan, Saudi Arabia, South Korea, Sri Lanka, Taiwan, Thailand, and Turkey. For Europe, the countries include Bulgaria, Croatia, Cyprus, Czech Republic, Estonia, Greece, Hungary, Latvia, Poland, Portugal, Romania, Russia, Slovakia, and Ukraine.

Table 3.1 presents the monthly returns statistics for the developed markets. We found a lower average return of $0.26 \%$ and standard deviation of $6.9 \%$ compared with the emerging markets. Overall, the the preliminary analysis also shows that the average returns and standard deviation in the emerging stock markets is much higher compared to developed markets. Descriptive statistics of monthly stock market returns for emerging markets are presented in Table 3.2. We can observe that the average returns of the majority of the emerging markets are positive. For the African region, the average return is $0.21 \%$ with a standard deviation of $6.9 \%$. In the European region the average return is $-0.03 \%$ with a standard deviation of $10.9 \%$ and for Americas the average return is $0.58 \%$ and standard deviation is $9.5 \%$. The average monthly is $0.33 \%$ and standard deviation is $9.76 \%$ for Asia. We can observe that average monthly returns of all emerging markets are positive except Cyprus and Thailand. For the emerging markets, the highest mean is $5.3 \%$ with a standard deviation of $17.5 \%$ for Brazil.

Further, the difference between the minimum and the maximum monthly returns is fairly large, which is further evidence of the higher volatility in the emerging markets. The skewness of the series indicates that the majority of 
Table 3.2: Descriptive Statistics of Monthly Returns (Emerging Markets)

The table presents the summary statistics mean, standard deviation, skewness, kurtosis minimum and maximum of local returns for emerging equity markets. We used the countries listed on the emerging market data base (EMBD). EMBD classify emerging markets into two categories, major markets and frontier markets. Returns are calculated from the main stock exchange index of each country. The residual based diagnostics i.e., autocorrelation of returns and squared returns along with ARCH LM test up to five lag is also presented in the last three column of table. The significant coefficients are denoted with bold and italic, bold, italic on 1\%,5\% and 10\% respectively. All results except residual based diagnostics are presented as percentages.

\begin{tabular}{|c|c|c|c|c|c|c|c|c|c|}
\hline & Mean & Std. Dev. & Skewness & Kurtosis & Min & Max & $A C$ & $A C^{2}$ & ARCH LM \\
\hline \multicolumn{10}{|l|}{ Africa } \\
\hline Egypt & 1.46 & 8.91 & 0.04 & 4.14 & -33.32 & 31.93 & 0.180 & 0.126 & 0.107 \\
\hline Kenya & 0.63 & 6.68 & 0.91 & 9.74 & -25.67 & 41.29 & 0.134 & 0.261 & 0.367 \\
\hline Morocco & 0.94 & 4.21 & 0.02 & 5.51 & -17.92 & 17.88 & 0.138 & 0.161 & 0.105 \\
\hline Namibia & 0.93 & 2.86 & -0.01 & 4.61 & -8.81 & 9.68 & 0.112 & 0.154 & 0.214 \\
\hline Nigeria & 1.24 & 8.02 & -0.26 & 9.01 & -41.26 & 39.48 & 0.117 & 0.247 & 0.211 \\
\hline South Africa & 1.21 & 6.09 & -1.44 & 10.44 & -39.47 & 16.79 & 0.106 & 0.112 & 0.001 \\
\hline Tunisia & 0.81 & 3.89 & 0.46 & 6.67 & -14.25 & 19.17 & 0.112 & 0.103 & 0.076 \\
\hline \multicolumn{10}{|l|}{ Americas } \\
\hline Argentina & 1.93 & 15.45 & 2.59 & 23.76 & -49.62 & 133.4 & 0.125 & 0.211 & 0.097 \\
\hline Brazil & 5.30 & 17.47 & 0.55 & 7.48 & -69.31 & 70.31 & 0.290 & 0.363 & 0.651 \\
\hline Chile & 1.32 & 6.14 & -0.35 & 7.11 & -35.46 & 18.87 & 0.147 & 0.116 & 0.091 \\
\hline Colombia & 1.04 & 6.38 & 0.01 & 3.87 & -20.88 & 21.53 & 0.079 & 0.176 & 0.019 \\
\hline Jamaica & 1.17 & 7.37 & 1.14 & 7.37 & -26.03 & 36.93 & 0.117 & 0.229 & 0.295 \\
\hline Mexico & 1.79 & 7.93 & -0.28 & 5.54 & -34.98 & 36.23 & 0.134 & 0.131 & 0.181 \\
\hline Peru & 1.47 & 9.39 & -0.55 & 7.67 & -50.54 & 30.94 & 0.180 & 0.143 & 0.078 \\
\hline Trin \& Tobago & 0.95 & 3.75 & 0.92 & 8.66 & -14.57 & 22.75 & 0.120 & 0.246 & 0.246 \\
\hline Venezuela & 2.72 & 12.09 & 0.41 & 7.09 & -49.52 & 53.13 & 0.133 & 0.227 & 0.081 \\
\hline \multicolumn{10}{|l|}{ Asia } \\
\hline Bahrain & 0.19 & 3.76 & -0.47 & 4.37 & -13.50 & 9.25 & 0.202 & 0.299 & 0.056 \\
\hline Bangladesh & 0.68 & 10.30 & 0.79 & 10.75 & -35.88 & 64.53 & 0.105 & 0.239 & 0.283 \\
\hline China & 0.91 & 11.61 & 1.06 & 7.03 & -26.81 & 61.69 & 0.111 & 0.182 & 0.047 \\
\hline India & 1.26 & 8.52 & 0.25 & 4.85 & -27.29 & 44.02 & 0.128 & 0.157 & 0.085 \\
\hline Indonesia & 1.21 & 8.88 & 0.79 & 15.34 & -37.85 & 69.37 & 0.105 & 0.237 & 0.065 \\
\hline Israel & 1.08 & 6.78 & -0.61 & 4.17 & -23.32 & 18.81 & 0.107 & 0.132 & 0.079 \\
\hline Jordan & 0.57 & 4.99 & 0.26 & 5.67 & -21.20 & 21.15 & 0.104 & 0.218 & 0.162 \\
\hline Korea & 0.72 & 8.26 & 0.15 & 4.86 & -31.81 & 39.45 & 0.061 & 0.187 & 0.056 \\
\hline Malaysia & 0.51 & 7.47 & -0.54 & 7.74 & -42.89 & 29.44 & 0.156 & 0.208 & 0.116 \\
\hline Oman & 0.64 & 6.51 & -0.01 & 5.82 & -25.02 & 27.78 & 0.147 & 0.258 & 0.318 \\
\hline Pakistan & 1.25 & 9.01 & -0.62 & 6.89 & -44.87 & 29.69 & 0.157 & 0.129 & 0.075 \\
\hline Philippines & 1.15 & 9.03 & 0.08 & 6.47 & -34.22 & 43.22 & 0.117 & 0.187 & 0.064 \\
\hline Saudi Arabia & 0.97 & 7.32 & -0.85 & 5.22 & -27.75 & 18.73 & 0.127 & 0.205 & 0.389 \\
\hline Sri Lanka & 1.02 & 8.06 & 0.34 & 4.62 & -28.98 & 33.21 & 0.103 & 0.149 & 0.043 \\
\hline Taiwan & 0.67 & 10.34 & -0.27 & 6.68 & -49.34 & 40.64 & 0.130 & 0.297 & 0.344 \\
\hline Thailand & -0.05 & 10.03 & -0.14 & 5.49 & -36.80 & 38.64 & 0.074 & 0.290 & 0.145 \\
\hline Turkey & 2.84 & 14.28 & 0.41 & 4.95 & -49.48 & 58.65 & 0.107 & 0.249 & 0.017 \\
\hline \multicolumn{10}{|l|}{ Europe } \\
\hline Bulgaria & 1.05 & 9.61 & -0.72 & 8.10 & -47.63 & 35.04 & 0.127 & 0.151 & 0.266 \\
\hline Croatia & 0.54 & 7.32 & -0.57 & 7.56 & -31.08 & 29.68 & 0.144 & 0.302 & 0.393 \\
\hline Cyprus & -0.47 & 11.18 & 0.55 & 6.73 & -35.64 & 54.15 & 0.128 & 0.170 & 0.419 \\
\hline Czech & 0.07 & 7.13 & -0.83 & 5.48 & -31.64 & 20.49 & 0.074 & 0.143 & 0.203 \\
\hline Estonia & 1.11 & 7.84 & -0.06 & 8.16 & -35.87 & 37.03 & 0.152 & 0.188 & 0.213 \\
\hline Greece & 0.51 & 9.83 & 0.39 & 5.44 & -32.67 & 40.97 & 0.104 & 0.153 & 0.029 \\
\hline Hungary & 0.75 & 8.75 & 0.16 & 9.37 & -43.01 & 47.87 & 0.111 & 0.188 & 0.023 \\
\hline Latvia & 1.09 & 9.12 & -0.81 & 7.45 & -37.69 & 35.89 & 0.129 & 0.173 & 0.027 \\
\hline Poland & 0.35 & 9.21 & -0.38 & 6.88 & -43.55 & 34.12 & 0.157 & 0.197 & 0.087 \\
\hline Portugal & 0.35 & 5.96 & -0.47 & 4.43 & -23.34 & 17.19 & 0.116 & 0.204 & 0.204 \\
\hline Romania & 0.97 & 10.52 & -0.72 & 5.98 & -44.05 & 29.95 & 0.138 & 0.322 & 0.101 \\
\hline Russia & 2.04 & 13.05 & -0.43 & 5.71 & -53.29 & 45.58 & 0.125 & 0.269 & 0.169 \\
\hline Slovakia & 0.13 & 8.86 & 3.09 & 29.53 & -36.87 & 75.83 & 0.154 & 0.286 & 0.126 \\
\hline Ukraine & 1.41 & 13.37 & -0.25 & 6.17 & -55.74 & 44.52 & 0.178 & 0.185 & 0.224 \\
\hline
\end{tabular}


emerging and all of the developed market series are negatively skewed. The kurtosis for the majority of the markets is high showing the distribution of returns has a high peak. This is not surprising as the financial return's distribution has a tendency of be leptokurtic due to volatility clustering.

The autocorrelation statistics of returns and squared returns series is also reported in Table 3.1 and Table 3.2. Autocorrelation in the squared residual is significant and positive, indicating the presence of autoregressive conditional heteroskedasticity (ARCH), or volatility clustering Nelson (1991) effects for all the equity markets. Further, we also performed Engle's (1982) ARCH test. The results confirm the existence of the $\mathrm{ARCH}$ effect in the series for almost all markets at lag one. This indicates that the GARCH class of models would be appropriate for modelling the stock market returns.

\subsection{Description of Model}

Volatility is commonly measured as the standard deviation of daily price changes, or as a by-product of estimation of an econometric volatility model. One standard approach to modeling volatility is through the so-called GARCH class of models. From the data section we can conclude on the basis of statistics of squared residuals and Engle's (1982) ARCH test that there is evidence of conditional heteroscedasticity in the return series. In this study we used a univariate General Autoregressive Conditional Heteroscedastic (GARCH) model, an extension of work developed by Engle (1982), and Bollerslev (1986). Nelson (1991) introduced the Exponential GARCH to avoid imposing non-negativity restrictions when estimating the values of $\mathrm{GARCH}$ parameters which is more useful than GARCH because it allows good news and bad news to have a different impact on volatility ${ }^{2}$. We are not really interested in testing the Exponential GARCH model but only a volatility model that will account robustly for conditional heteroscedasticity, so that we can better justify the effect of political risk on return and volatility.

We formulate four models which allow the change and/or squared change of political risk components from the ICRG to affect the mean and variance of the stock returns. Models 1, 2, and 3 are nested in model 4 which includes both political risk measure's variables (Change and squared change) in both equations. In addition, we investigate the optimal choice of lag over which the changes in political risk components are calculated. In particular, we consider lags $j=1,3,6,12,24$ which will allow us to comment on the time scale over which the market is pricing changes in the country's political environment. In all models, economic and financial risk is included as a control variable. For

\footnotetext{
${ }^{2}$ A significant number of previous studies, summarized by Hamilton (1994), support the use of the EGARCH model.
} 
each country we estimate the following time series model:

\section{Model 1}

$$
\begin{gathered}
r_{t}=\phi_{0}+\phi_{1} r_{t-1}+\phi_{2} \Delta \mathrm{RM}_{t-1}^{j}+\phi_{3} \Delta \mathrm{X}_{t-1}^{j}+\epsilon_{t} \\
\log \left(\sigma_{t}^{2}\right)=\omega+\alpha f\left(z_{t-1}\right)+\beta_{1} \log \left(\sigma_{t-1}^{2}\right)+\beta_{2} \Delta \mathrm{RM}_{t-1}^{j}+\beta_{3} \Delta \mathrm{X}_{t-1}^{j}
\end{gathered}
$$

\section{Model 2}

$$
\begin{gathered}
r_{t}=\phi_{0}+\phi_{1} r_{t-1}+\phi_{2}\left(\Delta \mathrm{RM}_{t-1}^{j}\right)^{2}+\phi_{3}\left(\Delta \mathrm{X}_{t-1}^{j}\right)^{2}+\epsilon_{t} \\
\log \left(\sigma_{t}^{2}\right)=\omega+\alpha f\left(z_{t-1}\right)+\beta_{1} \log \left(\sigma_{t-1}^{2}\right)+\beta_{2}\left(\Delta \mathrm{RM}_{t-1}^{j}\right)^{2}+\beta_{3}\left(\Delta \mathrm{X}_{t-1}^{j}\right)^{2}
\end{gathered}
$$

\section{Model 3}

$$
\begin{gathered}
r_{t}=\phi_{0}+\phi_{1} r_{t-1}+\phi_{2} \Delta \mathrm{RM}_{t-1}^{j}+\phi_{3} \Delta \mathrm{X}_{t-1}^{j}+\epsilon_{t} \\
\log \left(\sigma_{t}^{2}\right)=\omega+\alpha f\left(z_{t-1}\right)+\beta_{1} \log \left(\sigma_{t-1}^{2}\right)+\beta_{2}\left(\Delta \mathrm{RM}_{t-1}^{j}\right)^{2}+\beta_{3}\left(\Delta \mathrm{X}_{t-1}^{j}\right)^{2}
\end{gathered}
$$

\section{Model 4}

$$
\begin{gathered}
r_{t}=\phi_{0}+\phi_{1} r_{t-1}+\phi_{2} \Delta \mathrm{RM}_{t-1}^{j}+\phi_{3}\left(\Delta \mathrm{RM}_{t-1}^{j}\right)^{2}+\phi_{4} \Delta \mathrm{X}_{t-1}^{j}+\phi_{5}\left(\Delta \mathrm{X}_{t-1}^{j}\right)^{2}+\epsilon_{t} \\
\begin{array}{c}
\log \left(\sigma_{t}^{2}\right)=\omega \\
+\alpha f\left(z_{t-1}\right)+\beta_{1} \log \left(\sigma_{t-1}^{2}\right)+\beta_{2} \Delta \mathrm{RM}_{t-1}^{j}+\beta_{3}\left(\Delta \mathrm{RM}_{t-1}^{j}\right)^{2} \\
+\beta_{4} \Delta \mathrm{X}_{t-1}^{j}+\beta_{5}\left(\Delta \mathrm{X}_{t-1}^{j}\right)^{2}
\end{array}
\end{gathered}
$$

In the above equations, $\Delta \mathrm{RM}_{t-1}^{j}$ is the change $\left(\Delta \mathrm{RM}_{t-1}^{j}=\mathrm{RM}_{t-1}-\mathrm{RM}_{t-j-1}\right)$ in the political risk measure from the ICRG data. The risk components are government action, conflict, quality of governance and political risk and are explained in detail in section 2.3 of Chapter 2 and $j=1,3,6,12,24$ month lags.

Political risk is fitted into the models 1 to 4 in three ways separately. In the first, the three political risk components Government Action (GA), Conflict $(\mathrm{CON})$ and Quality of Governance (QG) feature as independent explanatory variables (RM) see table 2.5 for details of components, whereas Economic Risk (ER) and Financial Risk (FR) are included as control variables (X).

In the second, aggregate political risk (RM) is included and again ER and FR (X) are also used. Finally, only the composite risk index is used and there are no control variables. The twelve individual ICRG variables do not change of enough for these to be effectively used for monthly data.

The constant terms are denoted by $\phi_{0}$ and $\omega$ where $\epsilon_{t}$ is the error term at 
time $t$. The impact of the last period conditional variance is denoted by $\beta_{1}$. If the $\beta_{1}$ is positive, that means a positive change in stock prices is associated with further positive change and vice versa.

From the model we expect an increase in political risk components to decrease the returns and we expect a negative coefficient for $\phi_{2}$ and $\phi_{3}$. This suggests that as the political risk components increase, the uncertainty about the future policies of the government also increase, which affects the investors' decisions and lowers the returns. As for the volatility of the political risk components the coefficient, $\beta_{2}$ and $\beta_{3}$ in the variance equation should be positive and significant, because as the volatility of political risk increases the volatility of the returns should also increase. The stationary restriction for an EGARCH $(1,1)$ model is that the $\beta_{1}$ is less than one $(\beta<1)$ and in the case of symmetry, where the magnitudes of positive and negative shocks have equal impact on the variance. we can write the log likelihood function for the univariate EGARCH model in the following way,

$$
L(\Theta)=-\frac{T}{2} \log (2 \pi)-\frac{1}{2} \sum_{t=1}^{T} \log \left(\sigma_{t}^{2}\right)-\frac{1}{2} \sum_{t=1}^{T} \frac{\left(r_{t}-\mu_{t}\right)^{2}}{\sigma_{t}^{2}}
$$

where $\Theta$ is the parameter vector to be estimated and $T$ is the number of observations and $r_{t}=\mu+\epsilon_{t}$ as specified in equations (3.20), (3.12), (3.14) and (3.16).

\subsection{Results}

\subsubsection{Appropriate model and lag}

We began the empirical analysis by estimating Models 1 to 4 . For each country, we estimated the four models at each lag separately. Also, the level of aggregation is a focus and we estimated three alternatives: political risk components, political risk, and composite risk. The Akaike information criterion (AIC) was obtained and the best (smallest AIC) is presented in Table 3.3 for developed markets. Only the best model and related results are presented here, whereas detailed results with each model and all lags are presented in Appendix A, Tables A.2 to A.4. The model is the best model among four models and lag is the best lag i.e., 1, 3, 6, 12, 24 month lags as determined by the smallest $\mathrm{AIC}^{3}$.

\footnotetext{
${ }^{3}$ We extend all analysis to lag 36. For, comparison, all model lose 36 month observations i.e. undesirable to have unnecessary large lag. We note that in almost all cases, use of lag 36 is inferior to use of lag 24. Therefore, we conclude lag 24 is reasonable choice. We find only 2 countries for developed and 4 with emerging with 36 lags compare to 8 and 21 with 24 lags for political risk components. No country found with better AIC for emerging markets with 36 lags of political risk.
} 
Table 3.3: Developed Markets

\begin{tabular}{|c|c|c|c|c|c|c|c|c|c|}
\hline \multirow[t]{3}{*}{ Countries } & \multicolumn{9}{|c|}{ Best Model } \\
\hline & \multicolumn{3}{|c|}{ Political Risk Components } & \multicolumn{3}{|c|}{ Political Risk } & \multicolumn{3}{|c|}{ Composite Risk } \\
\hline & $\mathrm{AIC}$ & Model & Lag & AIC & Model & Lag & $\mathrm{AIC}$ & Model & Lag \\
\hline Australia & -3.5083 & 4 & 3 & -3.4031 & 1 & 1 & -3.3998 & 1 & 3 \\
\hline Austria & -2.7678 & 3 & 12 & -2.7217 & 4 & 24 & -2.6957 & 4 & 24 \\
\hline Belgium & -3.1600 & 4 & 24 & -3.1490 & 3 & 1 & -3.1370 & 3 & 6 \\
\hline Canada & -3.4466 & 1 & 6 & -3.4786 & 1 & 1 & -3.4066 & 3 & 1 \\
\hline Denmark & -3.0166 & 3 & 24 & -3.0061 & 2 & 12 & -3.0208 & 2 & 12 \\
\hline Finland & -2.2615 & 2 & 6 & -2.2281 & 4 & 24 & -2.2335 & 4 & 1 \\
\hline France & -3.0092 & 4 & 24 & -2.9946 & 4 & 24 & -3.0059 & 4 & 24 \\
\hline Germany & -2.7688 & 3 & 24 & -2.7358 & 4 & 6 & -2.7377 & 1 & 6 \\
\hline Hong Kong & -2.4200 & 4 & 24 & -2.3426 & 3 & 24 & -2.2849 & 1 & 24 \\
\hline Ireland & -2.9075 & 4 & 24 & -2.8806 & 3 & 12 & -2.8858 & 3 & 12 \\
\hline Italy & -2.7209 & 4 & 24 & -2.6965 & 3 & 24 & -2.6548 & 1 & 24 \\
\hline Japan & -2.9537 & 2 & 6 & -2.9346 & 4 & 3 & -2.9216 & 4 & 6 \\
\hline Netherlands & -3.1553 & 1 & 24 & -3.1322 & 4 & 24 & -3.0946 & 1 & 24 \\
\hline New Zealand & -3.0835 & 4 & 12 & -3.0870 & 1 & 12 & -3.0315 & 1 & 3 \\
\hline Norway & -2.5985 & 4 & 12 & -2.5737 & 4 & 1 & -2.5200 & 4 & 1 \\
\hline Singapore & -2.6891 & 4 & 6 & -2.7151 & 4 & 6 & -2.5942 & 4 & 6 \\
\hline Spain & -2.7170 & 3 & 24 & -2.6455 & 2 & 24 & -2.6265 & 1 & 24 \\
\hline Sweden & -2.7471 & 3 & 1 & -2.7109 & 4 & 6 & -2.6590 & 2 & 6 \\
\hline Switzerland & -3.3061 & 1 & 12 & -3.2717 & 4 & 24 & -3.2560 & 1 & 3 \\
\hline UK & -3.4148 & 1 & 3 & -3.4074 & 4 & 3 & -3.4222 & 1 & 3 \\
\hline USA & -3.5381 & 4 & 24 & -3.4703 & 4 & 24 & -3.4507 & 4 & 24 \\
\hline
\end{tabular}

Columns 2 to 4 show the results for the risk components. We found Model 4 was best for 10 markets out of 21 (48\%). The best lag to use for analysis for the majority of the developed markets was lag 24 (10 countries provide best AIC using lag 24).

Moving towards political risk, the results are in columns 5 to 7 of Table 3.3. Model 4 performs best among all models as it's best for 13 markets (62\%) and the best lag to use is lag 24 for 9 countries. The last three columns of the table present the results for the best model and lag for composite risk. Model 1 and model 4 are best for the majority of the markets with 9 and 7 countries respectively. For composite risk lag 24 is best for 7 markets. Next we analysed the level of aggregation across three alternatives and conclude that political risk components provide lowest AIC compared to political risk and composite risk. In the next step we examined the level of aggregation across three variables i.e. political risk components, political risk and composite risk. Most of the previous research only focuses on the political risk, however our aim here is to find an appropriate variable for a proxy of political risk from ICRG data. There might be chance that political risk as a composite is too coarse to find the impact on stock market return and volatility. The results conclude that political risk components provide lowest AIC compared to political risk and composite risk for the developed markets. 
Table 3.4 presents the results of the best model on the basis of AIC for emerging markets. Table 3.4 is divided into four groups: first is the results for African region, second for the Americas, third for Asia and fourth for the European region. Only the best model and related results are presented here, whereas the detailed results for each model and all lags are presented in Appendix A, Tables A.5 to A.7. The results reveal that Model 4 is the most popular among all for the emerging markets when the political risk components are used (i.e., for half of the countries this is the best model). The next next step is to find the best lag for each country and we conclude that lag 24 is the best for the majority of the countries (as 26 out of 47 countries are with lag 24). Lag 12 is the least frequent for the emerging markets in the sample.

Results using political risk as a component in our models are also presented in columns 5 to 7 of Table 3.4. Here again, Model 4 is best for 19 out of 47 emerging markets, whereas Model 2 is best for 12 out of 47 emerging markets. Model 3 and Model 1 are best for 8 emerging markets. As for the best lag, we find the mixed evidence like lag 24 is the best for $36 \%$ markets, 3 and 6 for $21 \%$ each and lags 6 and 12 with only $11 \%$ each.

The last three columns of Table 3.4 present the results for the composite risk (including political, economic, and financial risk) for the emerging markets. The results are mixed as Model 4 and Model 1 are best with an equal number of countries 15 for each model (64\% of all emerging markets), where as models 2 and 3 are best for ten and seven countries respectively. The next question of interest is which lag is best to use for composite risk and we find lag 24 is best for 16 markets (34\% of all emerging markets). However, lag 1 is the best lag for $28 \%$ of markets and lag 12 is only for $8 \%$ of markets. We conclude for all markets that Model 4 and Lag 24 are best for the majority of emerging and developed markets.

When we analysed the level of aggregation, results were similar to developed markets. The lowest AIC (best model) was found for the political risk components for the majority of emerging markets (34 out 47). The next step is to use these models and lags to estimate the impact of political risk on emerging and developed markets. Overall we conclude for both developed and emerging markets that important information is lost if political risk or composite risk are used.

\subsubsection{Political risk exposure from the mean equation}

The results from the estimation of the mean equation from the best model (Model 1 to Model 4) for developed markets are presented in Table 3.5 and Table 3.6. The results presented in Table 3.5 are related to the question, do political risk components, political risk and composite risk affect the interna- 
Table 3.4: Emerging Markets

This table displays the best model among the four models discussed in the methodology section for the emerging markets. The best model is chosen on the basis of AIC. AIC stands for Akaike information criterion, model is the best model among four models and lag is the best lag i.e., 1, 3, 6, 12, 24 month lags. The political risk components are Government Actions, Conflict, and Quality of Governance as explained in

\begin{tabular}{|c|c|c|c|c|c|c|c|c|c|}
\hline \multirow[t]{3}{*}{ Countries } & \multicolumn{9}{|c|}{ Best Model } \\
\hline & \multicolumn{3}{|c|}{ Political Risk Components } & \multicolumn{3}{|c|}{ Political Risk } & \multicolumn{3}{|c|}{ Composite Risk } \\
\hline & $\mathrm{AIC}$ & Model & Lag & $\mathrm{AIC}$ & Model & Lag & $\mathrm{AIC}$ & Model & Lag \\
\hline \multicolumn{10}{|l|}{ Africa } \\
\hline Egypt & -2.0826 & 3 & 12 & -2.1079 & 4 & 1 & -2.0411 & 1 & 1 \\
\hline Kenya & -3.0158 & 4 & 6 & -2.9267 & 2 & 3 & -2.9083 & 2 & 24 \\
\hline Morocco & -3.6597 & 4 & 1 & -3.6796 & 4 & 1 & -3.5789 & 2 & 1 \\
\hline Namibia & -4.6932 & 4 & 24 & -4.5496 & 4 & 24 & -4.4143 & 4 & 6 \\
\hline Nigeria & -2.6605 & 1 & 3 & -2.6178 & 1 & 6 & -2.5630 & 3 & 1 \\
\hline South Africa & -2.9195 & 2 & 1 & -2.8626 & 4 & 1 & -2.8305 & 2 & 6 \\
\hline Tunisia & -3.8760 & 4 & 24 & -3.7785 & 4 & 24 & -3.7886 & 4 & 1 \\
\hline \multicolumn{10}{|l|}{ Americas } \\
\hline Argentina & -1.5142 & 4 & 24 & -1.4906 & 1 & 3 & -1.4875 & 1 & 1 \\
\hline Brazil & -1.5621 & 1 & 24 & -1.5334 & 2 & 24 & -1.5225 & 1 & 24 \\
\hline Chile & -2.9211 & 2 & 24 & -2.8591 & 1 & 24 & -2.8286 & 4 & 1 \\
\hline Colombia & -2.8360 & 4 & 24 & -2.8248 & 3 & 1 & -2.8168 & 4 & 6 \\
\hline Jamaica & -2.9056 & 4 & 3 & -2.8944 & 4 & 3 & -2.7913 & 1 & 24 \\
\hline Mexico & -2.4545 & 2 & 24 & -2.4625 & 3 & 12 & -2.4434 & 1 & 24 \\
\hline Peru & -2.1707 & 1 & 24 & -2.1241 & 4 & 24 & -2.0167 & 3 & 1 \\
\hline Trin \& Tobago & -4.0604 & 4 & 6 & -4.1108 & 4 & 3 & -3.9766 & 4 & 3 \\
\hline Venezuela & -1.9088 & 4 & 24 & -1.8115 & 2 & 12 & -1.6352 & 4 & 24 \\
\hline \multicolumn{10}{|l|}{ Asia } \\
\hline Bahrain & -4.0467 & 3 & 1 & -4.0643 & 4 & 3 & -3.9801 & 3 & 1 \\
\hline Bangladesh & -1.9786 & 4 & 24 & -1.9829 & 1 & 6 & -2.0105 & 1 & 6 \\
\hline China & -1.7194 & 4 & 12 & -1.6878 & 3 & 24 & -1.6960 & 4 & 24 \\
\hline India & -2.1647 & 2 & 24 & -2.1644 & 3 & 3 & -2.1571 & 3 & 3 \\
\hline Indonesia & -2.1974 & 4 & 24 & -2.1192 & 4 & 24 & -2.1195 & 1 & 1 \\
\hline Israel & -2.6179 & 3 & 24 & -2.6670 & 2 & 1 & -2.6314 & 2 & 24 \\
\hline Jordan & -3.3857 & 2 & 24 & -3.3752 & 2 & 24 & -3.3717 & 2 & 24 \\
\hline Malaysia & -2.7817 & 4 & 3 & -2.7748 & 2 & 3 & -2.7041 & 1 & 24 \\
\hline Oman & -3.0693 & 2 & 24 & -3.0757 & 4 & 24 & -2.9414 & 2 & 24 \\
\hline Pakistan & -2.1761 & 4 & 6 & -2.1489 & 1 & 3 & -2.0601 & 2 & 1 \\
\hline Philippines & -2.1929 & 1 & 3 & -2.1469 & 4 & 3 & -2.1003 & 4 & 3 \\
\hline Saudi Arabia & -2.7918 & 4 & 24 & -2.7228 & 4 & 1 & -2.7272 & 1 & 24 \\
\hline South Korea & -2.3922 & 3 & 1 & -2.3966 & 3 & 1 & -2.3164 & 4 & 1 \\
\hline Sri Lanka & -2.2175 & 1 & 1 & -2.2004 & 2 & 3 & -2.1960 & 2 & 3 \\
\hline Taiwan & -2.0132 & 1 & 12 & -2.0193 & 3 & 24 & -2.0285 & 1 & 12 \\
\hline Thailand & -2.1500 & 4 & 24 & -2.0615 & 4 & 12 & -2.0134 & 4 & 3 \\
\hline Turkey & -1.1842 & 1 & 3 & -1.1710 & 1 & 24 & -1.1349 & 3 & 1 \\
\hline \multicolumn{10}{|l|}{ Europe } \\
\hline Bulgaria & -2.3481 & 2 & 24 & -2.2723 & 4 & 24 & -2.1618 & 4 & 12 \\
\hline Croatia & -2.7976 & 4 & 24 & -2.8150 & 4 & 24 & -2.6332 & 4 & 3 \\
\hline Cyprus & -1.9668 & 4 & 24 & -1.8948 & 2 & 24 & -1.8813 & 1 & 3 \\
\hline Czech Republic & -2.7523 & 4 & 24 & -2.6183 & 3 & 24 & -2.6080 & 1 & 24 \\
\hline Estonia & -2.6779 & 4 & 6 & -2.6060 & 3 & 24 & -2.5603 & 4 & 3 \\
\hline Greece & -2.0156 & 4 & 24 & -1.9333 & 4 & 6 & -1.8818 & 1 & 3 \\
\hline Hungary & -2.2343 & 4 & 6 & -2.1670 & 1 & 12 & -2.1455 & 4 & 6 \\
\hline Latvia & -2.3403 & 1 & 24 & -2.1626 & 1 & 1 & -2.0968 & 3 & 24 \\
\hline Poland & -2.2183 & 3 & 12 & -2.2468 & 2 & 24 & -2.2007 & 2 & 12 \\
\hline Portugal & -2.9546 & 2 & 1 & -2.9724 & 2 & 1 & -2.9037 & 1 & 24 \\
\hline Romania & -1.9775 & 4 & 24 & -1.9025 & 4 & 12 & -1.8639 & 4 & 12 \\
\hline Russia & -1.6687 & 4 & 24 & -1.6157 & 2 & 6 & -1.6330 & 2 & 24 \\
\hline Slovakia & -3.0022 & 3 & 24 & -2.9524 & 2 & 6 & -2.8793 & 3 & 24 \\
\hline Ukraine & -1.6978 & 2 & 1 & -1.7516 & 4 & 1 & -1.5376 & 1 & 1 \\
\hline
\end{tabular}


tional equity returns and is there any difference across emerging and developed markets? We used the change and squared change (volatility) of these variables explained in the methodology. We found that only a few markets are exposed to the risk components. Table 3.5 presents the results for the risk components, political and composite risk. The first risk measure is government action (GA) which assesses the government stability, socioeconomic conditions and investment profile. If the government is not stable, then there is uncertainty about the future policies which can affect the asset prices. So as the uncertainty increases related to government actions, it should affect the stock returns. Columns 2 and 5 exhibit the results of government action (change and squared change). Only two countries have negative and significant results for both variables (change and squared change).

The second measure of the risk is the conflict $(\mathrm{CON})$, which is the internal conflicts, external conflicts, ethnic and religious tensions and results are presented in Table 3.5. We did not find any significant results for conflict measure (see column 3). For the conflict as a squared change, only three countries are with significant coefficients. Our third risk measure is the quality of governance (QG) which consists of democratic accountability, corruption, military in politics, law and order. As the uncertainty about this measure increases there should be a negative impact on the returns. For the quality of governance (change), we found only one market and for squared change (volatility) three markets with significant negative coefficients. Similar results were found for political risk as the change in column 8 is significant for 3 markets and for squared change in column 9 only one country. The last two columns of Table 3.5 present the results of composite risk. These are also not significant for the majority of the developed markets. Overall five countries have significantly results, three with the change and two with squared change.

Turing towards the emerging markets, Table 3.6 presents the coefficient of the risk components, political risk and composite risk. The result of the coefficient of government action is presented in column 2 (change) and column 5 (Squared change) of Table 3.6. Overall for the emerging market the risk associated with the monthly change in the government action measure is negative and statistically significant for ten markets. This implies that as the uncertainty about the government actions increases returns from the equity market decrease. The coefficient for government action measure (squared change) is significantly negative for six markets. This implies that as the volatility of government actions increases, returns from equity market decrease.

The results related to the conflict variable are in column 3 (change) and column 6 (Squared change) of Table 3.6. We found that the majority of the countries from the Asian region are affected by the conflict as six countries are with negative and statistical coefficient as compared to the Americas with 


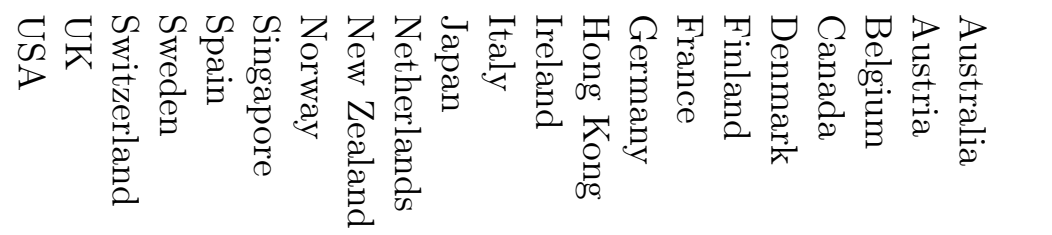

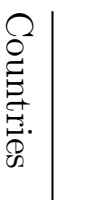

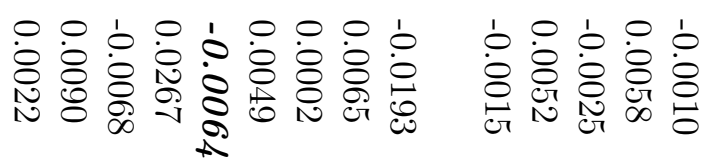

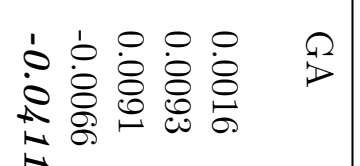

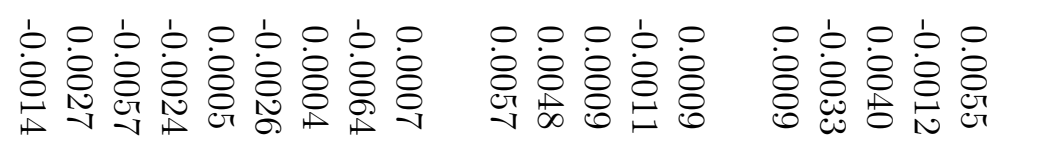

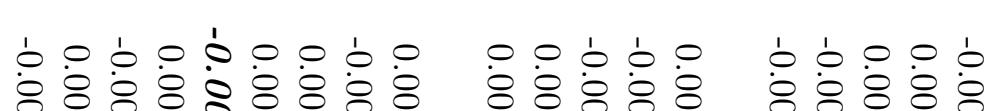

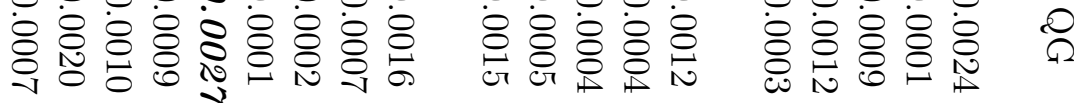

它

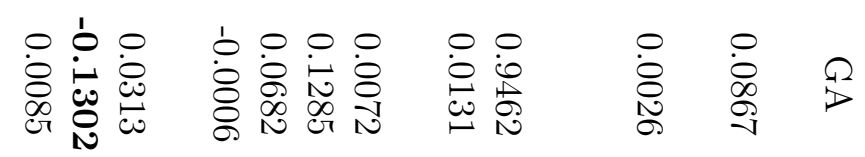

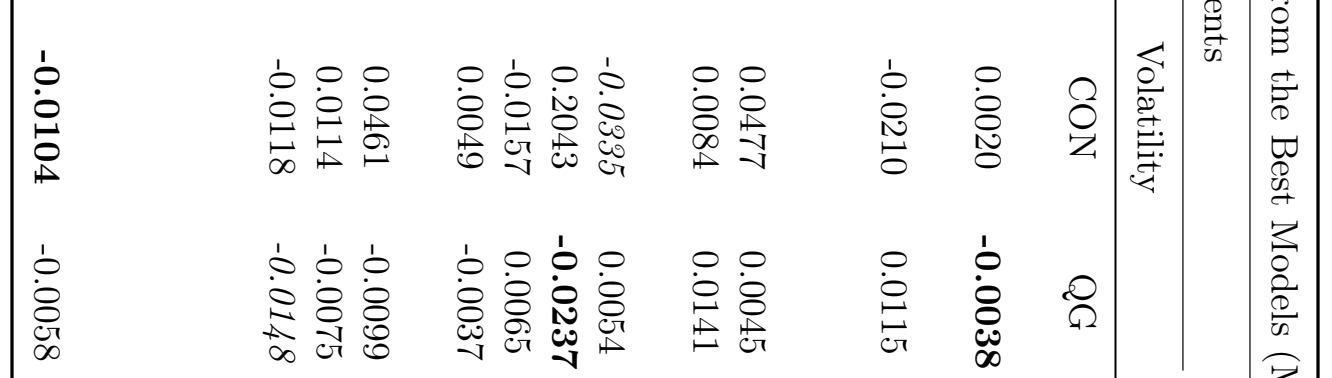

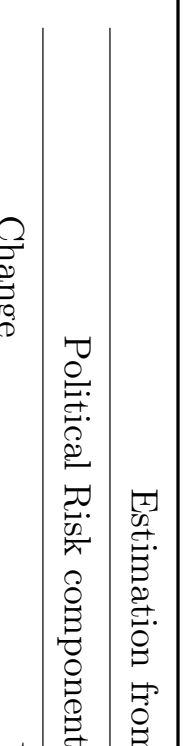

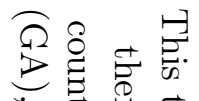

$\Omega$ 究

$0<{ }^{2}$

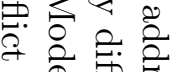

$\widehat{\Omega} \oplus \widehat{0}$

O०

艾菅

8 웅

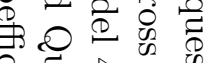

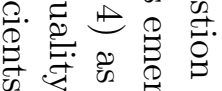

융

० व

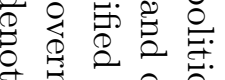

है

ঊ.

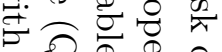

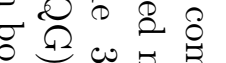

$\bar{\alpha} \dot{\omega}$

\%

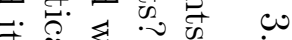

芦递尔

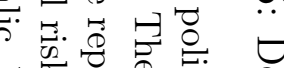

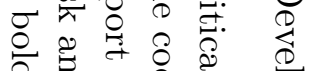

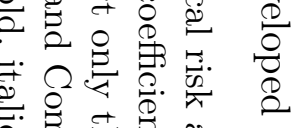

菅志志范

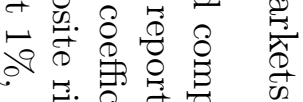

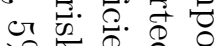

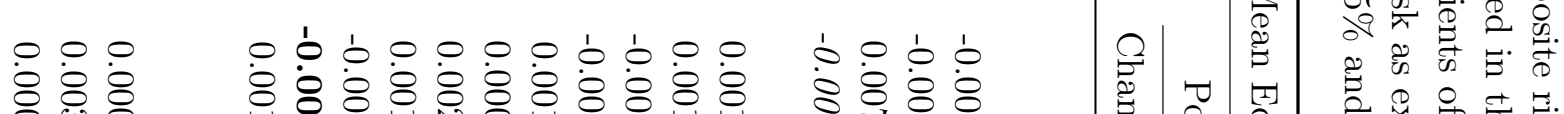

泵品

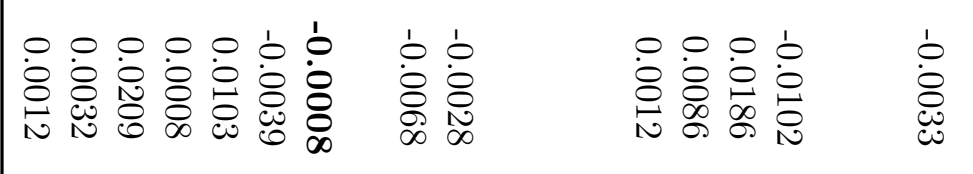

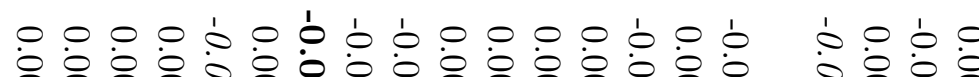

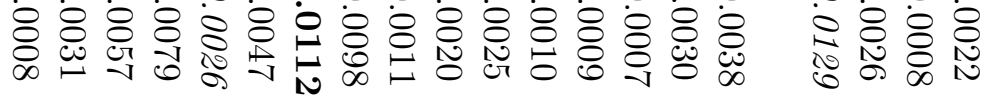

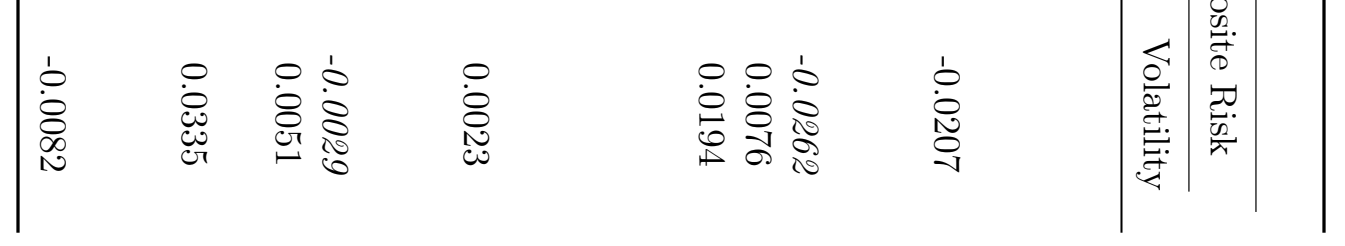

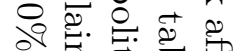

क

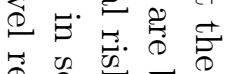

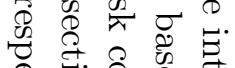

० 0 ० 80

त.

i

虽常宽

응

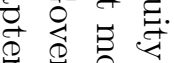

늉ㅇㅇ

영 क्ष

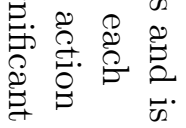


only one market (Trin \& Tobago) with significant negative returns. As for the African and European regions, we found negative significant results for the two markets from each region. Overall, for the emerging markets 11 countries' stock market returns are affected by the conflicts. The coefficient for conflict measure (squared change, results in column 6) is negative and statistically significant for six markets. This implies that as the volatility of conflict increases, returns decreases.

The results are presented in column 4 (change) and column 7 (Squared change) of Table 3.6 for quality of governance. The results are interesting as we found the mixed results for the emerging markets, as the coefficients are significantly negative for six markets in the Asian region; however no significant coefficient was found for the European region. Overall, eight emerging markets display significant negative results. The coefficient for quality of governance measure (squared change, results in column 7) is significantly negative for six emerging markets. This implies a negative relationship between volatility of quality of governance and returns.

Table 3.6 also displays the results for political risk in column 8 (change) and column 9 (squared change). We found interesting results as there are few markets that are significant for all political risk components but not for political risk. Overall, for the emerging market the risk associated with the change in political risk is negative and statistically significant for twelve markets. The coefficient for political risk (squared change, column 9) is significantly negative for seven markets. This implies that as the uncertainty of political risk increases returns from equity market decrease. The results of composite risk (both for change and squared change) are displayed in columns 10 and 11 of Table 3.6. It can be noted that composite risk (change) is not significant for the majority of emerging markets. The coefficient for composite risk (squared change, results in column 11) is significantly negative for six markets.

We conclude that emerging markets are more exposed to all risk variables (GA, CON, QG, Political risk and Composite risk) compared to the developed markets. The government action measure (change) is significantly negative for 10 out of 47 (with a ratio of $21 \%$ ) and two out of 21 (with a ratio of 9.5\%) for developed markets. As for the conflict measure (change), we found 11 out of 47 (with a ratio of 23\%) emerging and none for the developed markets. For the quality of governance measure (change) the coefficient is negative and significant for eight markets from emerging markets (with a ratio of 17\%) and one for the developed markets (with a ratio of $4.7 \%$ ).

Moving toward the square deviation of these variables, the government action measure is significantly negative for six out of 47 (with a ratio of 13\%) and two out of 21 (with a ratio of $9.5 \%$ ) for developed markets. As for the conflict measure, we found six out of 47 (with a ratio of 13\%) emerging and two for 


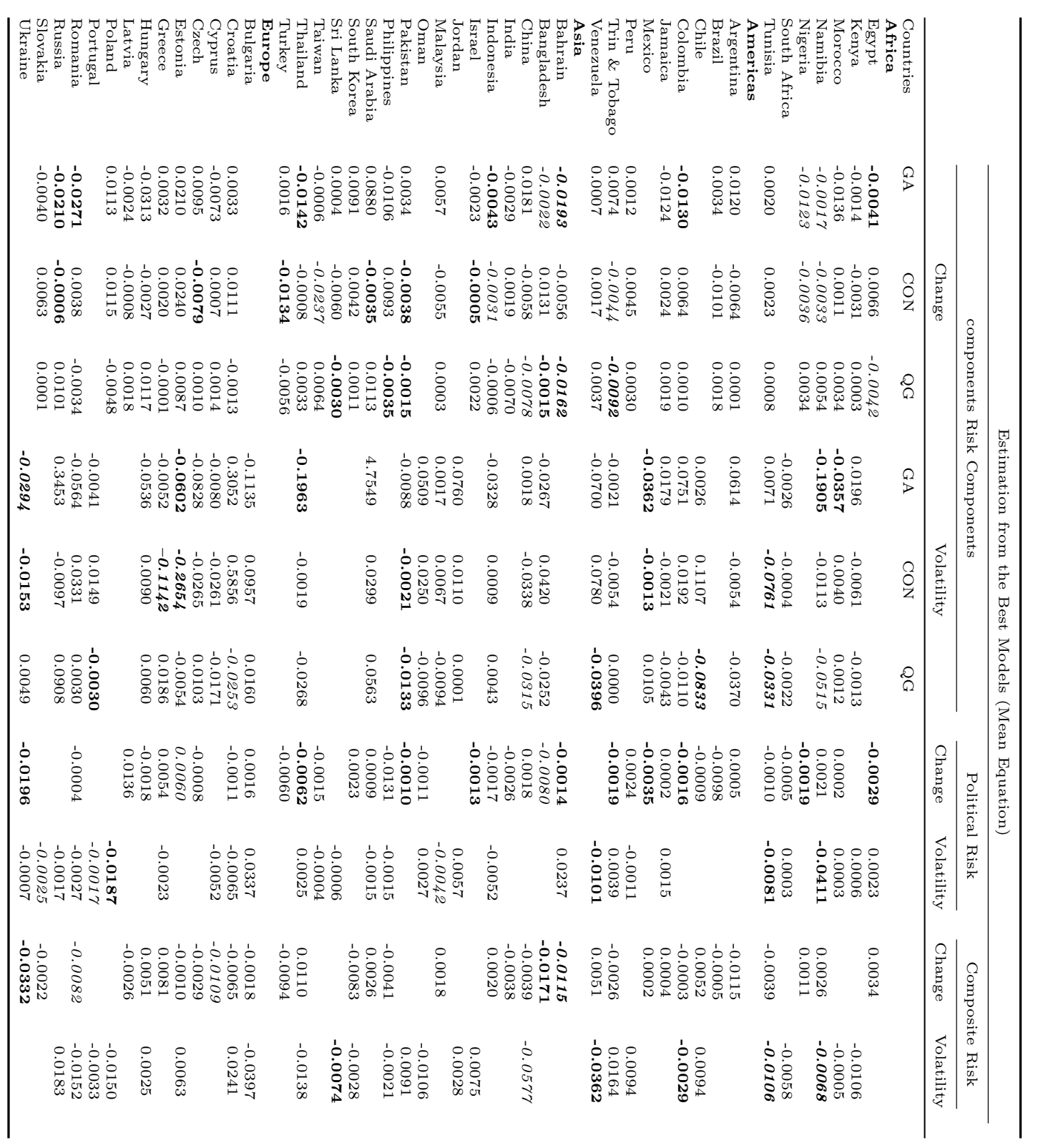

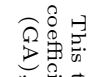

을

解.

每:

爱言亭

o

害要

品 :

0
0
0
0

年

요용

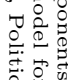

:

气

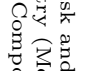

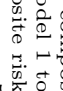

อ

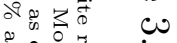

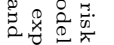

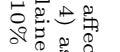

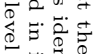

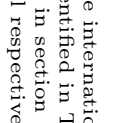

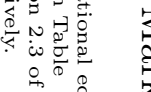

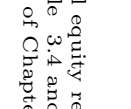


the developed markets. For the quality of governance measure the coefficient is negative and significant for eight markets from emerging markets (with a ratio of $17 \%$ ) and one for the developed markets (with a ration of $4.7 \%$ ).

Political risk is more important for the emerging markets than developed. A $26 \%$ ratio of the emerging markets is influenced by the change in political risk variable compared with only $9 \%$ for developed markets. Where as for the squared change the ratio of significant results is $15 \%$ and $4.7 \%$ for emerging and developed markets respectively. The ratio of significant results for the composite risk (change) is $11 \%$ for the emerging markets, whereas it's $14 \%$ for the developed markets. For the squared change it's 13\% for emerging markets and $9.5 \%$ for developed markets.

Overall we conclude that increase in political risk component, political risk and composite decrease the equity market returns for majority of the developed and emerging markets. The results are stronger and more significant for emerging markets. These results are in line with the research that increase in political risk decreases equity returns (see Cosset \& Suret (1995); Bilson et al. (2002); Lehkonen \& Heimonen (2015); Dimic et al. (2015) ).

\subsubsection{Political risk exposure from variance equation}

In this section we examine the following question "do political risk components, political risk and composite risk affect the international equity returns' volatility and is there any difference across emerging and developed markets? Columns 2 and 5 of Table 3.7 exhibit the results of government action (change and squared change). Only two countries are with positive and significant results. We did not find any significant results for conflict measure when measured as squared deviation (see column 6). For conflict as change, we found significant results for the US market only, for the quality of governance (Change) only two and for squared change (volatility) three markets with significant positive coefficients. Similar results were found for political risk and only three markets with significant positive results. The last two columns of Table 3.7 present the results of composite risk. Only five countries are with significant results, three with change and two with squared change.

The results from the estimation of the variance equation from the best model (Model 1 to Model 4) for emerging markets are presented in Table 3.8. Table 3.8 is divided into four parts. First is the results for the African region, second, is the Americas, third for Asia, and fourth for the European region. The result of the coefficient of government action is presented in column 2 (change) and 5 (Squared change) of Table 3.8. The results confirm that the volatility of the return increases as the uncertainty about government action (change) measure increases. The coefficient for government action measure is significantly positive 
for six emerging markets, where as the squared change of government action is significant for three markets in the African region and one for each in Asia and Europe. The conflict measure (change column 3) is positive and statistically significant for two markets from the African region, six from Asia, and three from Europe. The coefficient for conflict measure (squared change, results in column 6) is significantly positive for one market each from Africa, and, the Americas and two each from Asia and Europe.

Our third risk measure is the quality of governance $(\mathrm{QG})$ and results are presented in column 4 (change) and 7 (Squared change) in Table 3.8. The results are interesting as we find the mixed results across four regions. The coefficients are significantly positive for four markets in the Asian region; however no significance was found for the European region. The coefficient for quality of governance measure (squared change, results in column 7) is significantly positive for three markets from both the Americas and Asia. However, for Europe and Africa there were only 2 market from each region with positive significant results.

Table 3.8 also displays the results for political risk in columns 8 (change) and 9 (squared change). We found more significant results for both variables (change and squared change) compared to returns. The coefficient for political risk (change) is significantly positive for five countries from Europe, four from the Americas, three from Asia and only one from Africa. This implies that as political uncertainty increases the volatility of returns also increases. The coefficient for political risk measure (squared change, see column 9) is positively significant for five markets from the African, and two each from the other three regions. This implies a positive relationship between volatility of political risk and volatility of returns.

The results of composite risk (both for change and squared change) are displayed in columns 10 and 11 in Table 3.8. It can be clearly noted that composite risk (change) is significant for the majority of emerging markets from the European region. The coefficient for composite risk (squared change, results in column 11) is significantly positive for five markets from Africa, the Americas, and Asia. However, for the Americas only two markets were found with significant results.

We conclude from the volatility results that emerging markets are more exposed to all the risk variables (GA, CON, QG, political risk) than the developed markets. However, there is not much difference when we use the composite risk. The government action measure (change) is significantly positive for six out of 47 (with a ratio of 13\%) and two out of 21 (with a ratio of 9.5\%) for developed markets. As for the conflict measure (change), we found eleven out of 47 (with a ratio of $23 \%$ ) emerging and only one for the developed markets. For the quality of governance measure (change) the coefficient is negative and significant for 6 
CHAPTER 3. EFFECT OF POLITICAL RISK ON STOCK MARKET

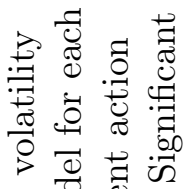

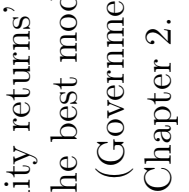

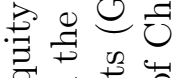

क्ष

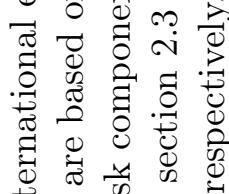

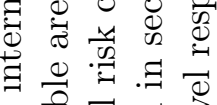

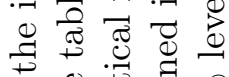

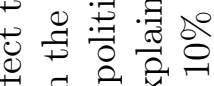

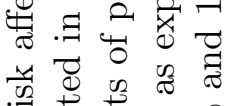

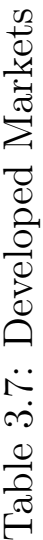

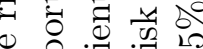

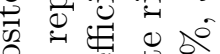

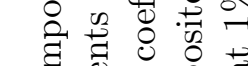

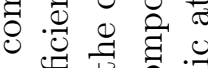

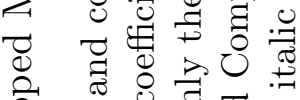

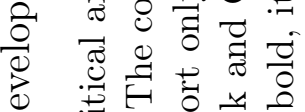

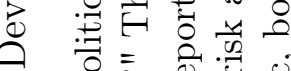

类

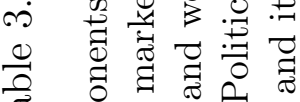

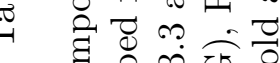

영

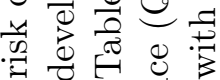

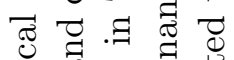

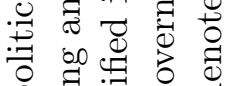

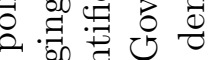

원

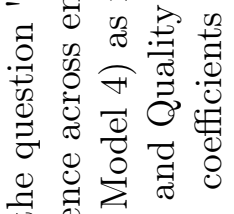

象

政

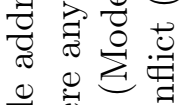

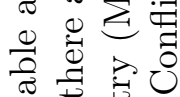

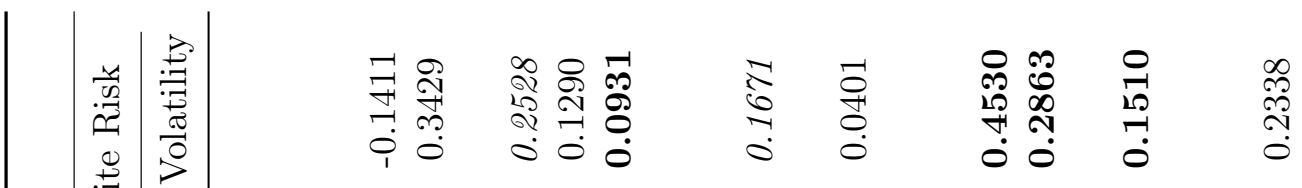

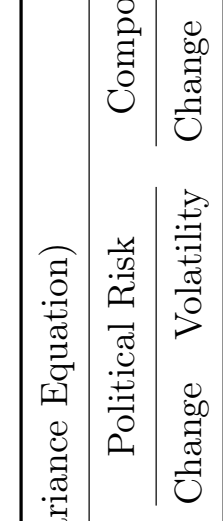

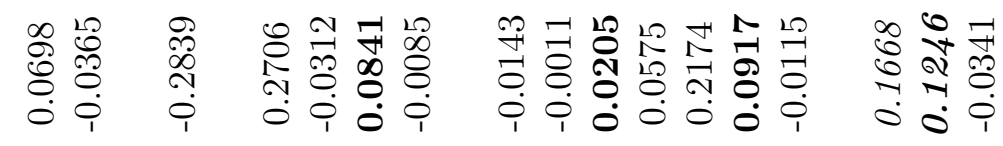

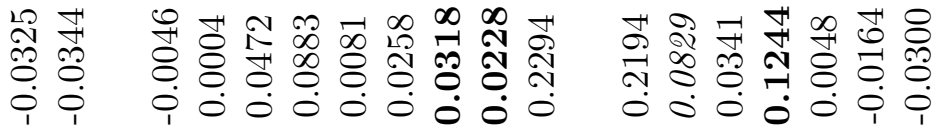

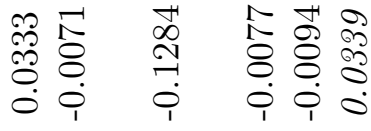

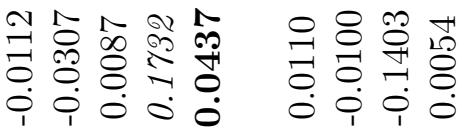

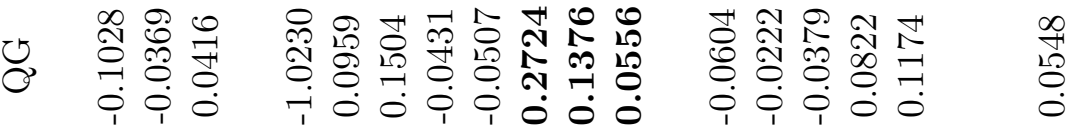

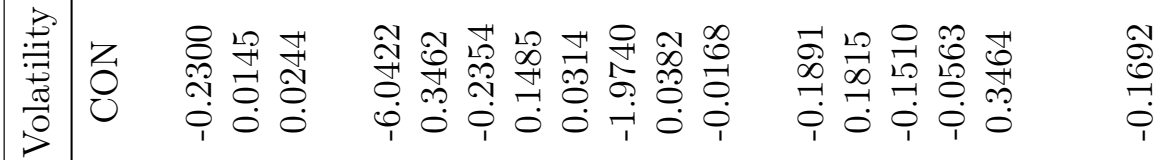

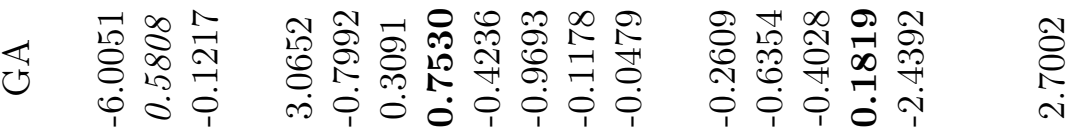

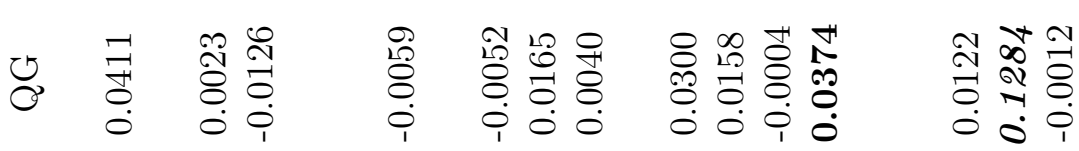

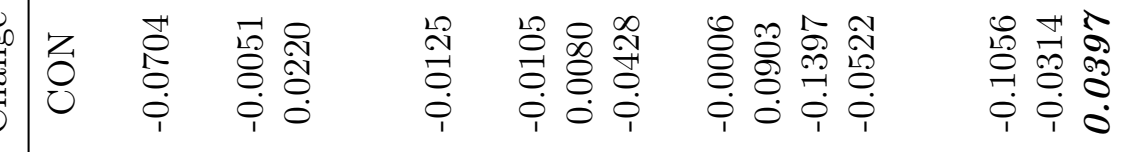

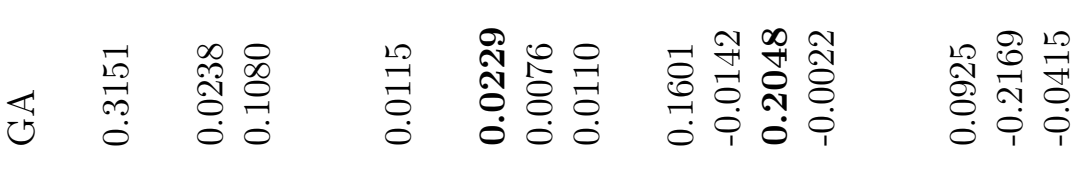

鄫敦 


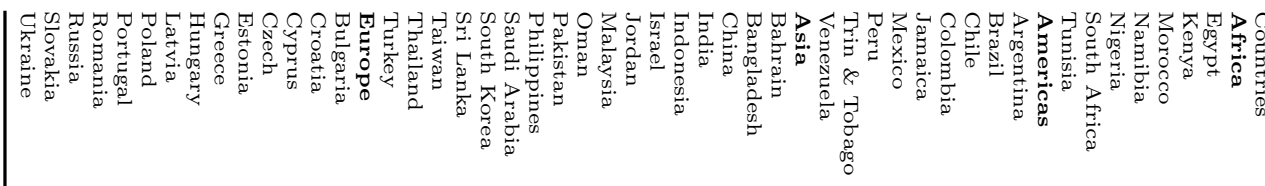

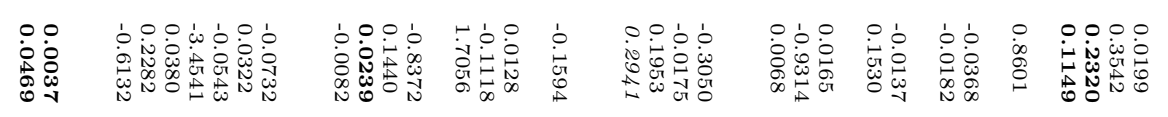

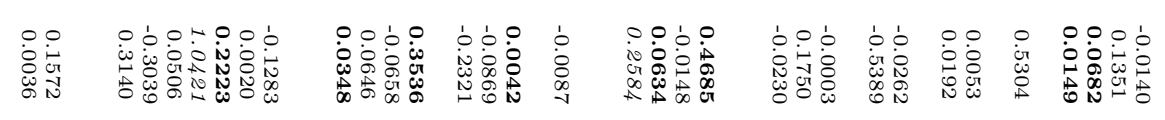

算

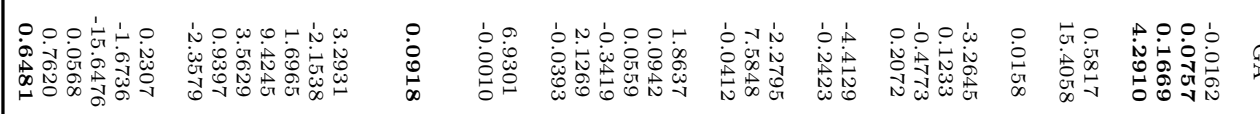

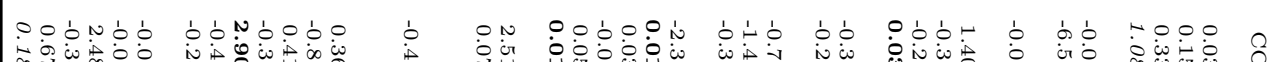

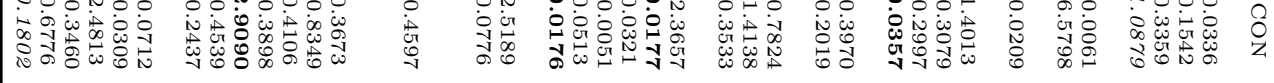

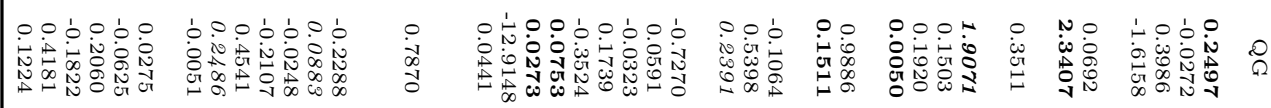

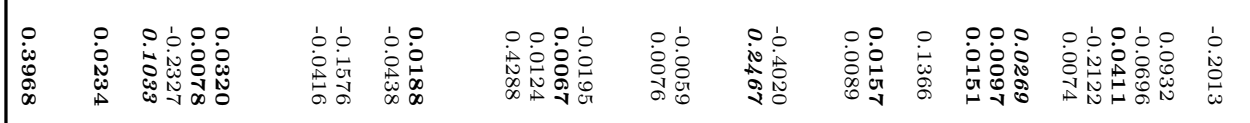

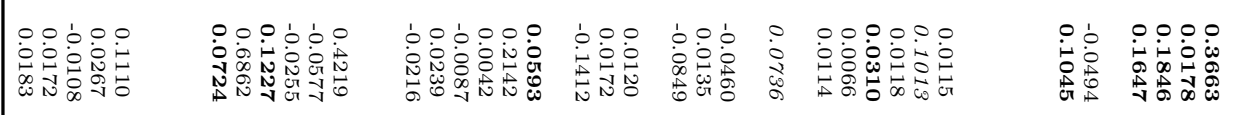

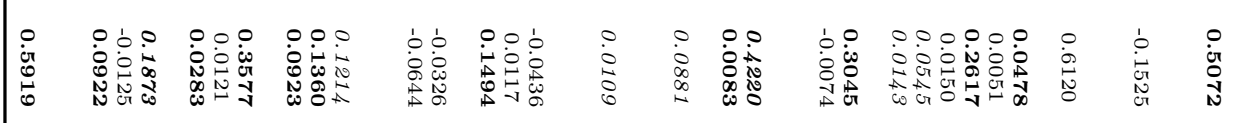

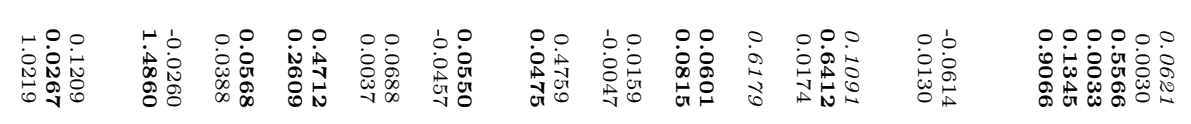


markets from emerging markets (with a ratio of $13 \%$ ) and two for the developed markets (with a ratio of $9.5 \%$ ).

Moving toward the squared change of these variables, the government action measure is significantly positive for five out of 47 (with a ratio of 11\%) and two out of 21 (with a ratio of 9.5\%) for developed markets. As for the conflict measure, we found six out of 47 (with a ratio of 13\%) for emerging markets and none for the developed markets. For the quality of governance measure the coefficient was positive and significant for ten markets from emerging markets (with a ratio of $21 \%$ ) and three for the developed markets (with a ratio of $14 \%$ ).

Political risk is more important for the emerging markets compared with developed. A $23 \%$ ratio of the emerging markets is influenced by the change in political risk variable compared with $14 \%$ for developed markets. For the squared change the ratio of significant results is $23 \%$ and $14 \%$ for emerging and developed markets respectively. The ratio of significant results for composite risk (change) is $32 \%$ for the emerging markets, whereas it's $23 \%$ for the developed markets. For the squared change it's 36\% for emerging markets and $29 \%$ for developed markets.

Overall we can conclude from the results of both developed and emerging markets that volatility of return increases with an increase in political risk. We also concluded that political risk components are more useful than political risk or composite risk. The findings are in line with the ongoing research related to political risk and stock market volatility. (see Bekaert \& Harvey (1997); Kabir Hassan et al. (2003); Pástor \& Veronesi (2013); Suleman \& Daglish $(2015))^{4}$.

\subsection{Discussion}

We hypothesis that when political uncertainty is not significant, this is generally due to absence of variation in political risk index. The political uncertainty is calculated as the standard deviation of $\triangle P R$. As the political uncertainty drives $s e(\beta)$, more uncertainty means smaller se. So we compare the political uncertainty with the significant level of coefficients. We find strong evidence that higher the political uncertainty leads to higher significant level. For the purpose of comparison, we divide the political uncertainty into three groups i.e. low, medium and high. The ranges for these three are presented in Table 3.9. We find that at low political uncertainty there is no significant at $10 \%$ level (23 emerging and 15 countries are in range of low political uncertainty). Whereas at

\footnotetext{
${ }^{4}$ For example Pastor and Veronesi propose a theoretical model that stock market volatility increase more when political risk is higher and show empirical evidence for USA. Suleman and Daglish (2016) find similar result for international markets by empirically testing Pastor and Veronesi for world markets
} 
Table 3.9: Political Uncertainty and Level of Significant

\begin{tabular}{lccccccc}
\hline Political & Range & $\begin{array}{c}\text { Developed } \\
\text { significant }\end{array}$ & $\begin{array}{c}\text { Developed } \\
\text { total }\end{array}$ & $\begin{array}{c}\text { Proportion } \\
\text { significant }\end{array}$ & $\begin{array}{c}\text { Emerging } \\
\text { significant }\end{array}$ & $\begin{array}{c}\text { Emerging } \\
\text { total }\end{array}$ & $\begin{array}{c}\text { Proportion } \\
\text { significant }\end{array}$ \\
Small & 0.00 to 0.99 & 0 & 15 & 0 & 0 & 23 & 0 \\
Medium & 1.01 to 1.99 & 1 & 4 & $25 \%$ & 13 & 18 & $72 \%$ \\
Large & 2.00 to 3.00 & 2 & 2 & $100 \%$ & 6 & 6 & $100 \%$ \\
\hline
\end{tabular}

medium political uncertainty $25 \%$ developed markets and $72 \%$ emerging markets are significantly show that increase in political uncertainty increase the significant level (1 out of 4 developed countries and 13 out of 18 emerging markets with significant results). Lastly the stronger results found for higher political uncertainty range as results shows strong results to our initial hypotheses that increase in political uncertainty have more impact on asset prices compared to low political uncertainty ( 2 out of 2 developed and 6 out of 6 emerging markets with significant results).

The next question arises can we compare the results across countries by using the regression coefficient equivalent between sample of developed and emerging markets. We are unable to perform this, because for each country the coefficient of $\triangle P R$ is estimated and has standard errors that depend on the individual countries among other thing. The set of regression coefficients for developed and emerging countries e.g.

$$
\begin{array}{ll}
\widehat{\beta_{z, i}} & i=1, \ldots, n_{d e v} \\
\widehat{\beta_{z, k}} & k=1, \ldots, n_{\text {emg }}
\end{array}
$$

are not iid random variables. The t-statistics could be considered iid drawings from $t_{T ? p}$ distribution but only if $H_{0}: \beta_{z, i}=0$ which we cannot guarantee.

\subsection{Conclusion}

In this chapter, we extended the ongoing research on political risk and its impact on stock market returns and volatility. Most of the research was conducted by using composite political risk and the main focus was on its implication on the returns. Further, there is no consistent modelling approach to fit political risk. So we extended the current debate on the link to political risk not only on returns but also on volatility of returns. First we started with the selection of the best model and the best lag for each country on the basis of AIC. We also investigated the level of aggregation by estimating three different alternatives (political risk components, political risk and composite risk). Then we used the best model and lag to analyse the impact of political risk on the return and volatility of developed and emerging markets.

Results reveal that the best result (lowest AIC) is obtained when political 
risk components are used both for developed and emerging markets. We found that model 4 with Lag 24 is the best for the majority of emerging and developed markets. Further, we also conclude that the impact of political risk components (GA, CON, QG) is more on emerging markets. Overall we find that impact of all the variables is more on volatility than on returns. 


\section{4 \\ Political risk, firm and industry volatility}

This chapter is an extension of the work presented in Chapter 3. Chapter 3 looks at the main stock market indices of each country, whereas this chapter examines the impact of political risk on individual firms and industry portfolios of both Pakistan and New Zealand ${ }^{1}$.

\subsection{Introduction}

In the literature, a majority of the empirical research on the link between political risk, stock market returns and volatility focused on the main index of the stock market (as in Chapter 3). However, only a few authors investigated a firm or industry level relationship.

The uncertainty generated from future political events, such as elections, and their relationship to investment and the stock market has been investigated by Durnev (2010) and Julio \& Yook (2012). Authors used a different measure for the proxy of political risk and reported significant increase in volatility due to an increase in political risk (for example, Boutchkova et al. (2012); Durnev (2010)). Julio \& Yook (2012) note a decrease in investment during election years, finding evidence to support the hypothesis that political uncertainty causes firms to reduce investment until electoral outcomes become known. Li \& Born (2006) support their hypothesis that uncertainty about US presidential elections is

\footnotetext{
${ }^{1}$ This chapter was circulated and presented with a title of "Political Risk and Risk Premia: Evidence from Firm Level Analysis." We are thankful for valuable comments and suggestions of the participants at the 56th New Zealand Association of Economists Annual Conference, 2015 and Victoria University Brown Bag Seminar Series, 2015.
} 
reflected in pre-election common stocks. They further indicate that if there is no dominant candidate, stock market volatility and average returns rise.

Pástor \& Veronesi (2013) concluded that government policies have heterogenous effects. They specified that stock prices are driven by three types of shocks: capital shocks, impact shocks, and political shocks. Political shocks are the result of learning about political costs, the uncertainty of which they refer to as political uncertainty of prospective policies. Their empirical results for the US market demonstrate thats stocks are more volatile and more correlated during high political uncertainty and when economic conditions are not good. Further, high risk premiums are reported during bad economic conditions and high political uncertainty. This theoretical model is further extended to option markets by Kelly et al. (2016). They examined the impact of political uncertainty (political events) on the equity index option market for 20 markets. Their empirical results confirm that equity options spanning political events are more expensive as they work as a hedge against the political risk.

But the question remains, does political risk, the uncertainty about possible government actions and policies have a direct effect on stock market returns and volatility? We examined the impact of political risk quantified by the ICRG on the return and volatility of all the firms and industry portfolios of Pakistan and New Zealand. We chose these two markets as the political system of both countries is parliamentary. However, the political system in Pakistan is more uncertain (i.e., higher PR values) compared to New Zealand. To our best knowledge this is the first empirical exercise using stock returns and volatility models to confirm the significance of the political risk at firm and industry levels for these countries. Further, we examine the hypothesis: are some industries more sensitive to political risk components and political risk than others?

Empirical results confirm that political risk has more impact on Pakistani firms compared to New Zealand firms and also that investors perceive the political risk differently (both positive and negative) across firms. This is because a change in government might be good news for some firms but bad for others. Overall, we conclude that the impact of political risk is more on volatility than returns. Further, the results from the political risk components of the returns and volatility exhibit a large impact on Pakistan industries. More specifically the impact of the conflict component is more on both return and volatility compared to the other two components (government action and quality of governance). We also conclude that there are industries that are more sensitive to political risk components and political risk than other industries.

The rest of the chapter is organized as follows. Section 2 describes the literature review. Data used in this paper is presented in Section 3. Section 4 discusses the methodology and section 5 provides empirical analysis. Section 6 is the conclusion. 


\subsection{Literature review}

Goriaev \& Sonin (2005) examine the type of political risk encountered by Russian firms using the stock market data. The following market model was used to investigate the impact of news related to Yukos on the stock prices:

$$
r_{t}=\alpha_{0}+\alpha_{1} \operatorname{Pos}_{t}+\alpha_{2} N e g_{t}+\alpha_{3} r_{m, t}+\epsilon_{t}
$$

where $r_{t}$ is the returns and $r_{m, t}$ returns of market index on day $t$. Dummy variables equal to 1 for Pos and Neg are used to represent positive and negative events respectively. The finding suggests that returns are mostly influenced by employee related charges rather than company related charges. Further, they found that during the first stage of the Yukos affair, the action taken by the state agencies had a negative impact not only on Yukos's returns but also on other Russian firms returns.

Industry level return volatility was investigated by Boutchkova et al. (2012). They constructed three annual volatility measures from the weekly returns: total, idiosyncratic and systematic, volatility for a period of 1990 to 2006. A range of political variables was used for the analysis such as political risk (ICRG), autocracy, national election, party orientation etc. The following panel regression is estimated for the empirical results:

$\ln \sigma_{\text {ind,t }}^{2, c}=\alpha_{i n d}+\delta_{c}+\eta_{t}+\beta_{1} \operatorname{Sen}_{\text {ind,t }}^{c} \operatorname{Pol}_{t}^{c}+\beta_{2}$ Pol $_{t}^{c}+\beta_{3} \operatorname{Sen}_{\text {ind, } t}^{c}+\beta_{1} X_{\text {ind, } t}^{c}+\epsilon_{\text {ind, } t}^{c}$

The above specification includes industry, country and year fixed effects, ind stands for industry, $c$ for country and $t$ years. $\ln \sigma_{\text {ind, } t}^{2, c}$ is the $\log$ of annual volatility, and the control variables $X_{i n d, t}^{c}$ include country economic and industry specific indicators. Using the realized volatility of weekly stock returns, they found that industries sensitive to politics have more volatile returns around national elections. Further, they also found a higher volatility for industries during political uncertainty that are more dependent on labor, contract enforcement and trade. The decomposition of volatility results conclude that idiosyncratic volatility is associated with global political risk whereas systematic is associated with local political uncertainty.

Julio \& Yook (2012) examined the impact of political uncertainty using the national election data as a source of uncertainty on the investment behavior of the firms. They used the annual data 248 elections in 48 countries for the period of 1980 to 2005. Country level data used in their paper include real GDP, central government spending, inflation, and real interest rate from the World 
Bank and money supply (M1) and government stability from ICRG. Further, the firm level data are used from the World scope data base. The following model was estimated for their analysis:

$$
I_{i, t}^{c}=\alpha_{i}+\delta_{t}+\beta_{1} E D_{t}^{c}+\beta_{2} E D_{t}^{c} X_{t}^{c}+\beta_{3} X_{t}^{c}+\beta_{4} Q_{i, t-1}+\beta_{5} C F_{i, t}+\beta_{6} \Delta G D P_{t-1}^{c}+\epsilon_{i, t}^{c}
$$

where $I_{i, t}^{c}$ stands for investment (capital expenditure scaled by the book value of total assets at the start of the year), $i$ stands for firms and $c$ for country. The election dummy is denoted by $E D$ equal 1 for an election year. The country specific characteristics $X_{t}^{c}$ include one of the following: common law, presidential system, or government stability. Other variables include $Q_{i, t-1}$ Tobin's $\mathrm{Q}, C F_{i, t}$ is cash flow, and $\triangle G D P_{t-1}^{c}$ denotes the change in real domestic product. Their finding suggest that firms reduce their investment on average by $4.8 \%$ during an election year compared to a non-election year. When they included the interaction of election dummy with country specific characteristics, they found a significant positive coefficient for the interaction term when government stability is used as a country characteristic. This suggests that firms reduce their investment significantly during relatively less stable government.

Lugovskyy (2012) addressed the question, does political risk translated as uncertainty about government actions and policies have a direct impact on asset prices by hypothesis that political risk is a contributing factor in asset pricing. The monthly data was used for the period 1927 to 2009 for cross-sectional and multivariate regression to evaluate the political risk premium. A dummy variable was used for the political regime equal to one otherwise zero. The finding suggests that the average excess returns are bigger when the government is under a Democratic Party compared to a Republic Party.

Frijns et al. (2012) examined the relationship between political crises and the level of stock market integration in emerging markets. Monthly stock market data at firm level were used for the period 1991 to 2006 and also political crises data from the International Crisis Behavior (ICB) project database. They used the following model for each country:

$$
\Delta R_{t}^{2}=\alpha_{0}+\beta_{1} \text { Crisis }_{t}+\beta_{2} X_{t}+\epsilon_{t}
$$

$\Delta R_{t}^{2}$ represents change in level of market integration, Crisis is the variable for international political crisis and $\mathrm{X}$ is the control variables. They conclude that the impact of political crises on the stock market integration depends on the characteristics of the crises. Furthermore, severe crises, crises that involve the US, regional crises, and crises that involve many parties have significantly negative effects on stock market integration.

The effect of political uncertainty on a firm's dividend policy was analysed by Huang et al. (2015b). They investigated that during political crises do firms 
terminate dividend payout? Is this more for multinational corporations? For the empirical analysis, they used the annual data of 35 countries from developed and emerging markets for a period 1990 to 2008. For the political risk proxy, international political crisis data was used from the International Crisis Behavior project database. During their sample period they found 99 international political crises. Their findings concluded that during high political risk t past dividend payers are more likely to discontinue dividends. Additionally, the impact of political risk is more for multinational corporations.

Suleman \& Daglish (2015) empirically examined Pastor and Veronesi's model by considering a panel of 57 emerging and developed markets. Their results were less clear for the international markets as only volatility of firms are affected by political risk during worse economic conditions but not the value-weighted average pairwise correlations. A higher risk premium is reported during political uncertainty during poor economic conditions.

More specifically, talking about impact of political risk on stock markets in New Zealand, Cahan, Malone, Powell \& Choti (2005) examined the link between the return and absolute returns during the governments of the Labour party and National party. They used the monthly data from Global Finance and New Zealand Statistics for a period 1931 to 1988 and 1988 to 2003 from DataStream. Their finding suggests that returns are lower under the Labour party compared to under National. The discussion on this issue was further analysed by Malone, Anderson \& Peng (2015). They examined how political orientation relates to stock market returns, especially small and large firms by using the firm level data for the period 1972-2010. Their findings suggest that party premium exists when the National party is in government and it's governed by small firms.

It can be concluded from the literature review that most of the research examined the impact of political risk (political events, political crises) by using the industry index and the main focus was on its implication on the returns. However, our study differs from others in three ways. First, we used the time series political risk measure from the ICRG as explained in Chapter 2. Second, in this study we extended it to the firm and industry level. Third, we also analysed the impact of political risk components and political risk on both return and volatility.

\subsection{Data}

The goal of Chapter 4 was to do a detailed analysis of two countries. Pakistan and New Zealand were obvious choices given the personal connection of author to these two countries. So the question become, thus are these a bad choice? We argue no, for the following reasons. First, New Zealand is a developed market and Pakistan is an emerging market. Second, both countries have 
similar parliamentary system. Third, Pakistan is more politicaly risky country as compared to New Zealand (see Figure 4.1). Lastly, there is lot of military involvement in politics in Pakistan which is different from New Zealand. The data on the firm level were obtained from DataStream and we divided the firms into different sectors according to the stock exchange classification for both New Zealand and Pakistan. We estimated the model for 185 firms divided into 18 industry indices for New Zealand: Agriculture \& Fishing, Building Materials \& Construction, Consumer, Energy, Finance \& Other Services, Food \& Beverages, Goods, Intermediate \& Durable, Investment, Leisure \& Tourism, Media \& Telecommunications, Mining, Ports, Primary, Property, Services, Textiles \& Apparel, and Transport.

The Pakistani data consist of 204 firms divided into 19 industries: Automobile \& Parts, Chemicals, Construction \& Materials, Equity Investment Instruments, Financial Services, Fixed Income Telecom, Food Producers, Forestry, General Industries, Household Goods, Industrial Engineering, Industrial Metal \& Mining, Life Insurance, Multiutilities, Nonlife Insurance, Oil \& Gas, Personal Goods, Pharma \& Biotech, and Travel \& Leisure. Political risk data used in this chapter is from ICRG data as explained in Chapter 2.

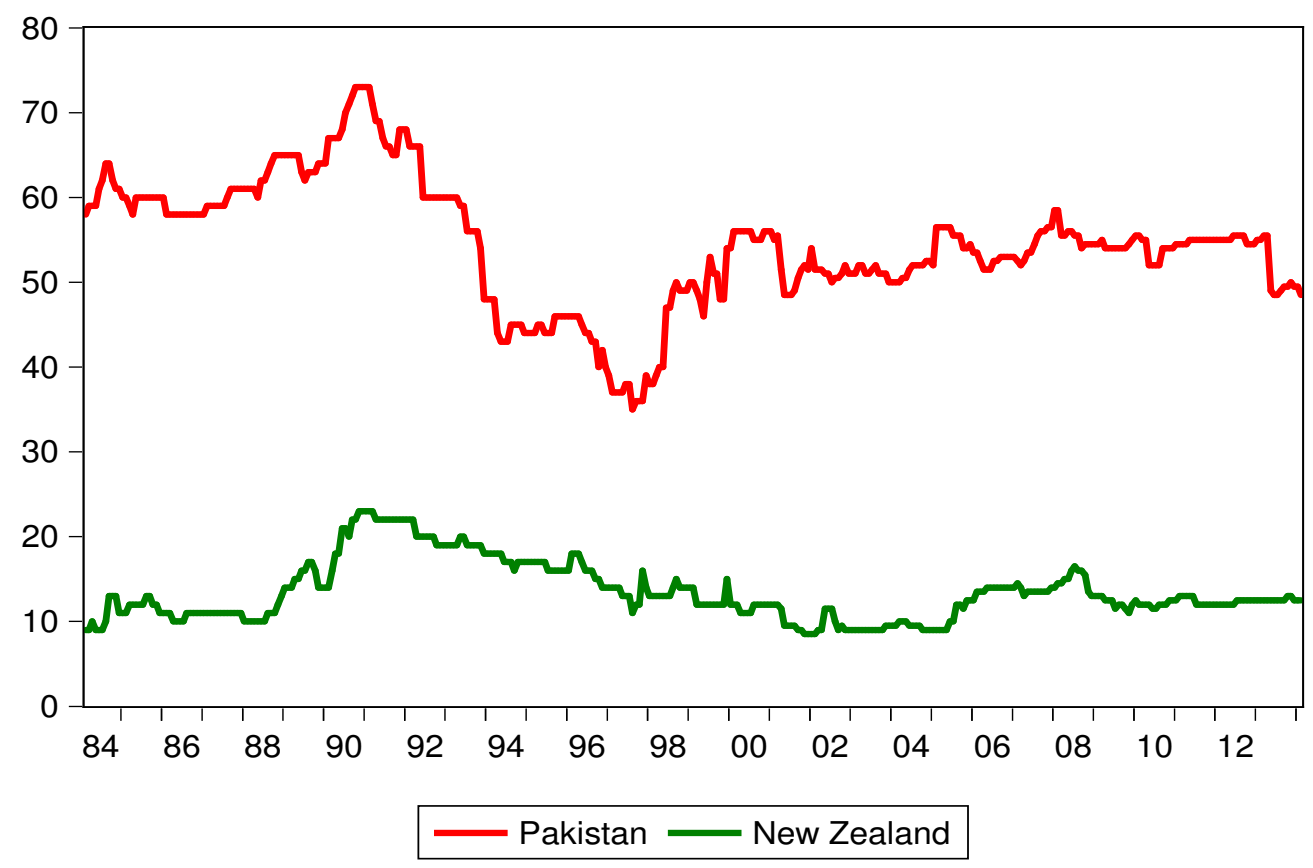

Figure 4.1: political risk

The political risk is by level and varies between 0 and 100, where higher values correspond to higher risk in the country.

The time series graphs of the political risk index for Pakistan and New Zealand are presented in Figure 4.1. The variation in the political risk for New 
Zealand is quite low. A high variation in the political risk is visible for Pakistan which is due to the political uncertainty in the country.

\subsection{Methodology}

In Chapter 3, we identified how to include political risk changes, which lag to calculate changes over and what level of aggregation to use at index level analysis for each country for political risk components, political risk and composite risk. So we continue with the same model as identified in Chapter 3 for Pakistan and New Zealand to analyse the impact of political risk components and political risk at firm and industry level. For each firm and industry the following time series model is estimated. Model 1 is used for each firm and industry using the political risk index, and Model 2 is used only for political risk components for industry portfolios:

Model 1

$$
\begin{gathered}
r_{i, t}=\phi_{0}+\phi_{1} r_{i, t-1}+\phi_{2} \Delta \mathrm{RM}_{t-1}^{j}+\phi_{3} \Delta \mathrm{X}_{t-1}^{j}+\epsilon_{i, t} \\
\log \left(\sigma_{i, t}^{2}\right)=\omega_{i}+\alpha_{i} f\left(z_{i, t-1}\right)+\beta_{1} \log \left(\sigma_{i, t-1}^{2}\right)+\beta_{2} \Delta \mathrm{RM}_{t-1}^{j}+\beta_{3} \Delta \mathrm{X}_{t-1}^{j}
\end{gathered}
$$

\section{Model 2}

$$
\begin{gathered}
r_{i, t}=\phi_{0}+\phi_{1} r_{i, t-1}+\phi_{2} \Delta \mathrm{RM}_{t-1}^{j}+\phi_{3}\left(\Delta \mathrm{RM}_{t-1}^{j}\right)^{2}+\phi_{4} \Delta \mathrm{X}_{t-1}^{j}+\phi_{5}\left(\Delta \mathrm{X}_{t-1}^{j}\right)^{2}+\epsilon_{i, t} \\
\begin{aligned}
\log \left(\sigma_{t}^{2}\right)= & \omega \\
+ & +\alpha f\left(z_{t-1}\right)+\beta_{1} \log \left(\sigma_{t-1}^{2}\right)+\beta_{2} \Delta \mathrm{RM}_{t-1}^{j}+\beta_{3}\left(\Delta \mathrm{RM}_{t-1}^{j}\right)^{2} \\
& +\beta_{4} \Delta \mathrm{X}_{t-1}^{j}+\beta_{5}\left(\Delta \mathrm{X}_{t-1}^{j}\right)^{2}
\end{aligned}
\end{gathered}
$$

where, $\Delta \mathrm{RM}_{t-1}^{j}$ is the change $\left(\Delta \mathrm{RM}_{t-1}^{j}=\mathrm{RM}_{t-1}-\mathrm{RM}_{t-j-1}\right)$ in the political risk from the ICRG data as explained in detail in section 2.3 of Chapter 2. $j$ is the order difference of $\Delta \mathrm{RM}_{t-1}^{j}$ and $j=3,12$ month lags when political risk is used ( 3 for Pakistan and 12 for New Zealand)and $j=6$, and 12 month lags when political risk components are used (6 for Pakistan and 12 for New Zealand). $r_{i, t}$ is the return for each firm or industry. Political risk is fitted into models 1 and 2 in two ways separately. In the first, aggregate political risk (RM) is featured as independent explanatory variables (RM), whereas Economic Risk (ER) and Financial Risk (FR) are included as control variables (X).

In the second, the three political risk components (RM), Government Action $(\mathrm{GA})$, Conflict (CON) and Quality of Governance (QG) are included and again ER and FR (X) are also used. The constant terms are denoted by $\phi_{0}$ and $\omega$ where as $\epsilon_{i, t}$ is the error term at time $t$. The impact of the last period conditional variance is denoted by $\beta_{1}$. If the $\beta_{1}$ is positive that means a positive change in 
stock prices is associated with further positive change and vice versa.

From the above models, we expect an increase in political risk would decrease the returns and expect a negative coefficient for $\phi_{2}$. This suggests that as political risk increases, the uncertainty about the future policies of the government also increases, which lowers the returns. As for the volatility of the political risk, the coefficient $\beta_{2}$ in the variance equation should be positive and significant, because as the volatility of political risk increases the volatility of the returns should also increase. The stationary restriction of an EGARCH $(1,1)$ model is that the $\beta_{1}$ is less than one $(\beta<1)$ and in the case of symmetry, where the magnitudes of positive and negative shocks have equal impact on the variance.

\subsection{Results}

\subsubsection{Political risk, firm returns and volatility}

The results from the estimation of the return and variance (EGARCH) equations (4.5) and (4.6) for the Pakistan and New Zealand firms are presented in Table 4.1 and Table 4.2. The first two columns are the names of industries and number of firms in each industry, columns 3 to 6 are from return equations where as column 7 to 10 from variance equations. We have presented the number of firms with positive and negative significant (at $10 \%$ or better), non significantly positive and non negatively significantly firms in Table 4.1 both for Pakistan and New Zealand. Firstly, we looked at the impact of political risk on the returns of Pakistani firms and found that 23 firms (11\%) of all firms with positive significant coefficients and 36 firms (18\%) with significant negative coefficients. However, there are quite a large number of firms with non-significant positive and negative results (34\% and 37\%).

Turning towards the impact of political risk on the volatility of the Pakistani firms reveals more interesting results. It is concluded from the results that the impact of political risk is more on volatility rather than returns. Columns 7 to 10 present the results of variance equations. We found that political risk increased the volatility of 85 firms $(42 \%)$, whereas it decreased the volatility of 23 firms (11\%). The number of non-significant firms was low as compare to our findings for returns (18\% non significant positive and $29 \%$ non-significant negative).

Table 4.1 also displays the results for the New Zealand firms and finds that results are weak compared to the Pakistani firms. The firms with positive significant coefficients are 16 and there are 17 with negative significant coefficients. Further, plenty of firms with non-significant positive and negative coefficients (81 with positive non-significant and 71 with negative non-significant). The re- 
Table 4.1: Political risk, firms' return and volatility

The table addresses the question "does political risk affect firm equity return and volatility?" Columns 3 to 6 in the table report the results from the following mean equation: $r_{i, t}=\phi_{0}+\phi_{1} r_{i, t-1}+\phi_{2} \Delta \mathrm{RM}_{t-1}^{j}+\phi_{3} \Delta \mathrm{X}_{t-1}^{j}+\epsilon_{i, t} \cdot \Delta \mathrm{RM}_{t-1}^{j}$ is monthly change in the political risk index from the international country risk guide. The volatility results in columns 7 to 10 are from the following variance equation: $\log \left(\sigma_{i, t}^{2}\right)=\omega_{i}+\alpha_{i} f\left(z_{i, t-1}\right)+\boldsymbol{\beta}_{1} \log \left(\sigma_{i, t-1}^{2}\right)+\boldsymbol{\beta}_{2} \Delta \mathrm{RM}_{t-1}^{j}+\boldsymbol{\beta}_{3} \Delta \mathrm{X}_{t-1}^{j}$. The results are the number of firms with positive and negative significant (at $10 \%$ or better), non significantly positive and non negatively significant firms.

\begin{tabular}{|c|c|c|c|c|c|c|c|c|c|}
\hline & \multicolumn{4}{|c|}{ Return } & \multicolumn{5}{|c|}{ Variance } \\
\hline & Firms & $\begin{array}{l}\text { Pos. } \\
\text { sig }\end{array}$ & $\begin{array}{l}\text { Pos. } \\
\text { nonsig }\end{array}$ & $\begin{array}{l}\text { Neg. } \\
\text { nonsig }\end{array}$ & $\begin{array}{l}\text { Neg. } \\
\text { sig }\end{array}$ & $\begin{array}{l}\text { Pos. } \\
\text { sig }\end{array}$ & $\begin{array}{l}\text { Pos. } \\
\text { nonsig }\end{array}$ & $\begin{array}{l}\text { Neg. } \\
\text { nonsig }\end{array}$ & $\begin{array}{l}\text { Neg. } \\
\text { sig }\end{array}$ \\
\hline Pakistan & & & & & & & & & \\
\hline $\begin{array}{r}\text { Automobile \& } \\
\text { parts }\end{array}$ & 10 & 1 & 4 & 3 & 2 & 4 & 3 & 2 & 1 \\
\hline Chemicals & 19 & 4 & 8 & 5 & 2 & 8 & 5 & 4 & 2 \\
\hline $\begin{array}{r}\text { Construction \& } \\
\text { materials }\end{array}$ & 24 & 2 & 7 & 11 & 4 & 10 & 5 & 6 & 3 \\
\hline Equity investment & 12 & 2 & 3 & 3 & 4 & 6 & 3 & 2 & 1 \\
\hline Financial services & 15 & 1 & 5 & 5 & 4 & 6 & 2 & 6 & 1 \\
\hline Fixed line telecom & 3 & 0 & 2 & 0 & 1 & 2 & 0 & 1 & 0 \\
\hline Food producers & 13 & 2 & 3 & 7 & 1 & 4 & 3 & 4 & 2 \\
\hline Forestry & 2 & 0 & 0 & 1 & 1 & 1 & 0 & 1 & 0 \\
\hline General industries & 9 & 1 & 2 & 3 & 3 & 5 & 0 & 2 & 2 \\
\hline Household goods & 4 & 0 & 3 & 1 & 0 & 1 & 1 & 2 & 0 \\
\hline $\begin{array}{r}\text { Industrial } \\
\text { engineering }\end{array}$ & 7 & 3 & 2 & 1 & 1 & 1 & 2 & 3 & 1 \\
\hline $\begin{array}{r}\text { Industrial metals } \\
\& \text { mining }\end{array}$ & 5 & 0 & 3 & 2 & 0 & 3 & 1 & 1 & 0 \\
\hline Life insurance & 3 & 0 & 1 & 2 & 0 & 2 & 0 & 1 & 0 \\
\hline Multiutilities & 3 & 1 & 0 & 2 & 0 & 1 & 1 & 1 & 0 \\
\hline Nonlife insurance & 11 & 2 & 1 & 5 & 3 & 3 & 3 & 3 & 2 \\
\hline Oil and gas & 11 & 2 & 3 & 4 & 2 & 6 & 1 & 2 & 2 \\
\hline Personal goods & 42 & 1 & 18 & 16 & 7 & 17 & 6 & 13 & 6 \\
\hline $\begin{array}{r}\text { Pharma and } \\
\text { biotech }\end{array}$ & 7 & 1 & 3 & 3 & 0 & 3 & 0 & 4 & 0 \\
\hline Travel \& leisure & 4 & 0 & 1 & 2 & 1 & 2 & 1 & 1 & 0 \\
\hline Total & 204 & 23 & 69 & 76 & 36 & 85 & 37 & 59 & 23 \\
\hline New Zealand & & & & & & & & & \\
\hline $\begin{array}{r}\text { Agriculture \& } \\
\text { Fishing }\end{array}$ & 7 & 0 & 3 & 2 & 2 & 2 & 2 & 2 & 1 \\
\hline $\begin{array}{l}\text { Building materials } \\
\quad \& \text { construction }\end{array}$ & 3 & 1 & 2 & 0 & 0 & 2 & 0 & 0 & 1 \\
\hline Consumer & 17 & 1 & 8 & 7 & 1 & 4 & 7 & 6 & 0 \\
\hline Energy & 9 & 0 & 3 & 2 & 4 & 1 & 5 & 3 & 0 \\
\hline $\begin{array}{r}\text { Finance \& other } \\
\text { services }\end{array}$ & 21 & 0 & 11 & 9 & 1 & 6 & 9 & 4 & 2 \\
\hline Food \& beverages & 2 & 1 & 0 & 0 & 1 & 0 & 1 & 1 & 0 \\
\hline Goods & 13 & 2 & 5 & 4 & 2 & 4 & 5 & 2 & 2 \\
\hline $\begin{array}{r}\text { Intermediate \& } \\
\text { durables }\end{array}$ & 9 & 1 & 5 & 2 & 1 & 3 & 3 & 1 & 2 \\
\hline Investment & 9 & 0 & 5 & 3 & 1 & 4 & 3 & 2 & 0 \\
\hline Leisure \& tourism & 3 & 0 & 0 & 3 & 0 & 2 & 1 & 0 & 0 \\
\hline $\begin{array}{r}\text { Media \& telecom- } \\
\text { munications }\end{array}$ & 4 & 1 & 2 & 1 & 0 & 1 & 2 & 1 & 0 \\
\hline Mining & 4 & 1 & 1 & 2 & 0 & 1 & 0 & 3 & 0 \\
\hline Ports & 4 & 0 & 1 & 3 & 0 & 1 & 3 & 0 & 0 \\
\hline Primary & 14 & 2 & 4 & 7 & 1 & 6 & 2 & 6 & 0 \\
\hline Property & 10 & 0 & 5 & 5 & 0 & 5 & 3 & 2 & 0 \\
\hline Services & 52 & 6 & 24 & 19 & 3 & 10 & 22 & 16 & 4 \\
\hline Textiles \& apparel & 2 & 0 & 0 & 2 & 0 & 1 & 1 & 0 & 0 \\
\hline Transport & 2 & 0 & 2 & 0 & 0 & 1 & 0 & 1 & 0 \\
\hline Total & 185 & 16 & 81 & 71 & 17 & 54 & 69 & 50 & 12 \\
\hline
\end{tabular}


sults related to impact of political risk on the volatility are displayed in columns 7 to 10 in Table 4.1. The volatility of the return increased for 54 firms (29\%) due to the political risk; however, volatility decreased for only 12 firms (7\%). There were quite a large number of firms with non-significant results (37\% positive and $27 \%$ negative).

Overall, we conclude from the results that Pakistani firms are more exposed to political risk compared to New Zealand firms and also the firms perceive the political risk differently which is why the results are different across firms. A change in political risk might be good news for some firms but bad for others.

The average coefficients of the firms across industries for both countries are in Table 4.2. The coefficients for the Pakistani firms are quite high both for returns and volatilities compared to New Zealand firms. For demonstration of size impact, we took an example of Financial sector for both countries (Financial services for Pakistan and Finance \& other services for New Zealand). The coefficient of the negative significant political risk is -0.125 for Pakistan and -0.083 for New Zealand. In economic terms, one standard deviation increase in political risk decreases the returns by $16.5 \%$ for Pakistani financial firms, Whereas it's $5.7 \%$ for New Zealand financial firms. Similar results were found for the impact of political risk on the volatility of the financial sector for both countries. We also found that the size of non-significant coefficients was large compared to significant coefficients for New Zealand. In terms of size, one standard deviation increase in the political risk leads to an increase in the volatility of returns by $30 \%$ for Pakistani financial firms whereas it's only by $4 \%$ for New Zealand. These findings are in line with research (see Cosset \& Suret (1995); Diamonte et al. (1996); Bilson et al. (2002)) that has found political risk has more impact on Pakistani (Emerging market) firms compared to New Zealand (Developed market).

\subsubsection{Political risk, industry return and volatility}

The results from the estimation of the return and the volatility (EGARCH) equations (4.5) to (4.8) for the Pakistan and New Zealand industries are presented in Table 4.3 and Table 4.4. In Table 4.3 we present the results from the mean equation for political risk components and political risk. The first column is the name of industries for both countries, columns 2 to 4 display the results from the change in political risk components and column 5 to 7 for squared change in political risk components. The result reveals that change in political risk components has significant negative impact on industries' returns. We found that government action (GA) is significant for only one industry which is Chemicals for Pakistan. However, no significant link was established for New Zealand. The results are stronger and more significant for conflict $(\mathrm{CON})$ as 
Table 4.2: Summary of estimation of political risk exposure

The table presents the summary of estimation for mean and variance equation. Columns 3 to 6 in the table report the results from the following mean equation: $r_{i, t}=\phi_{0}+\phi_{1} r_{i, t-1}+\phi_{2} \Delta \mathrm{RM}_{t-1}^{j}+\phi_{3} \Delta \mathrm{X}_{t-1}^{j}+\epsilon_{i, t} . \Delta \mathrm{RM}_{t-1}^{j}$ is monthly change in the political risk index from the international country risk guide. The volatility results are from columns 7 to 10 from the following variance equation: $\log \left(\sigma_{i, t}^{2}\right)=\omega_{i}+\alpha_{i} f\left(z_{i, t-1}\right)+\beta_{1} \log \left(\sigma_{i, t-1}^{2}\right)+\beta_{2} \Delta \mathrm{RM}_{t-1}^{j}+\beta_{3} \Delta \mathrm{X}_{t-1}^{j}$. The results are average value of political risk coefficient of all firms in each industry, positive and negative significant (at 10\% or better), non-significantly positive and non-negatively significantly firms.

\begin{tabular}{|c|c|c|c|c|c|c|c|c|c|}
\hline & \multicolumn{5}{|c|}{ Return } & \multicolumn{4}{|c|}{ Variance } \\
\hline & Firms & $\begin{array}{l}\text { Pos. } \\
\text { sig }\end{array}$ & $\begin{array}{l}\text { Pos. } \\
\text { nonsig }\end{array}$ & $\begin{array}{l}\text { Neg. } \\
\text { nonsig }\end{array}$ & $\begin{array}{l}\text { Neg. } \\
\text { sig }\end{array}$ & $\begin{array}{l}\text { Pos. } \\
\text { sig }\end{array}$ & $\begin{array}{l}\text { Pos. } \\
\text { nonsig }\end{array}$ & $\begin{array}{l}\text { Neg. } \\
\text { nonsig }\end{array}$ & $\begin{array}{l}\text { Neg. } \\
\text { sig }\end{array}$ \\
\hline Pakistan & & & & & & & & & \\
\hline $\begin{array}{r}\text { Automobile \& } \\
\text { parts }\end{array}$ & 10 & 0.176 & 0.003 & -0.004 & -0.164 & 0.137 & 0.142 & -0.019 & -0.112 \\
\hline Chemicals & 19 & 0.123 & 0.004 & -0.003 & -0.007 & 0.181 & 0.046 & -0.208 & -0.286 \\
\hline $\begin{array}{r}\text { Construction\& } \\
\text { materials }\end{array}$ & 24 & 0.115 & 0.004 & -0.005 & -0.013 & 0.156 & 0.009 & -0.291 & -0.045 \\
\hline Equity investment & 12 & 0.028 & 0.005 & -0.001 & -0.024 & 0.149 & 0.0368 & -0.079 & -0.040 \\
\hline Financial services & 15 & 0.022 & 0.002 & -0.007 & -0.125 & 0.227 & 0.049 & -0.176 & -0.013 \\
\hline Fixed line telecom & 3 & - & 0.007 & - & -0.001 & 0.182 & - & -0.020 & - \\
\hline Food producers & 13 & 0.022 & 0.011 & -0.004 & -0.008 & 0.212 & 0.028 & -0.240 & -0.089 \\
\hline Forestry & 2 & - & - & -0.002 & -0.012 & 0.210 & - & -0.009 & - \\
\hline General industries & 9 & 0.012 & 0.002 & -0.006 & -0.003 & 0.186 & - & -0.018 & -0.062 \\
\hline Household goods & 4 & - & 0.003 & - & -0.004 & 0.465 & 0.001 & -0.105 & - \\
\hline $\begin{array}{r}\text { Industrial } \\
\text { engineering }\end{array}$ & 7 & 0.031 & 0.003 & -0.001 & -0.011 & 0.367 & 0.045 & -0.041 & -0.177 \\
\hline $\begin{array}{r}\text { Industrial metals } \\
\& \text { mining }\end{array}$ & 5 & - & 0.006 & -0.005 & - & 0.279 & 0.015 & -0.223 & - \\
\hline Life insurance & 3 & - & 0.006 & -0.008 & - & 0.107 & - & -0.101 & - \\
\hline Multiutilities & 3 & 0.106 & - & -0.004 & - & 0.932 & 0.022 & -0.136 & - \\
\hline Nonlife insurance & 11 & 0.439 & 0.004 & -0.006 & -0.004 & 0.381 & 0.107 & -0.179 & -0.087 \\
\hline Oil and gas & 11 & 0.014 & 0.005 & -0.005 & -0.009 & 0.294 & 0.021 & -0.057 & -0.046 \\
\hline Personal goods & 42 & 0.021 & 0.003 & -0.006 & -0.017 & 0.159 & 0.056 & -0.067 & -0.098 \\
\hline $\begin{array}{r}\text { Pharma and } \\
\text { biotech }\end{array}$ & 7 & 0.205 & 0.002 & -0.005 & - & 0.103 & - & -0.029 & - \\
\hline Travel \& leisure & 4 & - & 0.006 & -0.004 & -0.031 & 0.139 & 0.036 & -0.033 & - \\
\hline New Zealand & & & & & & & & & \\
\hline $\begin{array}{r}\text { Agriculture \& } \\
\text { Fishing }\end{array}$ & 7 & - & 0.015 & -0.012 & -0.045 & 0.087 & 0.371 & -0.064 & -0.161 \\
\hline $\begin{array}{r}\text { Building materials } \\
\& \text { construction }\end{array}$ & 3 & 0.017 & 0.002 & - & - & 0.024 & - & - & -0.011 \\
\hline Consumer & 17 & 0.022 & 0.012 & -0.056 & -0.016 & 0.102 & 0.067 & -0.086 & - \\
\hline Energy & 9 & - & 0.016 & -0.002 & -0.044 & 0.011 & 0.094 & -0.107 & - \\
\hline $\begin{array}{r}\text { Finance \& other } \\
\text { services }\end{array}$ & 21 & - & 0.020 & -0.021 & -0.083 & 0.058 & 0.643 & -0.613 & -0.081 \\
\hline Food \& beverages & 2 & 0.039 & - & - & -0.120 & - & 0.067 & -0.028 & - \\
\hline Goods & 13 & 0.033 & 0.013 & -0.016 & -0.067 & 0.075 & 0.133 & -0.365 & -0.050 \\
\hline $\begin{array}{r}\text { Intermediate \& } \\
\text { durables }\end{array}$ & 9 & 0.026 & 0.013 & -0.007 & -0.014 & 0.044 & 0.054 & -0.002 & -0.051 \\
\hline Investment & 9 & - & 0.007 & -0.008 & -0.053 & 0.027 & 0.265 & -0.069 & - \\
\hline Leisure \& tourism & 3 & - & - & -0.005 & - & 0.274 & 0.073 & - & - \\
\hline $\begin{array}{l}\text { Media \& telecom- } \\
\text { munications }\end{array}$ & 4 & 0.013 & 0.002 & -0.001 & - & 0.069 & 0.145 & -0.502 & - \\
\hline Mining & 4 & 0.022 & 0.011 & -0.005 & - & 0.078 & - & -0.616 & - \\
\hline Ports & 4 & - & 0.003 & -0.004 & - & 0.082 & 0.452 & - & - \\
\hline Primary & 14 & 0.019 & 0.002 & -0.041 & -0.055 & 0.023 & 0.593 & -0.429 & - \\
\hline Property & 10 & - & 0.002 & -0.004 & - & 0.022 & 0.522 & -0.445 & - \\
\hline Services & 52 & 0.049 & 0.008 & -0.014 & -0.046 & 0.037 & 0.323 & -0.269 & -0.067 \\
\hline Textiles \& apparel & 2 & - & - & -0.025 & - & 0.066 & 0.136 & - & - \\
\hline Transport & 2 & - & 0.003 & - & - & 0.078 & - & -0.035 & - \\
\hline
\end{tabular}


risk a component as 11 industries have significantly negative coefficients. This confirms that as conflict increases return decreases. For New Zealand, only three industries were found with significant negative results. The results for the change in quality of governance shows that only three of the Pakistani industries have significant results whereas no significant results were found for New Zealand industries.

Columns 5 to 7 of Table 4.3 present the results from the squared change in the political risk components. No significant results were established for the squared change in government action variable for Pakistan; however, only two industries (finance and textile) are with significant negative coefficients for New Zealand. Three industries are significantly affected by the conflict measure from Pakistan (construction, food, and household) and New Zealand (consumer, mining, and ports). No significant results were found for the quality of governance for New Zealand industries, whereas four industries (automobile, food, life insurance, and personal goods) are significantly affected by the quality of governance component for Pakistan. We concluded from the results that conflict component is more significant among all the three political risk components for Pakistan and New Zealand. Further, we also found the the impact of political risk components is more on Pakistani industries compared to New Zealand.

The last column of Table 4.3 presents the results from the equation (4.5) for political risk. The results for Pakistani industries are more significant compared those of to New Zealand. Our results reveal that 10 out of 19 industries (52\% industries) were significantly influenced by political risk. However, only one industry (building materials) found a significant with negative coefficient for New Zealand. In economic terms, for example, one standard deviation increase in political risk decreases the return of equity investment industry by $15.7 \%$ in Pakistan. Whereas for New Zealand one standard deviation increase in political risk decreases the return of the building materials industry returns by only $1.6 \%$. So we conclude that there are some industries more sensitive to political risk than others. Further, the results also confirm the impact is more on Pakistani industries compared to New Zealand. These findings are in line with our initial results at main stock indices in Chapter 3.

The results from the estimation of the variance (EGARCH) equations (4.6) and (4.8) for the Pakistan and New Zealand industries are presented in Table 4.4. In Table 4.4 we present the results from the variance equation for political risk components and political risk. Columns 2 to 4 display the results from the change in political risk components and columns 5 to 7 for squared change in political risk components. The result confirms that change in political risk components has significant positive impact on the volatility of returns. Government action (GA) is significantly positive for five Pakistani industries. However, only two (building materials and consumer) are significant industries found for New 
Table 4.3: Estimation from the EGARCH (Mean Equation)

This table addresses the question"do political risk components, and political risk affect the industry returns and is there any difference across different industries?" The coefficients reported in the table are based on the best model for each country (Model 1 for political risk and Model 2 for political risk components) as identified in

Table 3.4. We reported only the coefficients of political risk components:

Government action (GA), Conflict (CON) and Quality of Governance (QG) and Political risk as explained in in section 2.3 of Chapter 2. The significant coefficients are denoted with bold and italic, bold, italic on 1\%, 5\% and $10 \%$ respectively. The

following models are used for estimation (Mean Equation). Model 1 is used for political risk and model 2 for political risk components. Model 1:

$$
r_{i, t}=\phi_{0}+\phi_{1} r_{i, t-1}+\phi_{2} \Delta \mathrm{RM}_{t-1}^{j}+\phi_{3} \Delta \mathrm{X}_{t-1}^{j}+\epsilon_{i, t} \text { and Model 2: }
$$

$$
r_{i, t}=\phi_{0}+\phi_{1}\left(r_{i, t-1}+\phi_{2} \Delta \mathrm{RM}_{t-1}^{j}+\phi_{3}\left(\Delta \mathrm{RM}_{t-1}^{j}\right)^{2}+\phi_{4} \Delta \mathrm{X}_{t-1}^{j}+\phi_{5}\left(\Delta \mathrm{X}_{t-1}^{j}\right)^{2}+\epsilon_{i, t} .\right.
$$

\begin{tabular}{|c|c|c|c|c|c|c|c|}
\hline & \multicolumn{6}{|c|}{ Political Risk Components } & \multirow{3}{*}{$\frac{\text { Political Risk }}{\text { Change }}$} \\
\hline & \multicolumn{3}{|c|}{ Change } & \multicolumn{3}{|c|}{ Volatility } & \\
\hline & GA & $\mathrm{CON}$ & QG & GA & $\mathrm{CON}$ & QG & \\
\hline \multicolumn{8}{|l|}{ Pakistan } \\
\hline Automobile \& parts & 0.0029 & -0.0024 & 0.0014 & -0.0006 & -0.0020 & -0.0189 & -0.0033 \\
\hline Chemicals & -0.0044 & -0.0025 & 0.0044 & -0.0001 & -0.0018 & -0.0048 & -0.0003 \\
\hline Construction \& materials & 0.0014 & -0.0100 & 0.0013 & -0.0001 & -0.0078 & 0.0191 & -0.0013 \\
\hline Equity investment & 0.0019 & -0.0098 & 0.0067 & -0.0043 & 0.0086 & -0.0059 & -0.0208 \\
\hline Financial services & 0.0011 & -0.0070 & 0.0055 & -0.0080 & 0.0036 & -0.0013 & -0.0026 \\
\hline Fixed line telecom & 0.0012 & -0.0057 & 0.0061 & 0.0108 & -0.0037 & -0.0010 & -0.0040 \\
\hline Food producers & 0.0025 & -0.0042 & -0.0132 & -0.0052 & -0.0055 & -0.0285 & -0.0117 \\
\hline Forestry & 0.0022 & -0.0054 & 0.0024 & 0.0035 & 0.0016 & 0.0010 & 0.0003 \\
\hline General industries & 0.0032 & -0.0002 & 0.0001 & -0.0083 & 0.0008 & -0.0086 & 0.0025 \\
\hline Household goods & -0.0022 & -0.0011 & -0.0023 & -0.0064 & -0.0068 & 0.0018 & -0.0008 \\
\hline Industrial engineering & 0.0010 & -0.0063 & 0.0074 & -0.0052 & 0.0044 & 0.0320 & -0.0008 \\
\hline Industrial metals \& mining & 0.0029 & -0.0045 & -0.0104 & 0.0057 & -0.0003 & -0.0191 & -0.0050 \\
\hline Life insurance & 0.0052 & -0.0065 & 0.0098 & 0.0105 & 0.0016 & -0.0248 & 0.0029 \\
\hline Multiutilities & 0.0001 & -0.0107 & -0.0101 & 0.0016 & -0.0021 & -0.0068 & -0.0038 \\
\hline Nonlife insurance & -0.0013 & -0.0092 & 0.0101 & -0.0075 & -0.0106 & -0.0085 & -0.0069 \\
\hline Oil and gas & -0.0020 & 0.0027 & -0.0042 & -0.0002 & -0.0001 & -0.0095 & -0.0019 \\
\hline Personal goods & 0.0035 & -0.0098 & -0.0180 & 0.0021 & -0.0016 & -0.0401 & -0.0007 \\
\hline Pharma and biotech & 0.0019 & -0.0020 & 0.0068 & 0.0070 & -0.0003 & -0.0013 & -0.0002 \\
\hline Travel \& leisure & -0.0013 & -0.0145 & -0.0015 & -0.0044 & -0.0018 & -0.0133 & -0.0090 \\
\hline \multicolumn{8}{|l|}{ New Zealand } \\
\hline Agriculture \& Fishing & 0.0031 & -0.0015 & 0.0053 & -0.0052 & -0.0246 & 0.0034 & 0.0024 \\
\hline Building materials & -0.0075 & 0.0035 & 0.0086 & -0.0049 & -0.3122 & -0.0453 & -0.0046 \\
\hline Consumer & -0.0022 & -0.0018 & -0.0050 & 0.0130 & -0.0972 & 0.0426 & -0.0010 \\
\hline Energy & -0.0006 & 0.0175 & 0.0127 & 0.0376 & -0.0917 & -0.1250 & 0.0018 \\
\hline Finance \& other services & -0.0020 & 0.0150 & 0.0323 & -0.0191 & -0.3075 & -0.0016 & 0.0002 \\
\hline Food \& beverages & 0.0006 & 0.0088 & 0.0263 & -0.0779 & -0.8511 & -0.1388 & -0.0108 \\
\hline Goods & 0.0043 & 0.0084 & 0.0130 & 0.0060 & -0.0138 & -0.0548 & 0.0033 \\
\hline Intermediate \& durables & 0.0030 & 0.0050 & 0.0202 & 0.0024 & 0.0920 & -0.0644 & 0.0019 \\
\hline Investment & 0.0017 & -0.0144 & 0.0089 & 0.0065 & 0.3521 & 0.0060 & 0.0011 \\
\hline Leisure \& tourism & -0.0004 & -0.0032 & 0.0076 & 0.0190 & 0.1888 & 0.0019 & 0.0413 \\
\hline Media & -0.0012 & 0.0040 & -0.0056 & -0.0129 & -0.0607 & -0.0424 & -0.0017 \\
\hline Mining & -0.0032 & 0.0187 & -0.0020 & -0.0211 & -0.4088 & -0.0176 & -0.0003 \\
\hline Ports & -0.0007 & 0.0063 & 0.0028 & 0.0076 & -0.0372 & 0.2224 & -0.0001 \\
\hline Primary & -0.0014 & -0.0119 & 0.0094 & 0.0048 & -0.0371 & -0.0053 & 0.0014 \\
\hline Property & 0.0000 & -0.0008 & 0.0008 & 0.0019 & 0.0202 & 0.0581 & 0.0001 \\
\hline Services & 0.0006 & -0.0033 & -0.0058 & -0.0064 & 0.0625 & 0.0084 & -0.0002 \\
\hline Textiles \& apparel & 0.0018 & 0.0078 & 0.0051 & -0.0379 & 0.0736 & -0.0749 & 0.0023 \\
\hline Transport & 0.0041 & -0.0176 & -0.0099 & -0.0071 & 0.1424 & 0.0956 & 0.0021 \\
\hline
\end{tabular}


Zealand. The results are stronger for the conflict $(\mathrm{CON})$ risk component as eight out of 19 industries have significantly positive coefficients. This confirms a positive relationship between conflict and volatility of the industry returns. However, no significant results were found for New Zealand industries. The results for the change in quality of governance confirm that impact is more on volatility compared to returns as seven industries are significantly influenced by this variable. In the case of New Zealand industries only three industries (building materials, energy, and property) have significant and positive results.

Columns 5 to 7 of Table 4.4 present the results from the squared change in the political risk components. Eight industries are with positive and significant coefficients for the squared change in the government action variable for Pakistan. Whereas five industries are with significant positive coefficients for New Zealand. Three industries are significantly affected by the conflict component for Pakistan (equity, industrial engineering, and oil \& gas) and only one for New Zealand (property). Only two significant results were found for the quality of governance for New Zealand industries (property and textile). As for Pakistan, five industries are significantly affected by the quality of governance component. We concluded from the results that all three political risk components have significantly influenced the volatility of returns for Pakistan and New Zealand industries. Further, we also found that the size of impact is more on Pakistani industries than New Zealand industries.

The last column of Table 4.4 presents the results from the equation (4.6) for political risk. The results for Pakistani industries are more significant compared to New Zealand's. Our results show that 11 out 19 industries (58\% industries) are significantly influenced by political risk. However, five industries (28\% industries) found positive and with significant coefficients for New Zealand. In terms of economic terms, for example, one standard deviation increase in political risk increases the volatility of returns of the equity investment industry by $68 \%$ in Pakistan. Whereas for New Zealand one standard deviation increase in political risk increases the volatility of returns of the building materials industry returns by only $7.16 \%$. We concluded from the results that there are some industries more sensitive to political risk compared to others. Further the results also confirm the impact of political risk is more on the volatility of Pakistani industries than New Zealand's.

\subsection{Conclusion}

In this chapter, we examined the impact of political risk on stock market returns and volatility at the firm and industry level. For the empirical analysis we used the data of two countries, New Zealand and Pakistan. Both countries have a similar political system which is a parliamentary system. However, New 
Table 4.4: Estimation from the EGARCH (Variance Equation)

This table addresses the question "do political risk components, and political risk affect the industry returns and is there any difference across different industries?" The coefficients reported in the table are based on the best model for each country (Model 1 for political risk and Model 2 for political risk components) as identified in Table 3.4. we reported only the coefficients of political risk components, Government action (GA), Conflict (CON) and Quality of Governance (QG) and Political risk as explained in section 2.3 of Chapter 2. The significant coefficients are denoted with bold and italic, bold, italic on 1\%,5\% and $10 \%$ respectively. The following models were used for estimation (Variance Equation). Model 1 is used for political risk and model 2 for political risk components. Model 1:

$\log \left(\sigma_{i, t}^{2}\right)=\omega_{i}+\alpha_{i} f\left(z_{i, t-1}\right)+\beta_{1} \log \left(\sigma_{i, t-1}^{2}\right)+\beta_{2} \Delta \mathrm{RM}_{t-1}^{j}+\beta_{3} \Delta \mathrm{X}_{t-1}^{j}$ and Model 2:
$\quad \log \left(\sigma_{t}^{2}\right)=$
$\omega+\alpha f\left(z_{t-1}\right)+\beta_{1} \log \left(\sigma_{t-1}^{2}\right)+\beta_{2} \Delta \mathrm{RM}_{t-1}^{j}+\beta_{3}\left(\Delta \mathrm{RM}_{t-1}^{j}\right)^{2}+\beta_{4} \Delta \mathrm{X}_{t-1}^{j}+\beta_{5}\left(\Delta \mathrm{X}_{t-1}^{j}\right)^{2}$.$$
\omega+\alpha f\left(z_{t-1}\right)+\beta_{1} \log \left(\sigma_{l-1}^{2}\right)+\beta_{2} \Delta \mathrm{RM}_{l-1}^{j}+\beta_{3}\left(\Delta \mathrm{RM}_{l-1}^{j}\right)^{2}+\beta_{1} \Delta \mathrm{X}_{l-1}^{j}+\beta_{5}\left(\Delta \mathrm{X}_{l-1}^{j}\right)^{2}
$$

\begin{tabular}{|c|c|c|c|c|c|c|c|}
\hline & \multicolumn{6}{|c|}{ Political Risk Components } & \multirow{3}{*}{$\frac{\text { Political Risk }}{\text { Change }}$} \\
\hline & \multicolumn{3}{|c|}{ Change } & \multicolumn{3}{|c|}{ Volatility } & \\
\hline & GA & $\mathrm{CON}$ & QG & GA & $\mathrm{CON}$ & QG & \\
\hline \multicolumn{8}{|l|}{ Pakistan } \\
\hline Automobile \& parts & 0.1627 & 0.1533 & 0.0078 & -0.0250 & -0.0372 & -0.6179 & 0.0322 \\
\hline Chemicals & 0.0577 & -0.0091 & 0.0541 & 0.0725 & 0.0242 & 0.0594 & 0.1308 \\
\hline Construction\& materials & 0.2593 & -0.0468 & 0.2953 & 0.1463 & -0.2431 & 0.7038 & 0.0731 \\
\hline Equity investment & 0.0714 & 0.2981 & 0.0927 & -0.0024 & 0.3995 & -0.1971 & 0.0915 \\
\hline Financial services & 0.1035 & -0.0393 & -0.0172 & -0.1760 & -0.1037 & 0.5181 & 0.0093 \\
\hline Fixed line telecom & 0.0759 & 0.3173 & 0.5666 & -0.2529 & -0.2686 & 0.1017 & 0.0292 \\
\hline Food producers & 0.2500 & 0.0040 & 0.3521 & 0.3786 & -0.0803 & 0.4361 & 0.0404 \\
\hline Forestry & -0.0469 & -0.0883 & 0.1001 & 0.0204 & 0.0316 & 0.3486 & 0.0246 \\
\hline General industries & 0.0642 & 0.0166 & 0.0755 & 0.0653 & 0.0052 & 0.0146 & 0.1738 \\
\hline Household goods & -0.1494 & -0.0407 & 0.0817 & 0.3059 & 0.1730 & -0.3229 & -0.0431 \\
\hline Industrial engineering & -0.0773 & -0.0094 & 0.1250 & -0.0445 & 0.1176 & -0.0283 & 0.0288 \\
\hline Industrial metals \& mining & 0.0064 & 0.0512 & 0.0434 & 0.0623 & 0.0667 & -0.0033 & -0.0802 \\
\hline Life insurance & 0.1259 & -0.1063 & -0.1093 & 0.2556 & -0.0227 & -0.2626 & -0.0213 \\
\hline Multiutilities & -0.1062 & 0.1894 & -0.2562 & -0.2765 & 0.0536 & -0.0463 & 0.0070 \\
\hline Nonlife insurance & 0.0207 & 0.1445 & 0.0947 & 0.1375 & 0.0493 & 0.1478 & 0.2949 \\
\hline Oil and gas & 0.1301 & 0.1215 & 0.4274 & 0.5190 & 0.3036 & -0.7244 & 0.2016 \\
\hline Personal goods & 0.0486 & 0.2080 & 0.1730 & 0.3355 & -0.0801 & 0.9686 & 0.0334 \\
\hline Pharma and biotech & 0.0778 & -0.0043 & 0.0420 & 0.1173 & -0.0967 & 0.0060 & -0.0057 \\
\hline Travel \& leisure & 0.1022 & 0.2050 & 0.0062 & -0.1185 & -0.0345 & -0.0268 & 0.0996 \\
\hline \multicolumn{8}{|l|}{ New Zealand } \\
\hline Agriculture \& Fishing & 0.0061 & -0.2775 & 0.4860 & 0.1330 & 0.3207 & 0.9118 & 0.0138 \\
\hline Building materials & 0.0070 & 0.0480 & 0.1851 & 0.1084 & 0.6211 & -0.3180 & 0.0216 \\
\hline Consumer & 0.0574 & 0.1109 & 0.2881 & 0.4077 & 0.9080 & -0.4112 & 0.0277 \\
\hline Energy & 0.0613 & 0.0873 & 0.2297 & 0.3969 & 0.0705 & 0.5459 & 0.0152 \\
\hline Finance \& other services & 0.0148 & -0.1829 & 0.0947 & 0.3277 & 0.9162 & 0.4886 & 0.0263 \\
\hline Food \& beverages & 0.1815 & 0.4895 & 0.5531 & 0.7153 & 0.3968 & -0.9140 & 0.3432 \\
\hline Goods & -0.0052 & 0.0295 & 0.0288 & 0.1142 & 0.3045 & -0.5284 & 0.0133 \\
\hline Intermediate \& durables & -0.0346 & 0.0934 & 0.0727 & 0.2562 & -0.1354 & -0.8092 & 0.2979 \\
\hline Investment & 0.0272 & -0.1921 & -0.2847 & -0.1821 & 0.9285 & 0.9856 & -0.1733 \\
\hline Leisure \& tourism & -0.0032 & 0.0614 & 0.0531 & 0.0529 & -0.1462 & -0.4436 & 0.0044 \\
\hline Media & 0.0122 & 0.0141 & 0.0327 & 0.3027 & -0.2125 & 0.0942 & 0.0221 \\
\hline Mining & -0.0126 & -0.0719 & 0.0307 & 0.1176 & -0.3687 & -0.7758 & 0.0307 \\
\hline Ports & -0.0642 & -0.3104 & 0.2071 & 0.9742 & -0.8623 & 0.8031 & 0.0595 \\
\hline Primary & -0.0232 & 0.3728 & 0.2032 & 0.2057 & 0.6452 & 0.7403 & 0.0248 \\
\hline Property & -0.0115 & 0.0699 & 0.1373 & 0.1595 & 0.9775 & 0.9612 & 0.0206 \\
\hline Services & 0.0163 & -0.0515 & -0.0084 & 0.1151 & 0.4183 & 0.1477 & 0.0168 \\
\hline Textiles \& apparel & -0.0603 & -0.2894 & 0.4256 & 0.6420 & -0.4843 & 0.7220 & 0.0264 \\
\hline Transport & -0.0048 & 0.1067 & -0.1078 & 0.1941 & -0.1636 & 0.3331 & 0.0139 \\
\hline
\end{tabular}


Zealand's political institutions are well developed compared to Pakistan's. The data at the firm level were obtained from DataStream and we divided the firms into different sectors according to the stock exchange classification for both New Zealand and Pakistan. We estimated the best model and lag as identified in Chapter 3 for 185 firms divided into 18 industry indices for New Zealand and 204 firms divided into 19 industries for Pakistan. Further industry portfolios data were also used to test whether some industries are more sensitive to political risk components and political risk than others.

Our results confirm that political risk is an important factor for stock markets, however, it's more important for Pakistani firms compared to New Zealand firms. The finding also suggest that volatility is more affected by both political risk components and political risk compared to returns. Further, empirical results from the industry portfolios confirm that the impact of political risk components is different across industries for both countries. We conclude that conflict component significantly influences the returns as compare to other two components for both countries. However, all the three risk components have significantly increased the volatility of returns for Pakistani industries. Overall results confirm that the impact of political risk differs across industries as there are industries more significantly influenced by political risk than others. 


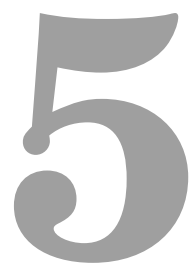

\section{Effect of political risk on exchange rate return and volatility}

This chapter focuses on the relationship between political risk, nominal exchange rate, and volatility of the exchange rate. Panel regression is used to analyze the impact of political risk on exchange rate return and volatility of emerging and developed markets. Further, we also examine the relationship between political risk and exchange rate volatility during the poor economic conditions ${ }^{1}$.

\subsection{Introduction}

Both in practice as well as in academic research, many factors are reported as potential determinants of the exchange rate. One of the factors that may affect the exchange rate in the short, medium and long term is political uncertainty. This is because it's difficult to measure what will happen during political unrest in a country. Studies making use of traditional models of exchange rate determination have been unable to find any important association between political risk and the nominal exchange rate (Isard (1995), or Cosset \& De La Rianderie (1985)). Moreover, the paucity of effective quantitative measures of political risk has often disheartened researchers from following rigorous empirical study in this regard. As a consequence, it has been hard to bring together the intuitive

\footnotetext{
${ }^{1}$ This Chapter was circulated and presented with a title of "Political Uncertainty and Exchange Rate Volatility". We are thankful to Toby Daglish, John Garfinkel, Robert Kirkby, James Key (discussant), Stuart Locke, Philp Ghaghori (discussant) and seminar participants at Victoria University Brown Bag Seminar Series 2014, WEAI 11th International Conference, Wellington, 2015 and PhD Symposium New Zealand Finance Colloquium, University of Waikato, New Zealand, 2015, for their valuable comments and suggestions.
} 
belief that political uncertainty has an effect on exchange rates.

Major progress has been made in considering how legislative politics and other political variables influence the behaviours of currency, equity, and bond markets. Political scientists have investigated the links between domestic politics and international financial markets, including currency markets. Their work provides valuable insight into how currency traders react to politics in young and emerging democracies. For instance, Bernhard \& Leblang (2002) illustrate that political events have a relationship with spot and forward exchange rates. They find forward exchange rates are a biased predictor of future exchange rates during electoral campaigns, cabinet negotiations, and cabinet dissolutions. Bachman (1992) and Blomberg \& Hess (1997) debate that elections influence the exchange rates.

The risk linked with international transactions increases the exchange rate volatility. Businesses and international investors are expected to utilize costly hedging instruments in an effort to manage this risk when exchange rate volatility is high. Because of it, larger exchange rate volatility can have a negative impact on international trade and financial flows among nations. Researchers mostly focus on events such as elections or amendment in the legislation as a source of political risk in a country. Political uncertainty was calculated in the past using political indicators such as elections or legislative outcomes. Leblang \& Bernhard (2006) employed these measures to investigate the impact of policy uncertainty on exchange rate volatility and found that political indicators manipulate exchange rate volatility.

This chapter examines the link between political risk and the nominal exchange rate returns and volatility,and we asked the following questions using political risk components constructed from ICRG data. First, does political risk have a different impact on emerging and developed markets? Second, what is the impact of political risk components on the floating, managed floating and fixed exchange rate? Third, how do political risk components i.e. government action, conflicts and quality of governance, affect the exchange rate return and volatility? Finally, we examine the relationship between political risk components, political risk, exchange rate volatility and exchange rate risk premium during bad economic conditions.

First we analyze the impact of political risk components constructed from the ICRG on the emerging and developed markets. We found that government action, conflict and political risk significantly reduce the exchange rate returns for both emerging and developed markets. For the exchange rate volatility, the results are stronger as all the political risk components have positive and significant results. However, in all cases the impact is more on emerging markets as compared to developed markets. The analysis of political risk components on the de jure classification of exchange rate shows floating exchange rates are 
more exposed compared to both the managed floating and fixed exchange rate. Further, the interaction of political risk and economic conditions confirms that exchange rate volatility increases more during high political uncertainty and bad economic conditions.

The rest of the chapter is organized as follows. Section 2 describes the literature review. Data and the motivation for the model used in this paper is presented in Section 3. Section 4 discusses the methodology and section 5 provides empirical analysis. Section 6 is the conclusion.

\subsection{Literature review}

Bachman (1992) explores political events for an explanation of the observed time-varying risk premium in foreign exchange markets, as political news is important to foreign exchange traders but has not been considered as a determinant of the forward bias. Forward bias means tendency of forward exchange rate to over estimate changes in spot rate. He proposed a model in which the forward bias changes when the governing party changes. Forward bias for each election was estimated using the monthly data for twelve months before and after each election. The data used in his study was spot and one month forward exchange rates from the International Money Market Year Book. The data is quoted in US dollars per unit of foreign currency and converted into British, Canadian and French and terms for these countries' elections. The following model is estimated with dummy variables for the post-election period:

$$
\Delta s_{t}=\alpha+\beta\left(f_{t}-s_{t}\right)+\alpha^{*}+\beta^{*}\left(f_{t}-s_{t}\right)+\epsilon_{t} .
$$

where $\Delta s_{t}=s_{t}-s_{t-1}$ and $s_{t}$ is the log spot exchange rate at period $t, f_{t}$ is the $\log$ forward rate determined at time $t$, for delivery at $t+1$, and $\epsilon_{t}$ is the error term. The second independent variable is set equal to zero before the election and equal to $f_{t}-s_{t}$ after the election and second constant $\alpha^{*}$ is estimated only for the period after the election $\left(\alpha^{*}=0\right.$ before the election and $\alpha^{*}=1$ after). Bachman (1992) empirical result supports the hypothesis that the elections affect the forward bias. The estimated coefficient $\alpha^{*}$ and $\beta^{*}$ for the six elections was significantly different from zero. The second important observation is that the forward bias fell after elections in five of the six elections.

Blomberg \& Hess (1997) suggest that standard exchange rate models perform poorly in out-of-sample forecasting when computed to the random walk. They test the hypothesis that the poor performance of these models may be due to omission of the political factors. They partition the data in three ways; 1) exchange rate and lagged approval ratings; 2) exchange rate and election cycle; 
3) exchange rate and political partisanship. They used the exchange rates and other economic variables from the USECON and IFS and the approval ratings data for the US, Germany and UK from the Gallup surveys. They used the following model including the political variables:

$$
\Delta s_{t}=\alpha_{0}+\gamma_{j} \Delta s_{t-j}+\delta_{i j} \Delta X_{i, t-j}+\beta_{1} P A R T_{t}+\beta_{2} E L E_{t}+\beta_{3} A P P R_{t}+\epsilon_{t} .
$$

where, $X_{i}$ is the economic variable that can affect the exchange, PART is the political variable capturing partisan effect, ELE is the variable for proxy opportunistic manipulation of the economy due to an upcoming election and APPR is the variable for the approval ratings and their effect on the exchange rates. Political factors are important in determining exchange rate and lagged approval ratings significantly influence the exchange rate of the selected countries. After adjusting the explanatory variables,Blomberg \& Hess (1997) focused on political variables explained $8 \%$ of the variation of the growth of nominal exchange. They also found that exchange rate movements affect a leader's approval ratings. Finally, they suggested that for the majority of exchange rates employed in the paper, the political model typically forecasts better than the random walk model by $5-15 \%$ in the short run.

Lobo \& Tufte (1998) examined the impact of politics on the currency market and investors in the foreign exchange market being sensitive to changes in the balance of political power close to major US elections. They examined the weekly volatility of the Japanese Yen, British Pound, German Mark and Canadian Dollar relative to the US Dollar through five US presidential terms for the period January 1973 to November 1992. They used the EGARCH-M with political risk variable as follows:

$$
\left(\Delta s_{t} \mid I_{t-1}\right) \sim f\left(\mu_{t}, \sigma_{t}, \nu\right) .
$$

where $f$ is the information available at time $t-1, I_{t-1}$ and function of conditional mean $\mu_{t}$ and variance $\sigma_{t}$.

$$
\mu_{t}=\sum_{i=1}^{4} \alpha_{i} Y E A R_{i}+\alpha_{5} D P T+\alpha_{6} E L E+\alpha_{7} D 85+\lambda \sigma_{t}-\theta \epsilon_{t-1}
$$

$\lambda$ links the first and second moment of distribution of $\Delta s_{t}$ and $\epsilon_{t-1}=\Delta s_{t}-\mu_{t}$ is the market innovation. $Y E A R_{i}$ is the zero one dummy variable for the four years in the electoral cycle, DPT is the partisan dummy takeing the value of one during the democratic regime otherwise zero, ELE takes the value of one in 16 weeks prior to a presidential or mid-term election and zero otherwise, and 
D85 controls for a structural shift following the Plaza Accord taking the value of one after September 1985 and zero otherwise.

$$
\begin{aligned}
\sigma_{t}^{2}= & \exp \left(\sum_{i=1}^{4} \beta_{i} Y E A R_{i}+\beta_{5} D P T+\beta_{6} E L E+\beta_{7} D 85+\phi \log \left(\sigma_{t-1}^{2}\right)+\right. \\
& \left.\gamma\left[\left|z_{t-1}\right|-E\left(z_{t-1}\right)+\delta z_{t-1}+\delta_{1}(E L E) z_{t-1}+\delta_{2}(D 85) z_{t-1}+\delta_{3}(E L E)(D 85) z_{t-1}\right]\right)
\end{aligned}
$$

Asymmetric effects are captured by $\delta$ and $\delta_{1}$ to $\delta_{3}$ capturing the impact of political variables. They found a strong political impact on the volatility for the Japanese Yen and Dutch Mark, particularly to US mid-term or presidential elections. They also found evidence in support of politics affecting currency markets in two ways: re-election motivation policy and through investor expectations of policy uncertainty close to major US elections.

Freeman et al. (2000) used the monthly exchange rate data from IFS and constructed four nominal exchange rate pairs corresponding to the number of Irish punts per British pound, Canadian dollars per US dollars, New Zealand dollars per Australian dollars, and Sweden krona per German mark for the period March 1979 to December 1995. They used the political variables that provided information about the likelihood of inflation, governments coming into or remaining in power. According to Freeman et al. (2000) there are 'informationally relevant' political factors as for as exchange rate determination is concerned and these factors vary across democracies. Political impact is weaker in countries with proportional representation electoral systems than in countries with majority-plurality systems.

Block (2003) examined the impact of structural political conditions on the likelihood of currency crises in emerging markets. He investigated the following questions: 1) currency crises are less likely under right-wing governments, 2) elections increase the likelihood of crises, 3) strong governments are less vulnerable to currency crises, and 4) the effect of democracy on the likelihood of crises is ambiguous a priori. The data set for his article consists of monthly observations from January 1975 to December 2000 on 23 emerging market economies. Variables included in the data are macroeconomic fundamentals and political factors. Key political variables include election dates (and other executive changes), political orientation of the ruling party (left, right or centre), degree of democracy and indicators of government 'strength', including a Herfindahl index of the party concentration of legislative opposition and the share of ruling party seats in the legislature. These political data are drawn from the World Bank's Database of Political Institutions, with the exception of the democracy indicator, which is drawn from the Polity IV database. The following equation 
is used to define the crisis:

$$
E M P_{i t}=\frac{\Delta E_{i t}}{\sigma_{i}^{E}}+\left(\frac{\Delta R_{i t}}{\sigma_{i}^{R}}\right)
$$

$\sigma_{i}^{E}$ and $\sigma_{i}^{R}$ are conditional standard deviations of the series $E$ nominal exchange rate and $R$ foreign reserves for country $i$. From here they define the crisis as $C R_{i t}$ which is equal to one if $E M P_{i t} \geq \mu^{E} M P_{i}+3 \sigma^{E} M P_{i}$ otherwise zero. Then the following regression used to test the impact of political risk:

$$
C 24_{i t}=\alpha+\beta X_{i t} \gamma P_{i t}+\varphi D+\delta_{i}+\epsilon_{i t}
$$

The crises variable is denoted by $C 24_{i t}$ and equal to one during any of the subsequent 24 months, otherwise zero. $X$ is a matrix of macroeconomic variables, $P$ is a matrix of political variables, $D$ is a matrix of dummy variables for years for Latin America and East Asia, $\delta_{i}$ is the time-invariant country-specific effects and $\epsilon$ is assumed to be iid and normal. Block (2003) findings suggest that a right-wing government is less susceptible to currency crises; 'strong' governments (those with larger legislative majorities and those that face more fragmented legislative opposition) are also less vulnerable. Democracy also reduced the likelihood of currency crises in emerging markets; yet, in contrast to previous studies, this article does not find a significant impact of elections on the likelihood of currency crises.

Hays et al. (2003) examined the consequences of financial globalization for democratization in emerging market economies by focusing on four Asian countries at different stages of democratic development. They tested the following proposition: 1) during electoral periods especially for elections in which there is a high degree of uncertainty about the outcome, 2) the more opinion polls and other sources of political information show declining support for incumbent executives, 3) the less stable incumbent coalitions are, 4) the higher the degree of overt popular opposition to the government and its policies (e.g., frequency of political riots), 5) among young democracies, the more consensual the form of government, the less impact political uncertainty will have on the probability of currency market switching to a high volatility regime, 6) only proposition 4 will hold for emergent democracies. They used the US dollar exchange rates for Indonesia, Philippines, South Korea, and Thailand between March 1998 and September 2000. Using political data of various events including a new events data series and the Markov regime switching model from empirical macroeconomics, they showed that in young and incipient democracies politics continuously causes changes in the probability of experiencing two different currency market equilibria: a high volatility 'contagion' regime and a low volatility 'fundamentals' regime. The kind of political events that affect 
currency market equilibration varies cross-nationally depending on the degree to which the polity of a country is democratic and its policy-making transparent.

Leblang \& Bernhard (2006) examined the relationship between government popularity and exchange rate movements in Britain from 1987. According to their argument, unexpected changes in the government's public support will affect exchange rate volatility. Where these public opinion shocks make political outcomes less certain, exchange rate volatility will increase. In turn, exchange rate volatility and unanticipated changes to exchange rate levels hurt the government's public support. To measure the government's popular standing, they employed the data on vote intention. Opinion polls ask the question, 'How would you vote if a general election were held tomorrow?' Respondents then identify which party they would choose to support. Typically, polling houses in Britain ask this question each month. Exchange rate data consist of weekly spot prices of the pound denominated in US dollars from June 1987 to June 2001. They merged the three polling houses Opinion Research International, ICM Research and Gallup as they ask the same question on voting intention at different times during each month and construct a weekly series from the results of these three poling houses from 1985 to 2001. They used the following econometric model:

$$
\Delta s_{t}=\alpha_{0}+\alpha_{1} X_{t-1}+\alpha_{2} P_{t-1}+\alpha_{3} N_{t-1}+\epsilon_{t}
$$

$X$ as a vector of variables includes lagged value of $\Delta s_{t}$, lagged changes in vote intention for the incumbent, lagged changes in unemployment and inflation, a dummy variable for British participation in EMS (European Monetary System) and a dummy variable Crisis to control the weeks following the pound's exit from EMS that can influence $\Delta s_{t} . P$ and $N$ are the positive and negative shock to vote intention, both lagged one period. $\epsilon_{t}$ is the error term with a mean and a variance. Conditional variance equation is defined as:

$$
\sigma_{t}^{2}=\omega+\beta_{1} \epsilon_{t-1}^{2}+\beta_{2} \sigma_{t-1}^{2}+\beta_{3} I_{t-1} .
$$

where $I$ denotes positive and negative shocks and the level of government support variables, weak, positive surprise consequential, positive surprise weak, negative weak consequential and negative surprise weak, all lagged one. Their results indicate exchange rate and opinion pols affect each other, that unexpected depreciation decreases the government's support and negative public opinion shocks lead to currency depreciation. Further, a unpredictability about the opinion pols of electoral outcomes increases the volatility of exchange rate.

Siokis \& Kapopoulos (2007) examined whether the Greek drachma exchange rate movements could be better understood by incorporating the dynamics of the political environment. Greece could be considered as an ideal laboratory to 
examine the impact of the elections on the drachma exchange rate dynamics, since its political environment is formed by the co-existence of three distinct characteristics: first, a partisan structure with two main political parties with well defined ideological differences. Second, an opportunistic structure with frequent pre-electoral relaxation of monetary and fiscal policy, and, third, a high density of elections. They used weekly Wednesday-close data for the Greek exchange rate relative to the US dollar and ECU from January 1980 to September 1998 and January 1982 to September 1998 respectively. $\Delta s_{t}$ denotes weekly percentage change in the weekly exchange rate measured as $\left(s_{t}-s_{t-1} \times 100\right)$ and conditional probability is based on the information set given as:

$$
\left(\Delta s_{t} \mid I_{t-1}\right) \sim f\left(\mu_{t}, \sigma_{t}, \nu\right) .
$$

The following mean equation is used in their paper including political risk variables:

$$
\begin{aligned}
\mu_{t}= & \alpha_{0}+\alpha_{1} D E V 83+\alpha_{2} D E V 85+\alpha_{3} D E V 98+\alpha_{4} E L E+ \\
& \alpha_{5} P P A S+\alpha_{6} P N D+\lambda \sigma_{t}-\theta \epsilon_{t-1} .
\end{aligned}
$$

where $D E V$ is the one zero dummy variable for three devaluations for 1983 , 1985 and 1998, election dummy ELE takes the value of one 16 weeks prior to election day and otherwise zero, $P P A S$ is the partisan effect dummy and represents socialistic party and takes the value of one when in power, otherwise zero, $P N D$ is the other partisan effect dummy, the Conservative party taking the value of one when in power, otherwise zero and finally, $\lambda$ links the first and second moments. The conditional variance equation is described as follows:

$$
\begin{aligned}
\sigma_{t}= & \exp \left(\beta_{0}+\beta_{1}\left[\left(\left|\xi_{t-1}\right|\right)-E\left(\left|\xi_{t-1}\right|\right)\right]+\delta \xi_{t-1}+\beta_{2} D E V 83+\beta_{3} D E V 85+\right. \\
& \left.\beta_{4} D E V 98+\beta_{5} E L E+\beta_{6} P P A S+\beta_{7} P N D+\varphi \log \left(\sigma_{t-1}^{2}\right)\right)
\end{aligned}
$$

where $\delta$ captures the asymmetric effects and $\varphi$ the persistence of volatility and all other variables are as defined above. They conclude that the political variables in the form of electoral cycle impact the volatility of exchange rate and volatility in the foreign exchange market peaked as the election period approached. For the partisan effects, they found that the mean of exchange rate relative to ECU is largely affected by the conservative party. As an election approaches the volatility of the GRD/ECU exchange rate increases. Further, past innovation exerts an asymmetric impact on the conditional volatility of the exchange rate of the Greek drachma against the ECU and US.

Cermeño et al. (2010) studied the link between depreciation rates and elections in Latin America and tested whether elections affect the predictability of 
the real exchange rate. They also examined, whether the central bank reforms had any effect on the existence or strength of the electoral effect on exchange rates, and is financial liberalization an important variable in explaining changes in electoral effects on the real exchange rate. They used the monthly exchange rate data of nine Latin countries and used the real exchange rate as it is more directly linked to economic outcomes for the period 1980-2000. Their model is based on Cermeno and Grier (2006) for both conditional and unconditional heteroscedasticity and conditional cross-sectional correlation of the error terms:

$$
\begin{aligned}
\Delta \ln \left(s_{i t}\right)= & \alpha_{0}+\alpha_{j} \Delta \ln \left(R_{i t-j}\right)+\alpha_{13} \Delta \ln \left(\text { totma }_{i t}\right)+\alpha_{14} \Delta \ln \left(\text { openma }_{i t}\right) \\
& +\alpha_{15} \Delta \ln \left(\text { govma }_{i t}\right)+\alpha_{16} \Delta \ln \left(\text { tbill }_{t}\right)+\mu \text { Post }_{i t}+\epsilon_{i t}
\end{aligned}
$$

$s_{i t}$ is the real exchange rate (RER) for country $i$ at time $t$. Further, they suggested best fitting lag structure of the independent variables and found that 12 lags of the RER and 3-month moving average of terms of trade (totma), openness (openma), and government spending (govma), and US t.bill rate (tbill) is contemporaneously related to the RER in the countries in the sample. Post is an electoral dummy variable constructed from the Georgetown's Political Database and $\epsilon$ is the error term assumed to be distributed multivariate normal with mean zero and time-varying variance covariance matrix, which is a $9 \times 9$ symmetric matrix that is positive definite for all periods $t$. The 9 diagonal elements of $H_{t}$ i.e the $h_{i i t}$ are given below the equation as follow:

$$
\begin{aligned}
h_{i t}= & \Phi_{1} \epsilon_{i i t-1}^{2}+\Phi_{2} h_{i i t-1}+\Phi_{3} B r_{t}+\Phi_{4} C h_{t}+\Phi_{5} C_{0} l_{t}+\Phi_{6} C r_{t} \\
& +\Phi_{7} E c_{t}+\Phi_{8} M e x_{t}+\Phi_{9} \text { Per }_{t}+\Phi_{10} U r_{t}+\Phi_{11} V e_{t}+\theta \text { Post }_{i t}
\end{aligned}
$$

$\mu$ and $\theta$ are the key coefficients for testing the electoral effect on the real exchange rate. They estimated for each country pair the 36 unique off-diagonal elements as;

$$
h_{i k t}=\rho_{i k} \times h_{i i t} \times h_{k k t} .
$$

They found post-election exchange rate movements are also significantly less predictable. They also found that the relationship between elections and the real exchange rate depreciation after central bank reform, and the post reform real exchange rates are also significantly less volatile. Further, they showed that adding financial liberalization to the model, it seems to have a strong effect on the conditional variance of the real exchange rate than does central bank reforms.

Liu \& Pauwels (2012) investigated whether external political pressure from the United States, the European Union, Japan and major international organizations has a significant impact on both the daily returns and the conditional volatility of the Renminbi central parity. They also examined the effect of 
external political pressure on market expectations using the Renminbi nondeliverable forward rates. Political pressure is the public statements on China's exchange rate policy from the United States, the European Union, Japan, and major international organisations such as the International Monetary Fund, the G7 group, the Asian Development Bank and organization for Economic Cooperation and Development. They also used the monthly macroeconomic news and indices as exogenous control variables. The following model is used for estimation:

$$
\Delta s_{t}=\alpha_{0}+\alpha_{1} X_{t-1}+\alpha_{2} I_{t-1}^{f}+\alpha_{3} D_{t-1}+\epsilon_{t}
$$

where $X_{t-1}$ is a $K \times 1$ vector of macroeconomic news surprises relevant to the conditions of monetary policy, economic activity and external imbalances, $I_{t-1}^{f}$ is a $l \times 1$ vector that contains political pressure indicators and $D_{t-1}$ is a vector of dummies tracking the reforms of the RMB exchange rate and $\epsilon_{t}$ is the error term with a mean and variance, and the variance term is given as:

$$
\sigma_{t}^{2}=\omega+\beta_{1} \epsilon_{t-1}^{2}+\beta_{2} \sigma_{t-1}^{2}+\beta_{3} I_{t-1}^{f}
$$

They found that US and non-US political pressure does not have a significant influence on the Renminbi's daily returns but they have significant impact on the conditional volatility. They also found that a non-deliverable forward market is highly responsive to macroeconomic surprise news and there is evidence that Sino-US bilateral meetings affect the conditional volatility of the non-deliverable forward rate.

Krol (2014) investigated the relationship between the economic policy uncertainty and exchange rate volatility for industrial and emerging markets. For the economic policy uncertainty measure two indices developed by Baker et al. (2013) for the US, Euro area and Canada and Brogaard \& Detzel (2015) for the emerging markets were used. Both indices use the internet search of the articles which are related to economic policy uncertainty. According to Krol (2014), the reason for using these indices is that proxy of election dates to measure policy uncertainty does not capture policy implementation by a new government. The following model is used to estimate the impact of economic policy uncertainty on exchange rate volatility:

$$
\sigma_{i, t}=\alpha+\beta_{1} E P U_{i, t}+\beta_{2} E P U_{u s, t}+\gamma X_{i . t}+\epsilon_{i, t}
$$

In the above equation, $\sigma_{i, t}$ is the volatility of exchange rate which is calculated as the standard deviation of daily exchange rate (percentage change) within a month. Policy uncertainty for the United States and other countries in the sample is represented with $E P U_{u s, t}$ and $E P U_{i, t}$ respectively. $X$ represents control variables such as inflation, industrial production growth etc. Results confirm an 
increase in volatility of the exchange rate of few currencies in response to both home and US economic policy. Further, for the industrial economies, exchange rate volatility increased during the bad economic conditions.

Filippou, Gozluklu \& Taylor (2015) examined the relationship between political risk and currency by using the cross-section of momentum strategies. They proposed a global political risk measure relative to the US which calculated the difference between the political environment of US and other countries in the sample. Data of daily spot and one month forward exchange rates against the US dollar for the period January 1985 to January 2014 of forty eight countries from developed and emerging markets were used in their empirical analysis. For the proxy of political risk, they used the data from the ICRG. The following model used for their empirical estimation:

$$
W M L_{t+1}^{f, h}=\alpha^{f, h}+\beta \Delta P R_{t}+\gamma Z_{t}+\epsilon_{t+1}^{f, h}
$$

In the above equation $f$ is the construction period and is equal to 1,3 and 6 , whereas the holding period for the currency momentum which is always equal to one month is represented by $h$. Their results confirm that global political risk is significant for the cross-section of currency momentum.

It can be concluded from the literature review that most of the research examined the impact of political events such as elections, change in cabinet or the opinion polls regarding the outcome of the elections on exchange rate returns and volatility. This study differs from others in the following ways. First, we used a quantitative measure of political risk that uses the monthly time series data for longer period. Second, we constructed three political risk components i.e., government action, conflicts and quality of governance from the political risk index as the composite political risk (as defined in Chapter 2) is too coarse to capture the political uncertainty at the country level. Third, the impact of these political risk components on exchange rate return and volatility. Lastly, we also examined the relationship between political risk, volatility and exchange rate risk premium during bad economic conditions.

\subsection{Data}

In this study we investigate the relationship between political risk, exchange rate return and volatility of 69 countries from emerging and developed markets for the period January 1984 to December 2013. Table B.1 in Appendix B lists all the developed and emerging markets used for analysis. In the literature we find two main approaches to measure the exchange rate regime, de jure and de facto regimes. The de jure classification is from the IMF's annual reports on the exchange arrangements and exchange restrictions whereas de facto classification 
is based on Reinhart \& Rogoff (2002). In this chapter, the IMF classification is used for exchange rate regimes which rank countries on the basis of exchange rate flexibility and future promise to exchange rate track. We classify countries into three groups: floating, managed floating, fixed ${ }^{2}$. Daily and monthly data on the exchange rate were obtained from the DataStream. We converted the monthly exchange rate data for each country into returns as follows: $\Delta s_{t}=$ $\log \left(s_{t}\right)-\log \left(s_{t-1}\right)$, where $s_{t}$ denotes the price of currency in US dollars in terms of other countries. The monthly volatility is calculated from the daily log returns within each month.

Following Menkhoff, Sarno, Schmeling \& Schrimpf (2012), we also calculated the excess returns to a US investor for holding foreign currency as follows: $R_{t+1}=f_{t}-s_{t+1}$, where $s$ and $f$ denotes log spot and a one month forward exchange rate. The economic variable data are from the IMF's International Financial Statistics via DataStream. We used economic variables that could influence the exchange rate returns such as inflation, industrial production growth and trade openness (measured as import plus export as a ratio of GDP).

Political risk is a qualitative measure and for analysing its contribution to financial data, we needed to quantify it. The explanation of the political risk components is explained in detail in Chapter 2. Similarly to exchange rate data, we converted the political risk components relative to the US and named it political risk components spread as follows: $R M S=\log \left(R M_{u s a}\right)-\log \left(R M_{i}\right)$, where $R M_{\text {usa }}$ is the one of risk components (government action, conflict, quality of governance and political risk) for US from ICRG and $R M_{i}$ is the risk measure for country $i$. We also converted the economic variables relative to the US.

Descriptive statistics of exchange rate, political risk components and economic variables are presented in Table 5.1. The emerging markets mean return is positive, whereas for the developed markets, it is negative. However, the risk associated with emerging markets' returns is higher compared to those of the developed markets. Similar results were found for the monthly volatility as higher volatility is observed for emerging markets. It can be concluded from the descriptive statistics of political risk components that developed markets have a lower political uncertainty compared to the emerging markets. The political risk is positive (0.0489) for developed markets because the majority of the countries (such as Finland, New Zealand, Sweden and Switzerland etc) are less politically risky compared to the USA.

\footnotetext{
${ }^{2}$ Here fixed exchange rate doesn't mean that rate is not moving. "Fixed rate" typically move within specific bands, for example the band for Cyprus is $\pm 15 \%$, for Denmark $\pm 2.25 \%$, for Hungary $\pm 15 \%$ etc. For detail information please see the following web page: https://www.imf.org/external/np/mfd/er/2006/eng/0706.htm
} 
Table 5.1: Descriptive Statistics

All the data is relative to US dollars. Returns are the monthly log returns of nominal exchange rates. The monthly volatility is calculated from the daily log returns within each month. For the calculation of excess returns, one month forward rates are used. Political risk variables data is from the ICRG. We constructed three political risk components spread from ICRG data which are Government Action Spread (GAS), Conflict Spread (ConS), Quality of Governance Spread (QGS) and as well composite Political Risk Spread (PRS). ERS and FRS represent the economic and financial risk spreads respectively and are also from ICRG. We converted all the political risk components relative to the US as follow: $R M S=\log \left(R M_{\text {usa }}\right)-\log \left(R M_{i}\right)$, where $R M_{\text {usa }}$ is one of the risk measures for the US from ICRG and $R M_{i}$ is the risk measure for country $i$. The economic variables are inflation spread (INFS), industrial production spread (IPGS), and OpennessS (trade openness spread) measured as import plus export as ratio of GDP. All economic variables are also relative to the US like other risk measures.

\begin{tabular}{lcccccc}
\hline & All & \multicolumn{3}{c}{ Developed } & \multicolumn{3}{c}{ Emerging } \\
\hline Variables & Mean & SD & Mean & SD & Mean & SD \\
\hline Return & 0.5000 & 5.0249 & -0.0778 & 3.0610 & 0.8633 & 5.9071 \\
Volatility & 0.5086 & 0.6501 & 0.5689 & 0.2824 & 0.6729 & 0.7886 \\
Excess Return & 0.0005 & 0.0173 & 0.0001 & 0.0132 & 0.0008 & 0.0203 \\
GAS & 0.1817 & 0.2275 & -0.0567 & 0.1947 & -0.2603 & 0.2109 \\
ConS & -0.0153 & 0.3511 & 0.2245 & 0.3090 & -0.1472 & 0.2991 \\
QGS & -0.3917 & 0.4769 & 0.0027 & 0.4975 & -0.5843 & 0.3234 \\
PRS & -0.1607 & 0.2479 & 0.0489 & 0.1947 & -0.2925 & 0.1768 \\
ERS & -0.0411 & 0.2514 & 0.0993 & 0.2036 & -0.0895 & 0.2482 \\
FRS & -0.2785 & 0.6264 & -0.1258 & 0.4917 & -0.3289 & 0.6572 \\
IPGS & 0.0386 & 0.1743 & 0.0161 & 0.1384 & 0.0540 & 0.1935 \\
INFS & 0.1981 & 0.7065 & -0.0057 & 0.0857 & 0.3294 & 0.8788 \\
OpennessS & 2.1927 & 1.8055 & 1.7023 & 1.4265 & 2.6240 & 1.9850 \\
\hline
\end{tabular}




\subsection{Methodology}

We used the unbalanced panel data to estimate the effects of political risk variables on the nominal exchange rate return and volatility of nominal exchange rate returns. We starte our model selection procedure to run the Pool Ordinary Least Square (OLS) model under the assumption that individual effects in our model are equal to zero. We found significant effect of political risk variable on both exchange rate return and volatility. After that, we tested our model with the Generalized Least Squares (GLS) random effect model under the assumption that individual effect is not correlated with any regressor and differences are in their individual specific errors, not in their intercepts. Breusch \& Pagan (1980) developed the Lagrange multiplier (LM) test to compare the Pool OLS model with a GLS random effect model using the values of chi square and p-value. The significant value (18794.24) of chi square at $1 \%$ suggests that random effect is better than an OLS model. The random effect model assumes that intercept is constant over individual or time, but it can be varied across individual or time. To capture the variability between individual and time, a fixed effect model is considered better. So, we ran the fixed effect model and compare it with a random effect model using the Hausman specification test (Hausman 1978). A significant result of the test supports the fixed effects model. We used following model;

$$
\Delta s_{i t}=\alpha+\beta_{1} R M S_{i t}+\beta_{2} X_{i t}+\eta_{i}+\zeta_{t}+\epsilon_{i t}
$$

where $\Delta s_{i t}$ is the monthly log returns for country $i$ at time $t . R M_{i t}$ is the political risk components spread from the ICRG. We included these political risk components government action spread, conflict spread, quality of governance spread and political risk spread (for details on how these measured are constructed, please see Chapter 2 and the data section of this chapter) one by one in our fixed effect model so that we could examine the relationship between the political risk components individually with exchange rate return. $X_{i t}$ is the explanatory variables inflation spread, industrial production spread, and trade openness spread (measured as import plus export as ratio of GDP). The equation also includes country specific effect $\eta_{i}$ and time specific effects $\zeta_{t}$. We estimate the model second time using the monthly volatility of the exchange rate as follow:

$$
\sigma_{i t}=\alpha+\gamma_{1} R M S_{i t}+\gamma_{2} X_{i t}+\eta_{i}+\zeta_{t}+\epsilon_{i t}
$$

where $\sigma_{i t}$ is the monthly standard deviation calculated from log returns within a month for country $i$ at time $t^{3}$. $R M S_{i t}$ is the political risk components spread

\footnotetext{
${ }^{3}$ In the literature, researchers calculated the volatility mainly in two ways. First, monthly volatility from daily log returns (for example Krol (2014); Schnabl (2008); Devereux \& Lane (2003)). Second, used the volatility models such as GARCH class of models (for example Lobo \& Tufte (1998); Leblang \& Bernhard (2006); Liu \& Pauwels (2012)). We use the first
} 
as explained above. $X_{i t}$ are the explanatory variable inflation, industrial production, trade balance and money growth. The equation also includes country specific effect $\eta_{i}$ and time specific effects $\zeta_{t}$. For both regressions we used two way clustered standard errors, i.e., over country and time.

\subsubsection{Political risk, exchange rate volatility and economic conditions}

Pástor \& Veronesi (2013) found that during the time of high political uncertainty and weak economic conditions, volatility increases more (they showed that for the US stock market). We empirically examined their model on the currency market with a large set set of countries from developed and emerging markets. First, we examined a relationship between political risk and exchange rate volatility (positive or negative relationship). Later we examined the hypothesis "does exchange rate volatility become more important when political risk is high and economic conditions are worse"? The following model used with the interaction term for the economic conditions:

$$
\sigma_{i t}=\alpha+\gamma_{1} R M S_{i t}+\gamma_{2} R M S_{i t} I P G S_{i t}+\gamma_{3} X_{i t}+\eta_{i}+\zeta_{t}+\epsilon_{i t}
$$

Equation (5.22) is similar to equation (5.21), the only difference being the interaction term of risk measure and the economic conditions. We used the industrial production growth spread (IPGS) as a measure of economic conditions. As the higher value of IPG suggests good economic conditions, we expect a negative sign for interaction term $\left(\gamma_{2}<0\right)$.

\subsubsection{Political risk, economic conditions and risk premia}

We also examined the relationship between the exchange rate risk premia during weak economic conditions when political risk is high. The one month forward rate was used to calculate excess returns, and the list of countries used for empirical analysis is exhibited in Appendix B Table B.2. The following model was used for empirical analysis:

$$
R_{i t+1}=\alpha+\gamma_{1} R M S_{i t}+\gamma_{2} R M S_{i t} I P G S_{i t}+\gamma_{3} X_{i t}+\eta_{i}+\zeta_{t}+\epsilon_{i t}
$$

where, $R_{i t+1}$ is the risk premium (excess currency returns) calculated using spot and one month forward exchange rates (see data section for detail), and the coefficient of interest is the interaction term of political risk and economic conditions. We expect a negative coefficient for $\gamma_{2}$, because the investors will demand a higher return during the high political risk periods.

stream of literature to calculate exchange rate volatility. 


\subsection{Results}

\subsubsection{Political risk and exchange rate return}

The empirical results from the equation (5.20) for three groups, i.e., full sample, developed and emerging markets are presented in Table 5.2. The coefficient estimate of government action is negative and is statistically significant for the full sample and for the emerging markets. However, the impact is more significant for emerging markets. In economic terms one standard deviation increase in the government action spread leads to a decrease of $10.2 \%$ for emerging compared to $6.9 \%$ for developed markets. This could be due to the unstable government and low level of socioeconomic conditions in emerging markets.

Table 5.2. also presents the results from the regression using the political risk component named as conflict. The results show a significant negative coefficient for developed and emerging markets. In terms of size, one standard deviation increase in conflict spread decreases the returns only by $1.8 \%$ for developed and $24.5 \%$ for emerging markets. These results are in line with most recent conflict in Russia which has led to the decrease in the Russian ruble against the dollar and the euro by $2.5 \%$ and $1.5 \%$. The third component constructed from the data is that the quality of governance has no significant impact on developed and emerging markets.

The coefficient for the political risk is negative and statistically significant for developed and emerging markets. The size of coefficient is quite large for emerging markets. One standard deviation increase in the political risk spread leads to a decrease of only $1.2 \%$ in the developed markets, whereas it's $9.7 \%$ for emerging markets. The economic variables inflation and industrial production are positive and significant in the majority of cases. However, coefficient is negative and significant for openness. The results of $R^{2}$, number of observations used in the analysis are also reported the Table 5.2.

We continued to find more interesting results after dividing our sample into floating, managed floating, and fixed exchange rate. The results for these three regimes are presented in Table 5.3. The coefficient estimate of government action was negative and is statistically significant only for the floating exchange rate regime. In economic terms, one standard deviation increase in the government action spread leads to a decrease of $4.3 \%$ in exchange rate returns. The second testing variable was the conflict which is significantly negative for only the fixed exchange rate regime, whereas no significant results were found for floating and fixed exchange rate regimes. This is because the countries with fixed exchange rate regimes are suffering from internal as well as external conflicts. In terms of size effect, one standard deviation increase in conflict spread reduces the returns by $7.4 \%$. 


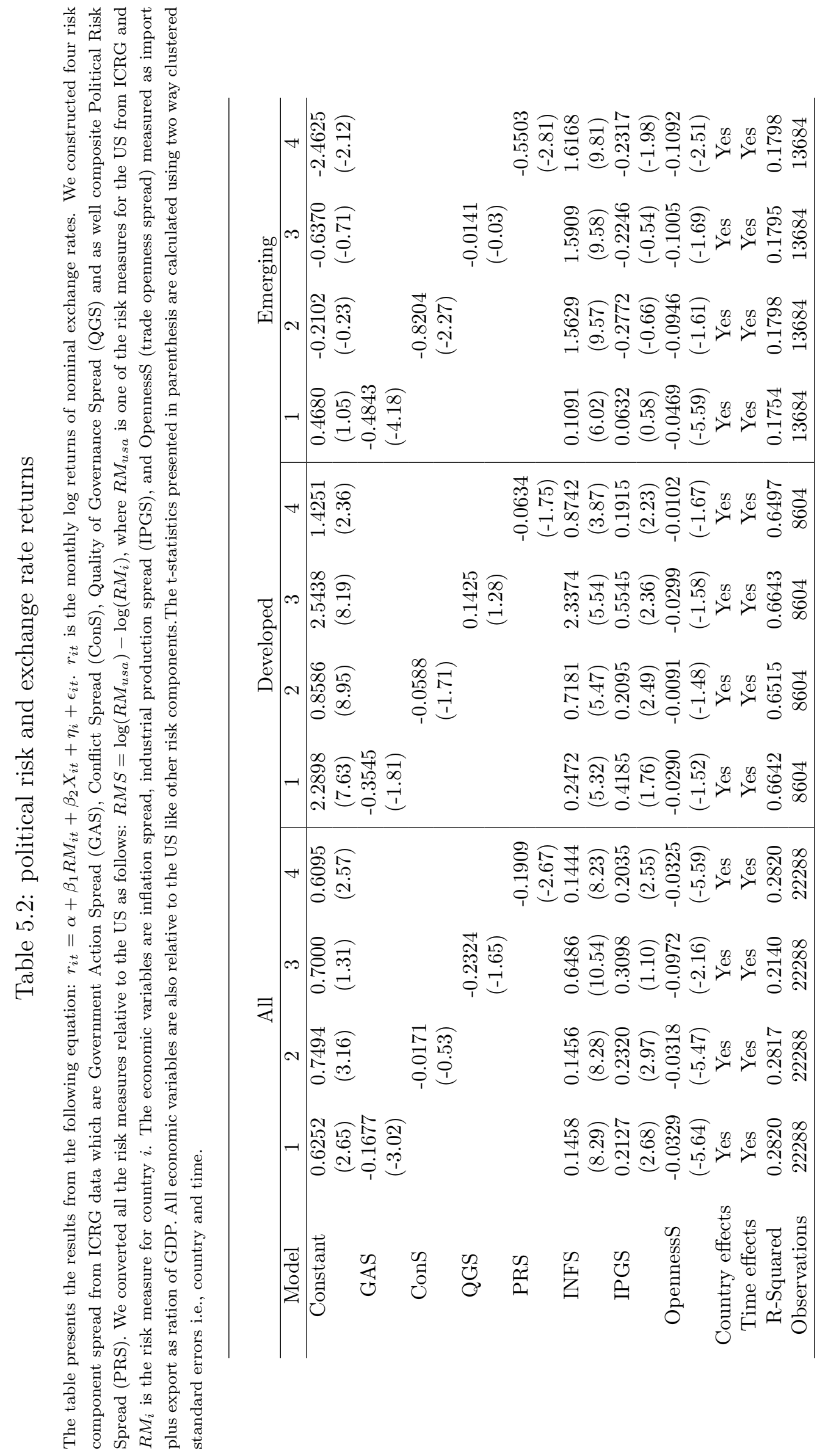


The quality of governance spread is significant and negative for both floating and managed floating exchange rates, whereas no significant results were found for the fixed exchange rate regime. The final component is the composite political risk which is the sum of the other three components government action, conflict, and quality of governance. The coefficient for the political risk is negative and statistically significant only for the floating exchange rate. However, no sign of significance was found for managed floating and fixed exchange rates. In terms of size effect, a one standard deviation increase in the political risk spread leads to a decrease of $5.8 \%$ in the floating exchange rate. The economic variables inflation, industrial production are positive and statistically significant for the majority of the cases. The results of $R^{2}$ and number of observations used in the analysis is also reported in the Table 5.3.

\subsubsection{Political risk and exchange rate volatility}

To analyze the impact of political risk variables on the exchange rate volatility, we estimated the equation (5.21) for three groups i.e., full, developed, and emerging markets, and results are presented in Table 5.4. The coefficient estimate of government action is positive and statistically significant for all three groups. The impact is stronger for emerging markets compared to developed markets (large coefficient size for emerging markets). One standard deviation increase in the government action spread leads to an increase in the volatility of exchange rate returns by $8 \%$ and $4.5 \%$ for developed markets. Similar results were found for the conflict component as both emerging and developed markets are influenced. In terms of size, one standard deviation increase in conflict component is related to an increase of $7.1 \%$ for emerging and $3.6 \%$ for the developed markets exchange rate volatility.

The impact of quality of governance spread on the exchange rate volatility is significantly negative for the developed as well as for emerging markets. However, no significant effect was found by using the full sample data. In terms of size, one standard deviation increase in the quality of governance spread leads to $7.1 \%$ and $17.3 \%$ increase in the volatility of developed and emerging markets respectively. The coefficient for the political risk was positive and statistically significant for all the three subgroups. However, the impact is more on emerging markets. One standard deviation increase in the political risk variables leads to an increase of $8.8 \%$ in the emerging markets. The economic variables inflation is significantly positive for the full sample and emerging markets whereas it's negative for the developed markets. The sign of the coefficients is negative for both industrial production and openness. The results of $R^{2}$ and number of observations used in the analysis are also reported in Table 5.4.

The empirical results from the equation (5.21) for the three different regimes 


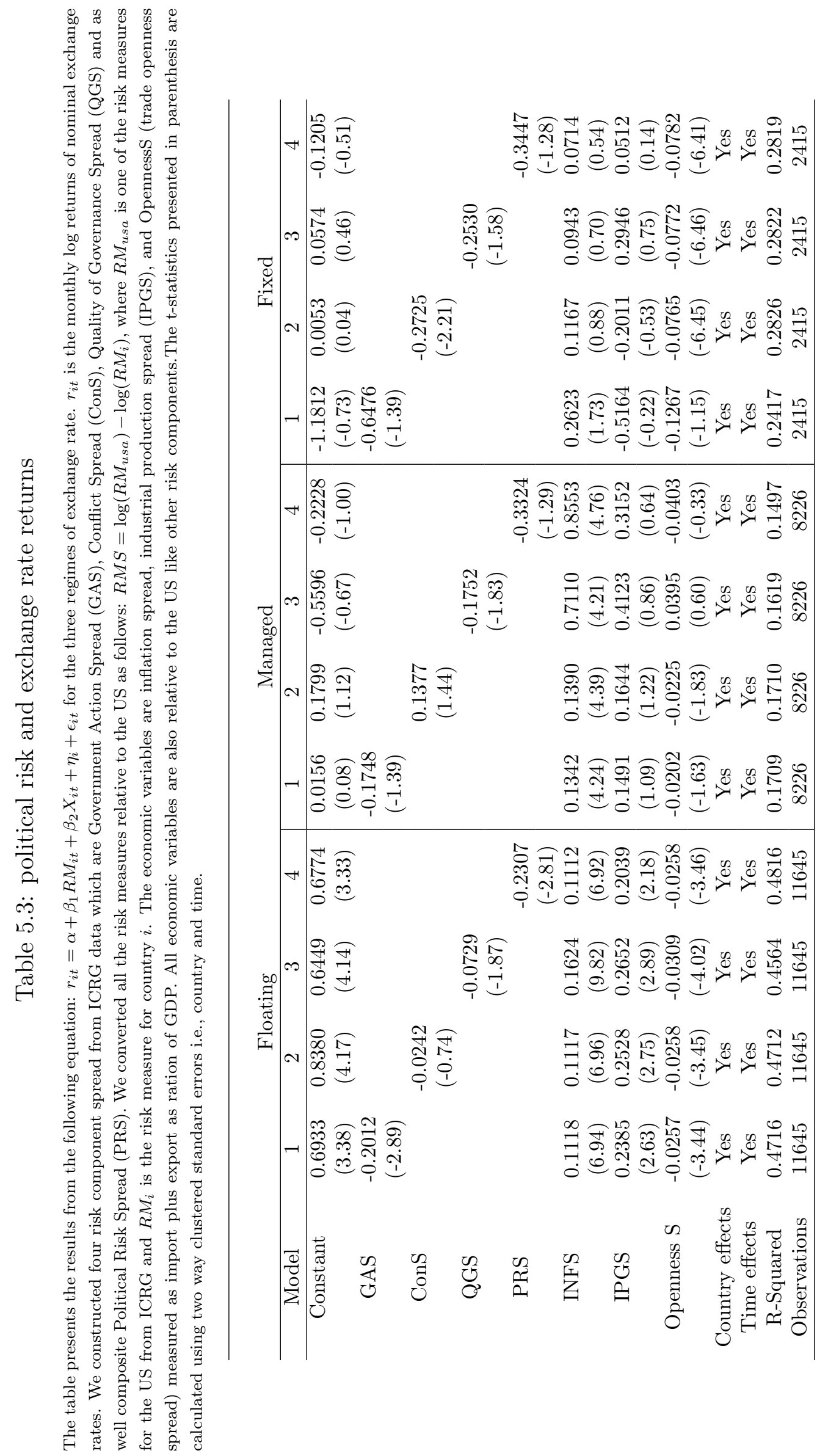




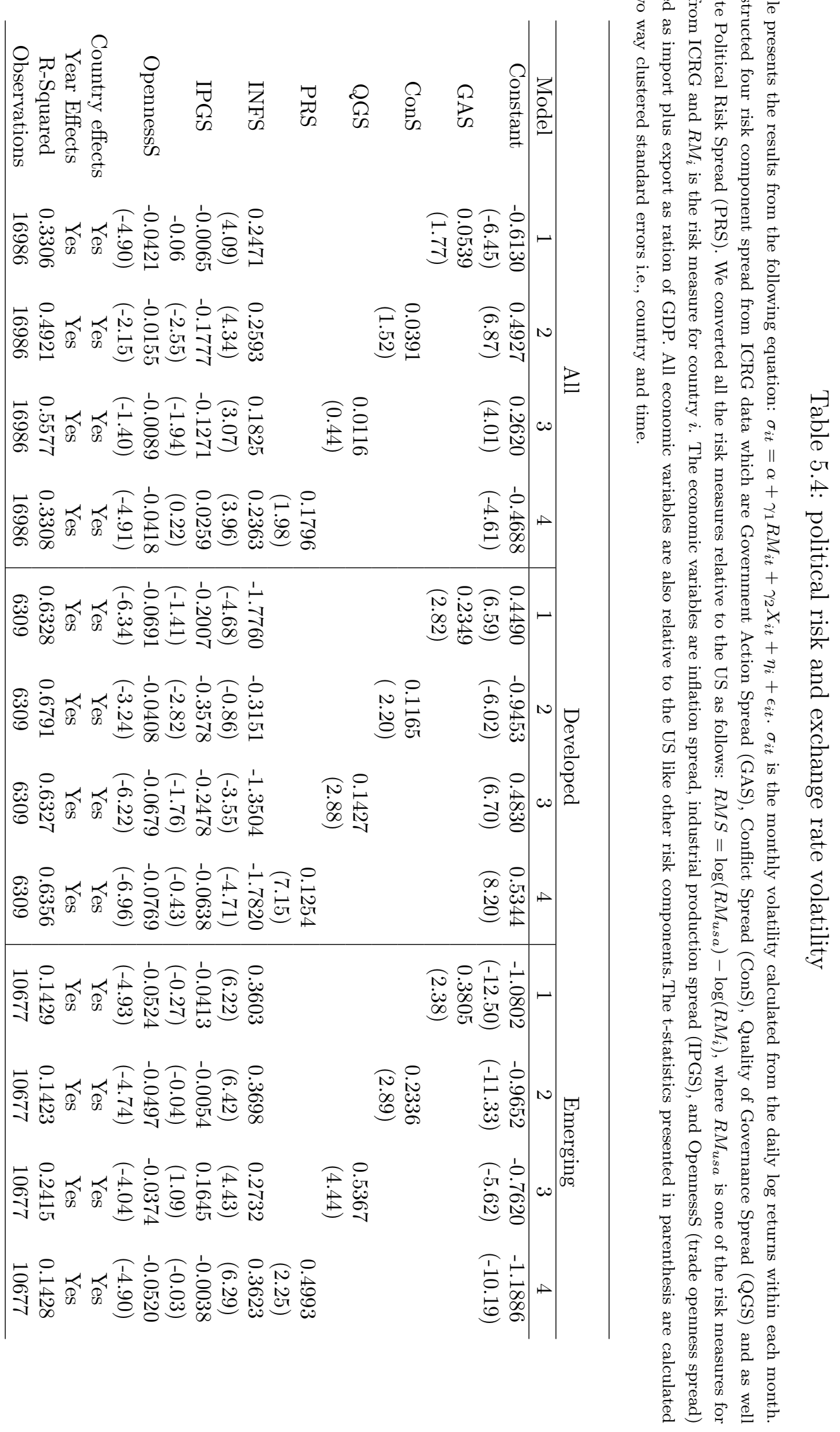


of exchange rate, floating, managed floating and fixed are presented in Table 5.5. We first considered the influence of the government action component which is constructed from three subcomponents i.e., government stability, socioeconomic conditions and investment profile on the volatility of exchange rate for three types of exchange rate regimes. The coefficient estimate of government action is statistically significant for floating and managed exchange rate regimes. In economic terms, one standard deviation increase in the spread leads to an increase in the exchange rate volatility by $6.2 \%$ for floating and only by $1.8 \%$ for managed float.

In the second regression, we examined the relationship between the exchange rate volatility and the conflict component. Results were positive and statistically significant for only the fixed exchange rate. In economic terms, an increase of one standard deviation in the conflict spread is associated with an increase in the volatility of exchange rate by $6.36 \%$. The variable quality of governance component is significantly positive for the floating exchange rate volatility. The size of the effect is small as one standard deviation increase in quality of governance spread is associated with $3.5 \%$ points increase in the volatility of floating exchange rate.

Lastly, we analyzed the composite political risk spread which is the sum of all the three risk components, i.e., government action, conflict and quality of governance. The coefficient for the political risk is positive and statistically significant only for floating exchange rate volatility. No sign of significance was found for managed floating and fixed exchange rate volatility. In terms of size effect, a one standard deviation increase in the political risk spread leads to an increase of $3.5 \%$ in exchange rate volatility. The economic variables inflation is positive and significant for only managed float, whereas industrial production and openness were negative for all the three exchange rate regimes. The results of $R^{2}$ and number of observations used in the analysis are also reported in the Table 5.5.

\subsubsection{Political risk, exchange rate volatility and economic conditions}

Table 5.6 presents the results of the political risk components for the full sample, developed and emerging markets from the equation (5.22). Here, we are more interested in the interaction term. According to hypothesis, volatility will be higher during higher political risk and bad economic periods. Our results are much stronger for the emerging markets as the coefficient of interaction term is negative and significant for all the four risk spreads. So we confirm that political risk becomes more important during poor economic conditions. The link is weak for developed markets as only quality of governance and political risk is with 


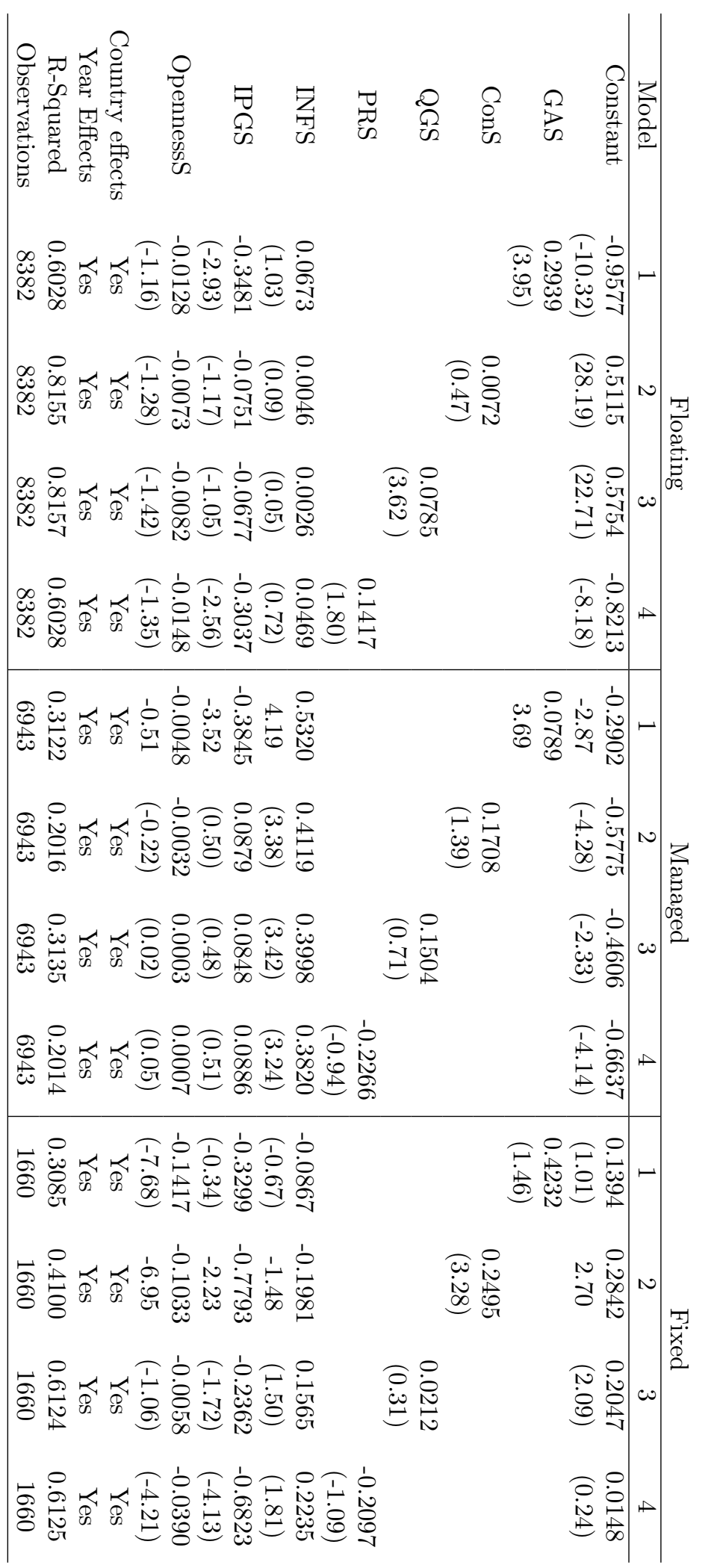

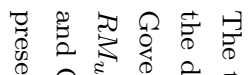
要 E.

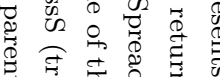

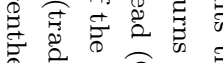
क. वे \% 造 宅 递官兽总

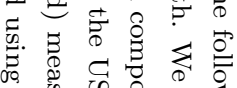

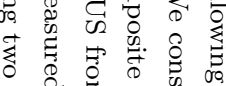
¿

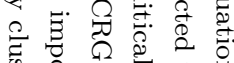

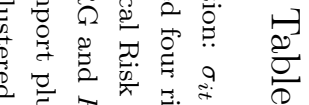

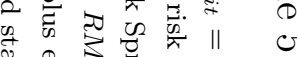

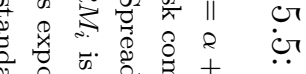

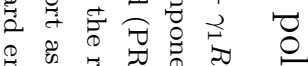

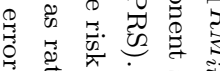

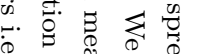

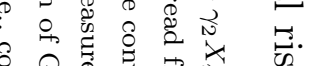
$\Omega$ 要

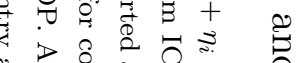

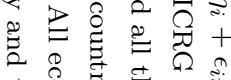

t. 8 है

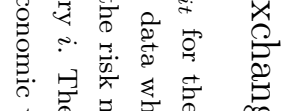

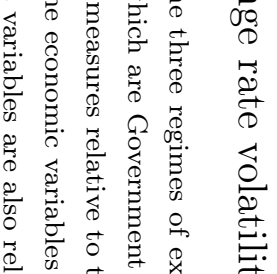

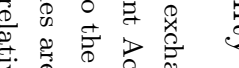
政

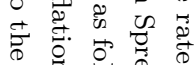
०

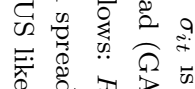

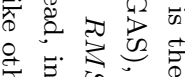

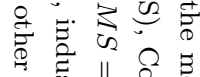
氜.

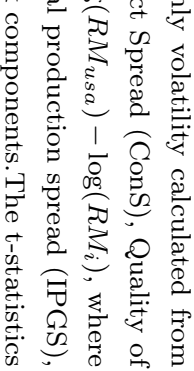


significant negative coefficients, whereas for the government action and conflict variable it is negative but not significant. These results are consistent with finding of Pástor \& Veronesi (2013) for US equity market, Suleman \& Daglish (2015) for developed and emerging equity markets, and Krol (2014) for currency market.

\subsubsection{Political risk, economic conditions and risk premia}

The results from equation (5.23), are presented in Table 5.7, are not strong either for developed or emerging markets. We investigated investors' demand for a higher risk premium during higher political risk and poor economic conditions. We found no clear evidence in favour of the link between political risk and risk premium as most of the coefficients for interaction were negative; however, it is only significant $\left(\gamma_{2}<0\right)$ for political risk. The risk measure conflict has a significant negative coefficient for emerging markets.

\subsubsection{Robustness check}

We also used the data for economic and financial risk from ICRG for the robustness of our results. Our sample increased from 69 countries to 104 countries and a list of countries is presented in Table B.3 Appendix B. The results for the equation (5.20) are presented in Table B.4 for developed and emerging markets and in Table B.5 for floating, managed floating and fixed exchange rate. For the emerging markets we found the similar results, i.e., emerging markets are more affected by political risk measures compared to with developed markets. For emerging markets, all the four components are negative and significant, whereas for developed markets only one risk component (government action spread) had significant results. So we can conclude that the impact of political risk is more on emerging markets. Moving toward the exchange rate regime, the managed floating regime is more affected by political risk as three components are significant compared to two for the floating exchange rate. No significant results were found for the fixed exchange rate.

The results using equation (5.20) with economic and financial risk from ICRG are presented in Table B.6 for emerging and developed markets and in Table B.7 for the three different exchange rate regimes. The results confirm that political risk spread is important for both emerging and developed markets. However, the size of coefficients is larger for emerging markets. The fixed and managed floating results are similar when we use the real economic variables. However, for the floating exchange rate we found only one significant coefficient which is different when real economic variables are used (inflation, industrial production and trade openness). 


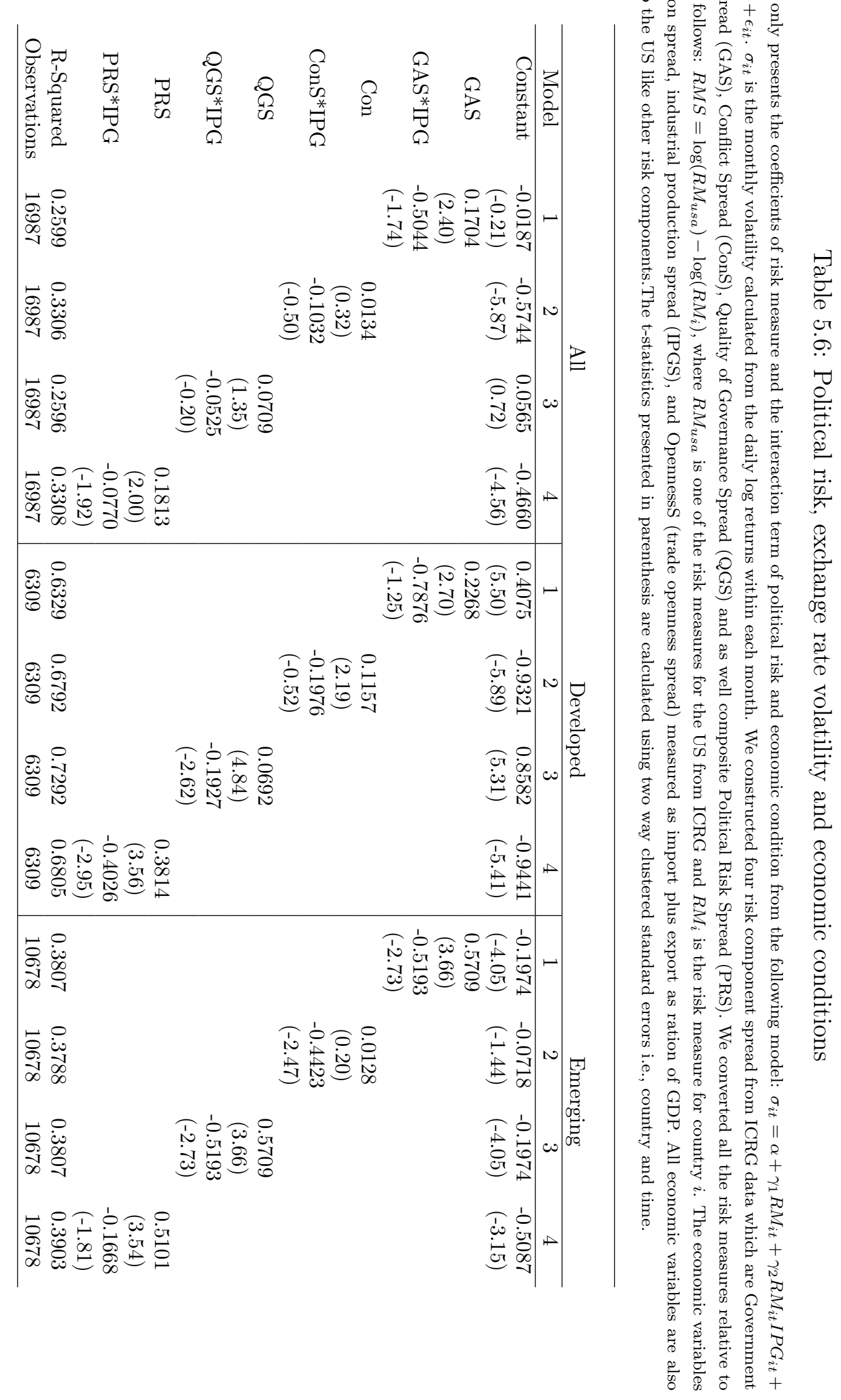




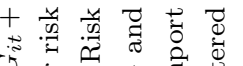

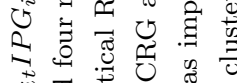

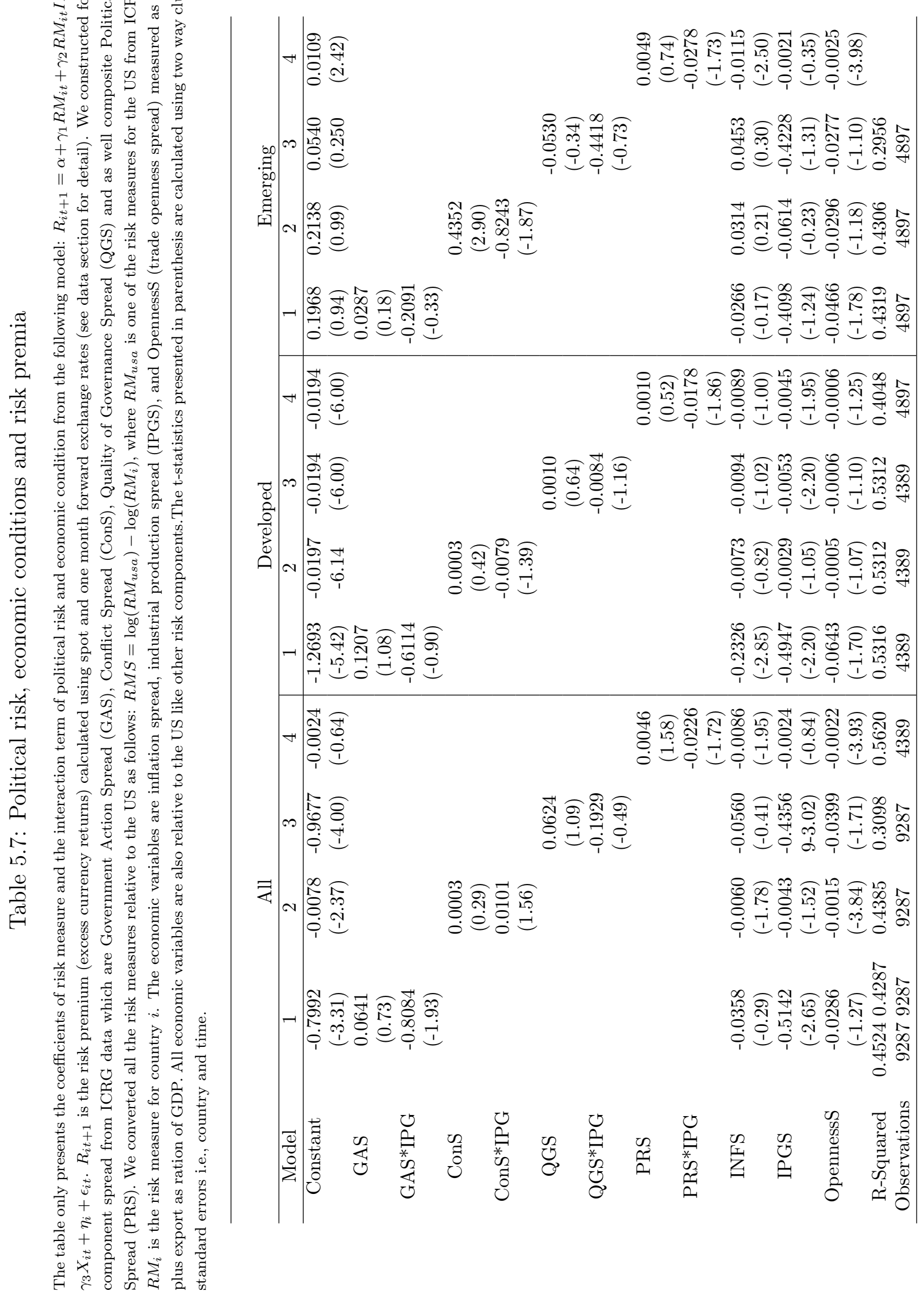




\subsection{Conclusion}

This chapter examined the relationship between political risk components and exchange rate returns and volatility. The political risk components for this study are constructed from the rating provided by the ICRG. First we analyzed the impact of political risk components such as government action spread, conflict spread, quality of governance spread and political risk spread on the emerging and developed markets. Our results reveal that emerging markets are more exposed to political risk. Further impact of political risk variables is more on the floating exchange rate compared to the managed floating and fixed exchange rate returns. One standard deviation increase in the political risk spread leads to a decrease in exchange rate returns by $9.7 \%$.

Turning towards the volatility dynamics, we found that both emerging and developed markets' volatility is influenced by all four political risk components. However, the size of impact is more on emerging markets. Further floating exchange rate volatility responds more to political risk components compared to the other two regimes. Our results are robust when analyzed by using economic and financial data from ICRG. Further, we also found a strong evidence that volatility increases more during a period of high political uncertainty and poor economic conditions for emerging markets. The results for exchange rate risk perima are mostly insignificant for the majority of the components. However, only political risk spread with significant coefficients for both emerging and developed markets. 


\section{6}

Conclusions

This chapter concludes the main findings of the thesis and future research directions.

\subsection{Conclusions}

First we examined how political risk affects the first and second moment of the returns. In particular, the focus was to examine whether stock market data seem to be affected by political risk as quantified by the ICRG. We investigated the following questions by using the data of 47 emerging and 21 developed markets. First, which model and lag was best to use when considering the data from the ICRG. As their is no set standard to use the lag of political risk data from the ICRG. Second, whether the political risk is priced in emerging as well as in developed markets. Third, the effect of political risk on the first as well as the second moment. Third, how change and squared change of the political risk measures, i.e., government action, conflicts and quality of governance, political risk and composite risk influence the stock returns and volatility across emerging and developed markets.

We began the investigation with the selection of the best model and the best lag for each country on the basis of AIC. We ran all four models individually with five different lags $(1,3,6,12,24)$. Once the best model and best lag were identified, we used them to analyze the impact of political risk on the return and volatility of developed and emerging markets. The result revealed that model 4 with Lag 24 was the best for the majority of emerging and developed markets. Further, we also conclude that the impact of risk measures (GA, CON, QG) is more on emerging markets. Overall, we found that impact of all the variables 
is more on volatility compared to returns.

The second research question is to use the best model and lag to analyze the impact of political risk as firms' returns as investors can perceive the political risk in different ways. So there might be some firms that are affected by the political risk and other not. For the empirical analysis we used the data of two countries, New Zealand and Pakistan. Both countries have similar political systems which is the parliamentary system. However, New Zealand's political institutions are well developed compared to Pakistan's. The data on the firm level were obtained from the DataStream and we divided the firms into different sectors according to the stock exchange classification for both New Zealand and Pakistan. We estimated the model for 185 firms divided into 18 industry indices for New Zealand and 204 firms divided into 19 industries for New Pakistan.

Empirical results confirm that political risk has more impact on Pakistani firms compared to New Zealand firms and also the investors perceive political risk differently (both positive and negative) across firms. This is because a change in government might be good news for some firms but bad for others. Overall, we conclude that impact of political risk is more on volatility compared to returns. The industry portfolio reveals that the conflict component has a significant effect on the return and volatility of returns for Pakistan. Overall, results confirms that there industries in the sample who are more exposed to political risk.

In Chapter 5 we examined the relationship between political risk measures with the nominal exchange rate return and its volatility. We constructed four political risk component spreads (government action spread, conflict spread, quality of governance spread and political risk spread) from the the ICRG data. Then we divided the data into developed and emerging markets to investigate which group of countries are affected by these components. The analysis was also estimated for the three exchange rate regimes, i.e., floating, managed floating, and fixed. Additionally, we also examined the relationship between political risk, volatility and risk premium during bad economic conditions. Data was used for over 100 emerging and developed markets for the period January 1984 to December 2013. We constructed three variables from exchange rate data: exchange rate return, monthly volatility from daily returns and excess returns using one month forward exchange rates.

First, we analyzed the impact of a political risk component spread such as government action, conflict, quality of governance and political risk on the emerging and developed markets. Our results reveal that emerging markets are more exposed to political risk spread. Further, impact of political risk component is more on the floating exchange rate compared to the managed floating and fixed exchange rate returns. Turning towards the volatility dynamics, we found that both emerging as well as developed market volatility is influenced 
by all four political risk components. However, the size of impact is more on emerging markets. Further, floating exchange rate volatility responds more to political risk spreads compared to the other two regimes. We also found a strong evidence that volatility increases more during a period of high political uncertainty and worse economic conditions mainly for emerging markets.

\subsection{Future research directions}

Chapter 3 presents the impact of political risk on return and volatility of both developed and emerging markets. We examine the impact of domestic political risk on equity markets. This can further extended by analysing the impact of global political risk on the return and volatility of equity markets. More specifically we can also look on the impact of USA political risk on emerging markets. Another extension of this paper is to examine the political risk spillover across emerging and developed markets or more specifically countries in the same region. We can also examine, does increase in political risk in one country affect the return and volatility of other countries'. For thats purpose multivariate volatility models will be appropriate to use.

We can examine the level of integration across emerging and developed markets and analyse whether political risk can be considered as an important factor which increases the stock market integration. For example, if the ISA political risk changes influence the emerging stock market integration, the investor can actually forecast the patterns in equity market return and make their portfolio allocations. Lastly, we can also analyse political risk spillover. For illustration, if the conflict component which is the subcomponent of political risk increase for India which suggests an increase in political risk. So through the spillover we can examine, is there any spillover from Indian to Pakistan or China.

Chapter 4 examines the impact of political risk on firm and industry portfolios returns. We can extend this research by considering the joint impact of political risk and economic variables. As there is a chance that firms and industries respond differently to the joint effect of political risk and economic conditions. A further extension of this research can include the analysis of specific sectors such as oil and gas, or transportation across emerging and developed markets. Further, we can also analyse the returns of industries by forming portfolios which are more affected by political risk and portfolios by less affected ones. Another extension could be to investigate stock market integration and assess whether or not domestic political risk can influence stock market integration. We can also examine the relationship between political risk and equity market liquidity. Are liquid stocks more affected by political risk than illiquid stocks?

Chapter 5 examines the relationship between political risk and exchange rate 
return and volatility using a panel data analysis. As a further extension, we can examine the role of USA's political risk on exchange rate more generally, i.e. not just via the risk spread. This will help us to understand how important is the role of USA political risk in determining the exchange rate exposure. We can also examine the relationship of political risk on an individual country's exchange rate returns and volatilities, more specifically on industrialised countries. We find weak evidence about the link between exchange rate risk perima during higher political risk and bad economic conditions. A further extension could be analysis over different time horizons such as 3 . 6 or 12 month periods. 
Appendices 



\section{A \\ Model diagnostics}

This section provides the details of each Model (Model 1 to Model 4 in Chapter 3) with with five different lags $(1,3,6,12,24)$. Each table presents the AIC values for each model at five different lags individually. Further, the best Model and best lag are also indicated in each table. Tables A.2 to A.4 display the AIC for developed markets starting with risk components, political risk and composite risk. All the three risks for the emerging markets are presented in Tables A.5 to A.7. Following equation is used for estimation of results for developed and emerging markets;

$$
\begin{gathered}
r_{t}=\phi_{0}+\phi_{1} r_{t-1}+\phi_{2} \mathrm{RM}+\phi_{3} \mathrm{X}+\epsilon_{t} \\
\log \left(\sigma_{t}^{2}\right)=\omega+\alpha f\left(z_{t-1}\right)+\beta_{1} \log \left(\sigma_{t-1}^{2}\right)+\beta_{2} \mathrm{RM}+\beta_{3} \mathrm{X}
\end{gathered}
$$

Table A.1: Models and variables used for the selection of best model

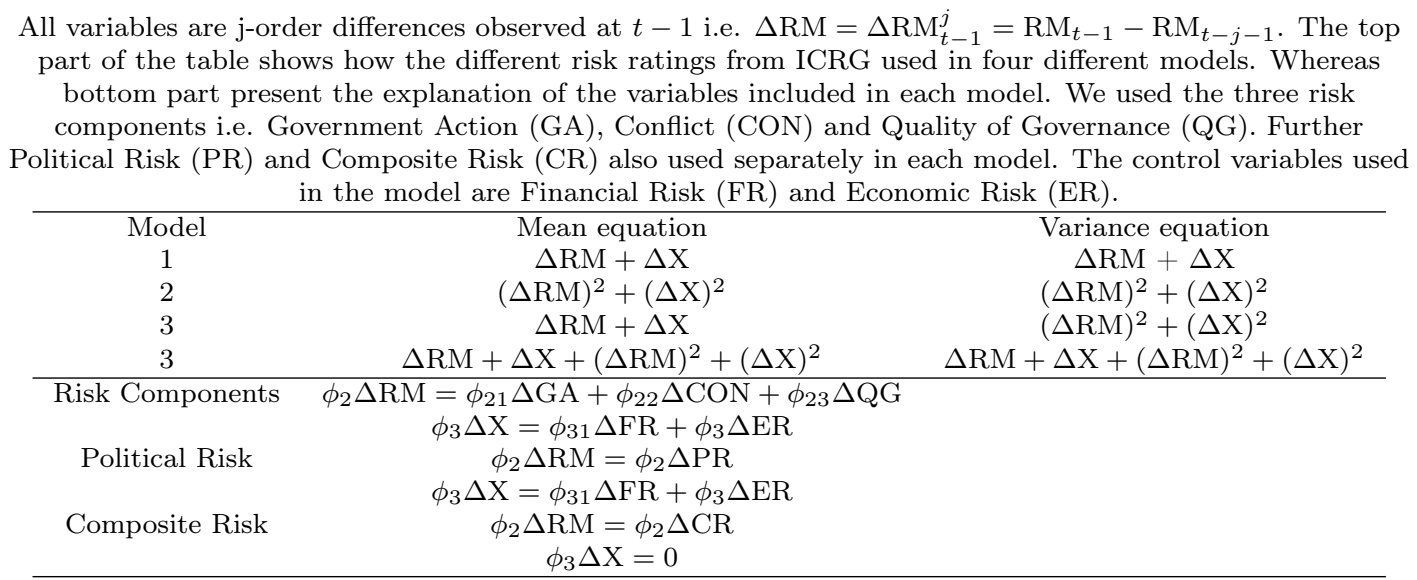




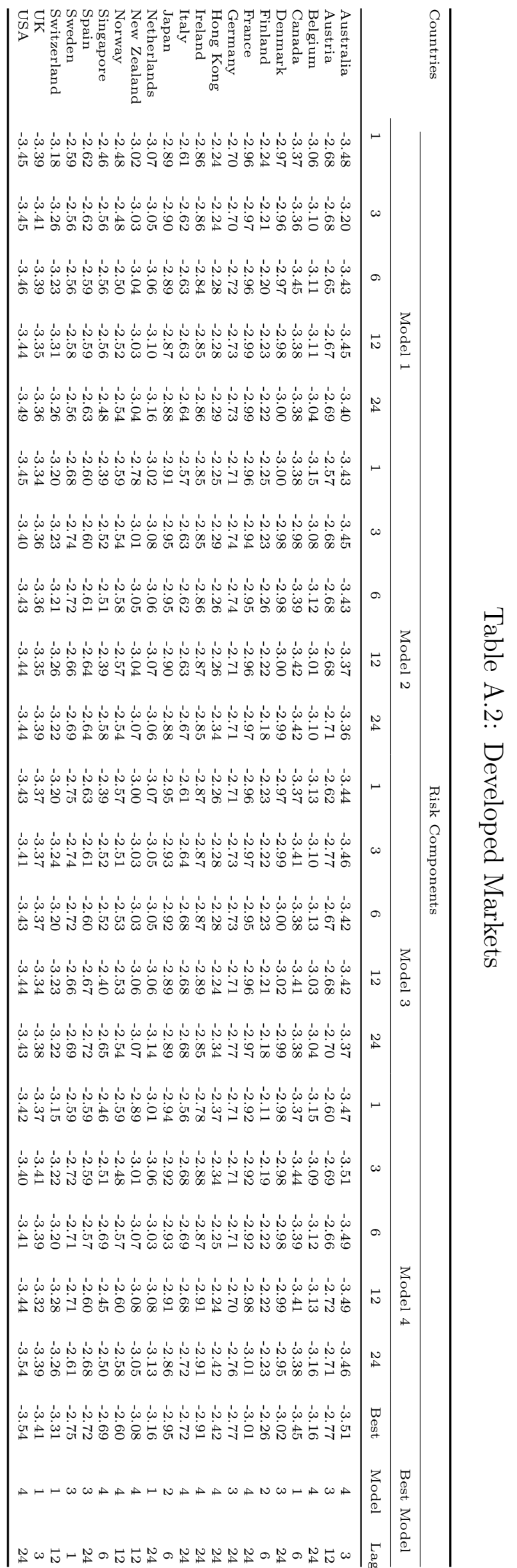




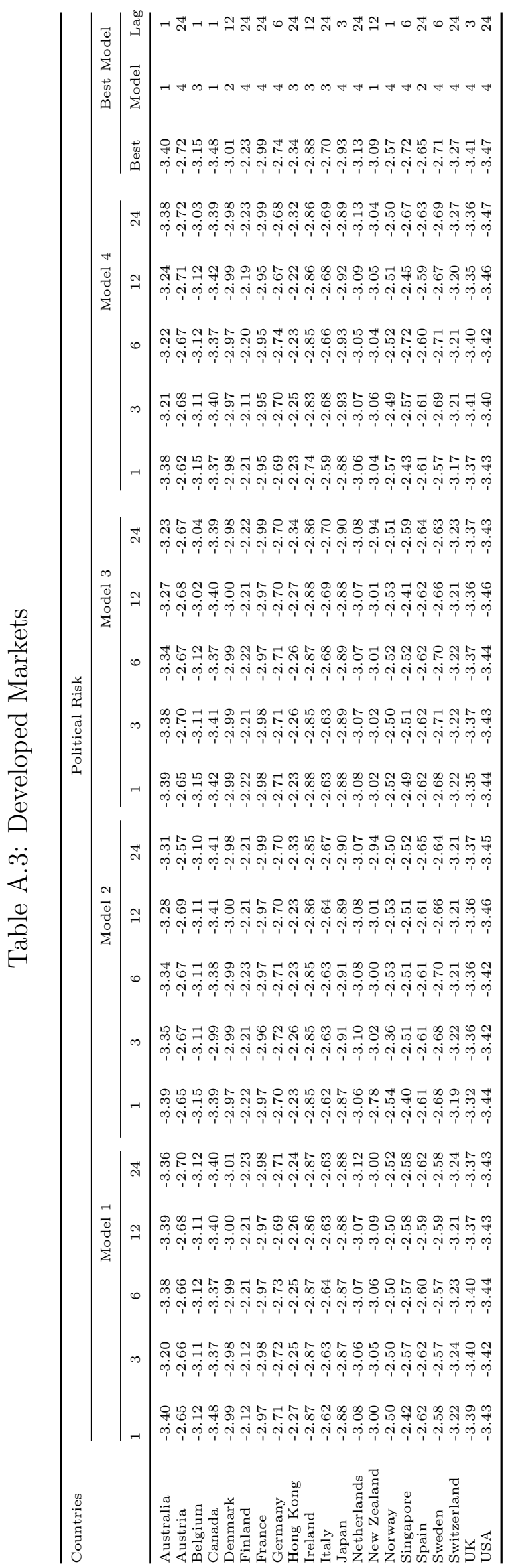




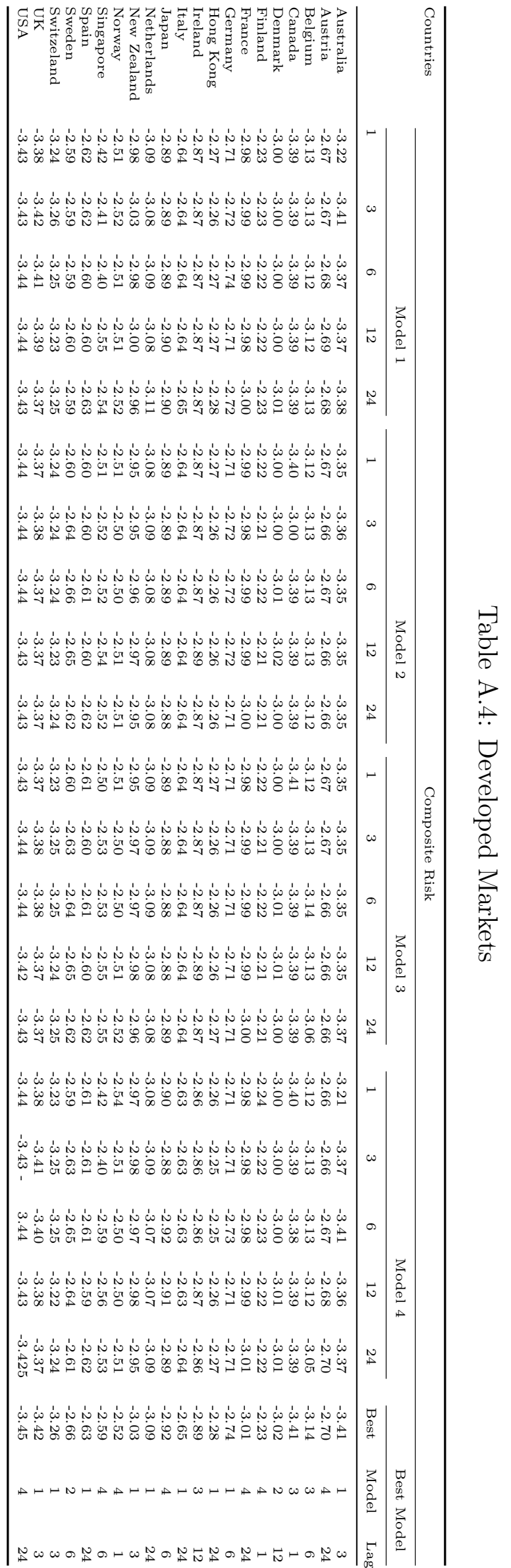




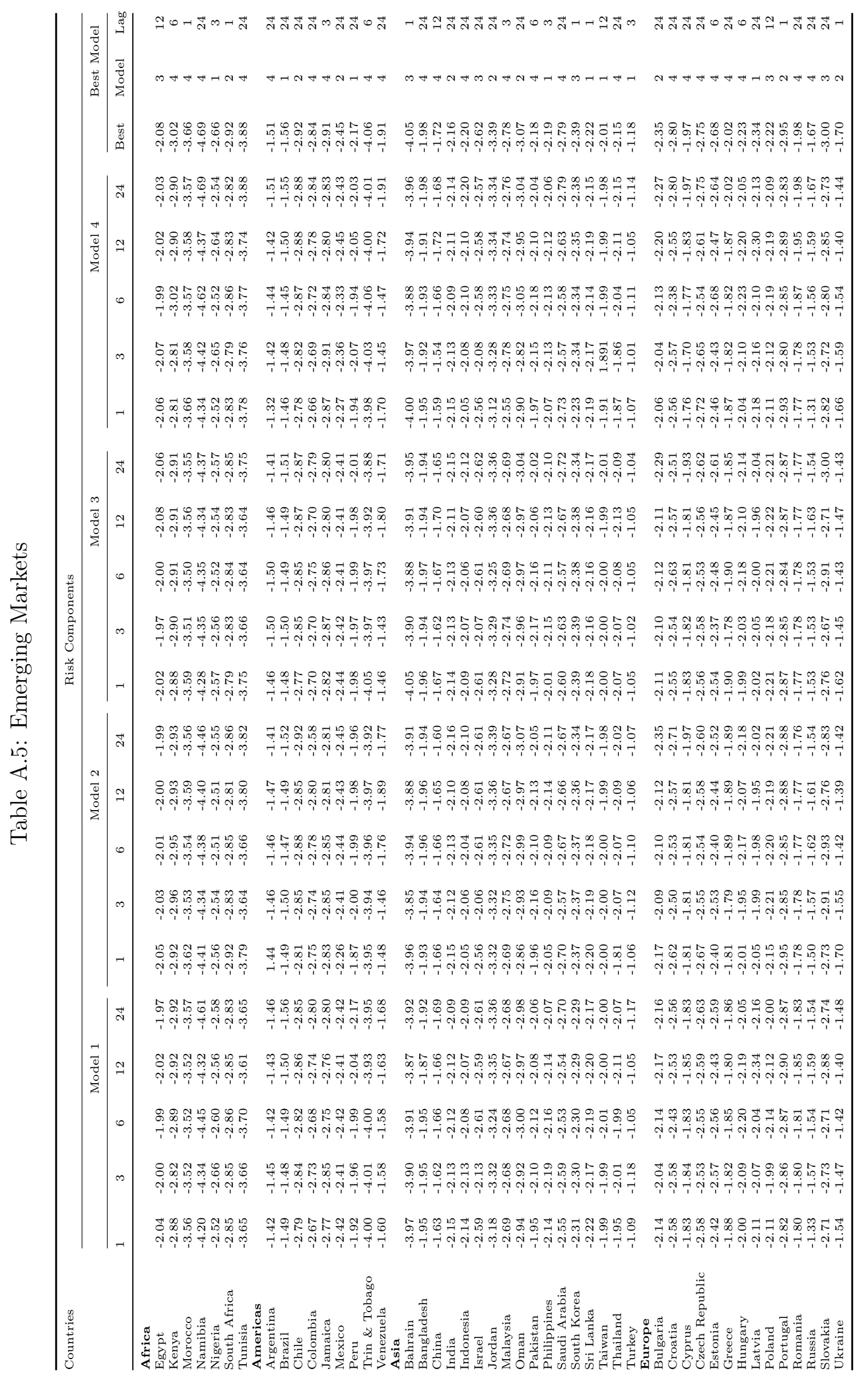




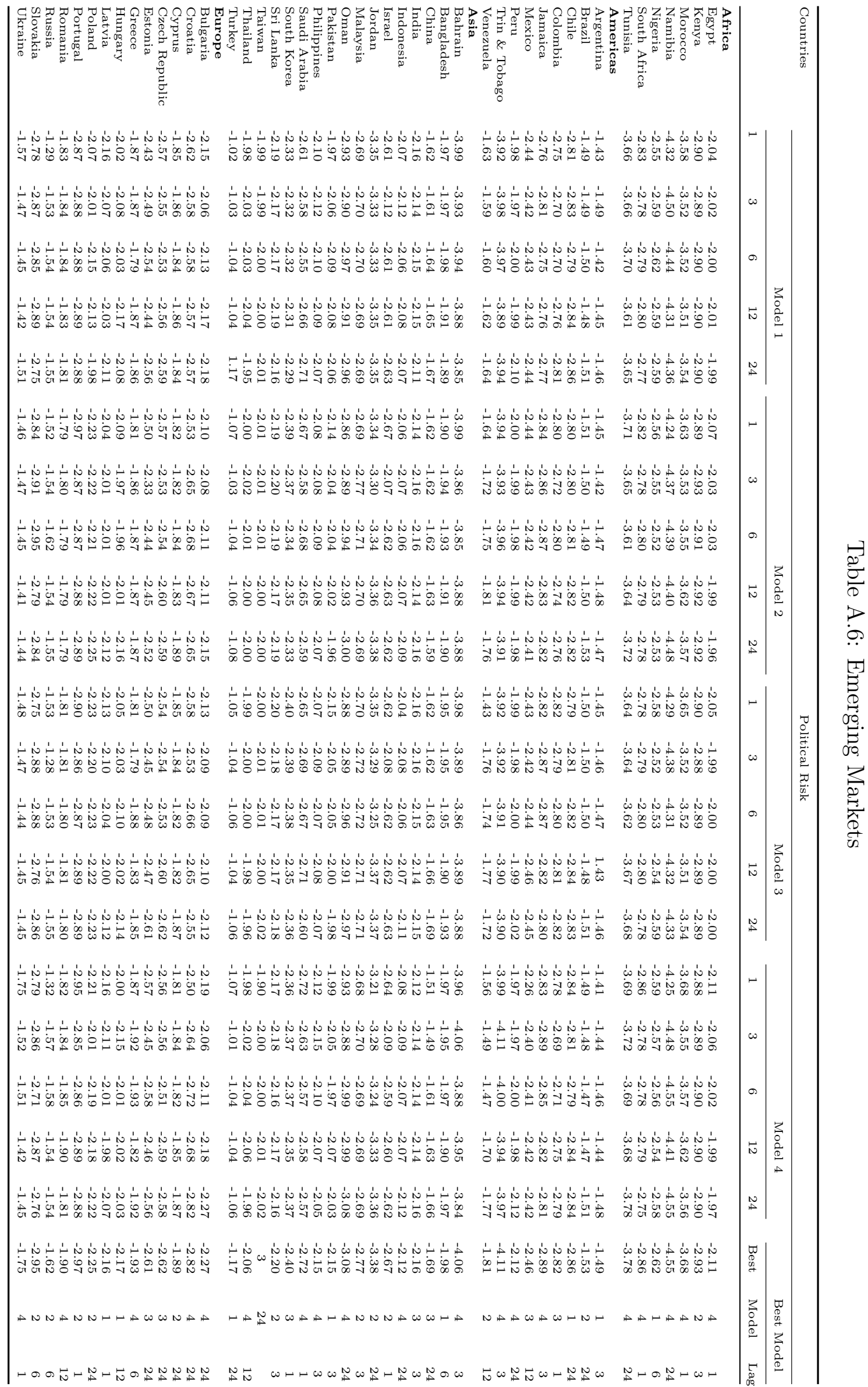




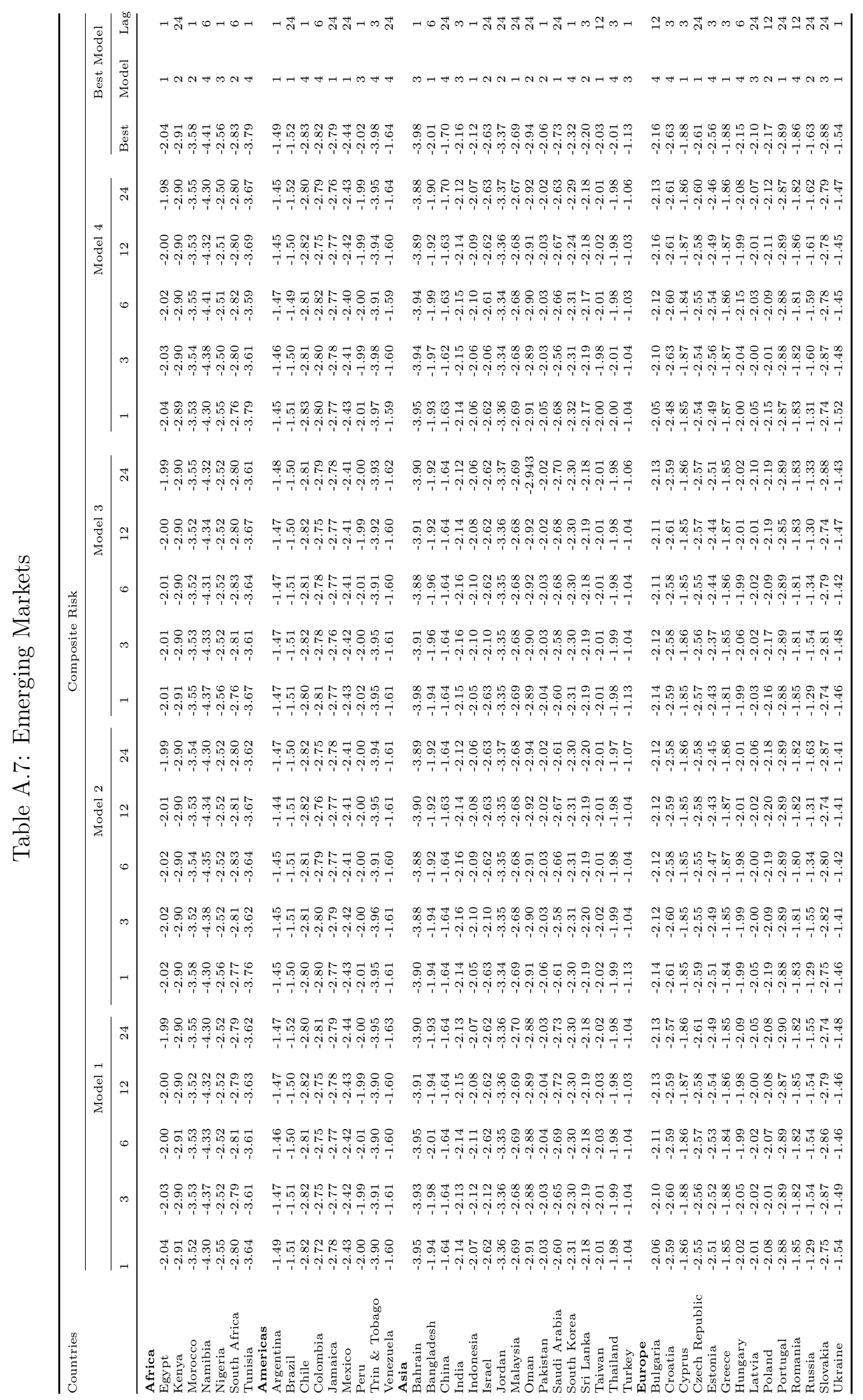




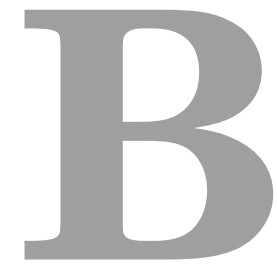

\section{Robustness checks}

This section presents the list of the countries used for analysis in Chapter 5 (both main and robustness check). The results related to robustness estimates from Chapter 5 are also presented in this appendix. Table B.1 to B.3 presents the list of countries used for analysis. Whereas B.4 to B.7 shows the results of robustness check. 
Table B.1: List of Countries

\begin{tabular}{cc|cccc}
\multicolumn{2}{l}{ List of countries with economic variables used in main analysis of Chapter 5 section 5.5 .1 and 5.5 .2}$. \\
\hline Developed & & Emerging & & & \\
Australia & Italy & Albania & Czech Republic & Latvia & Slovakia \\
Austria & Japan & Argentina & Ecuador & Lithuania & South Africa \\
Belgium & Luxembourg & Bangladesh & Egypt & Malaysia & South Korea \\
Canada & Netherlands & Bolivia & El Salvador & Malta & Sri Lanka \\
Denmark & New Zealand & Brazil & Estonia & Mexico & Taiwan \\
Finland & Norway & Bulgaria & Ghana & Pakistan & Thailand \\
France & Portugal & Chile & Hungary & Peru & Tunisia \\
Germany & Singapore & China & India & Philippines & Turkey \\
Greece & Spain & Colombia & Indonesia & Poland & Ukraine \\
Hong Kong & Sweden & Costa Rica & Israel & Romania & Russia \\
Iceland & Switzerland & Croatia & Kazakhstan & Serbia & \\
Ireland & United Kingdom & Cyprus & Kenya & &
\end{tabular}

Table B.2: List of Countries

\begin{tabular}{cc|ccc}
\multicolumn{4}{l}{ List of countries used to calculate excess returns using the one month forward rate. } \\
\hline Developed & & Emerging & & \\
Australia & Italy & Argentina & India & Romania \\
Austria & Japan & Bulgaria & Indonesia & Russia \\
Belgium & Netherlands & Chile & Israel & Serbia \\
Canada & New Zealand & China & Kazakhstan & Slovakia \\
Denmark & Norway & Colombia & Kenya & South Africa \\
Finland & Portugal & Croatia & Latvia & South Korea \\
France & Singapore & Cyprus & Lithuania & Sri Lanka \\
Germany & Spain & Czech Republic & Malta & Taiwan \\
Greece & Sweden & Egypt & Mexico & Thailand \\
Hong Kong & Switzerland & Estonia & Pakistan & Tunisia \\
Iceland & United Kingdom & Ghana & Philippines & Turkey \\
Ireland & & Hungary & Poland & Ukraine \\
\hline
\end{tabular}

Table B.3: List of Countries

List of countries for which economic and financial rating used from ICRG for robustness check in Chapter 5

\begin{tabular}{|c|c|c|c|c|c|}
\hline Developed & & Emerging & & & \\
\hline Australia & Spain & Albania & Egypt & Lithuania & Slovakia \\
\hline Austria & Sweden & Algeria & El Salvador & Malawi & South Africa \\
\hline Canada & Switzerland & Argentina & Estonia & Malaysia & South Korea \\
\hline Denmark & United Kingdom & Bahrain & Ethiopia & Malta & Sri Lanka \\
\hline Finland & & Bangladesh & Gambia & Mexico & Sudan \\
\hline France & & Belarus & Ghana & Morocco & Suriname \\
\hline France & & Bolivia & Guatemala & Namibia & Syria \\
\hline Germany & & Botswana & Guinea & Nicaragua & Taiwan \\
\hline Greece & & Brazil & Honduras & Nigeria & Tanzania \\
\hline Hong Kong & & Brunei & Hungary & Oman & Thailand \\
\hline Iceland & & Bulgaria & India & Pakistan & Trinidad \& Tobago \\
\hline Ireland & & Chile & Indonesia & Paraguay & Tunisia \\
\hline Italy & & China & Israel & Peru & Turkey \\
\hline Japan & & Colombia & Jamaica & Philippines & United Arab Emirates \\
\hline Luxembourg & & Costa Rica & Jordan & Poland & Uganda \\
\hline Netherlands & & Croatia & Kazakhstan & Qatar & Ukraine \\
\hline New Zealand & & Cyprus & Kenya & Romania & Uruguay \\
\hline Norway & & Czech Republic & Kuwait & Russia & Venezuela \\
\hline Portugal & & Dominica Republic & Latvia & Saudi Arabia & Vietnam \\
\hline Singapore & & Ecuador & Liberia & Serbia & Zambia \\
\hline
\end{tabular}




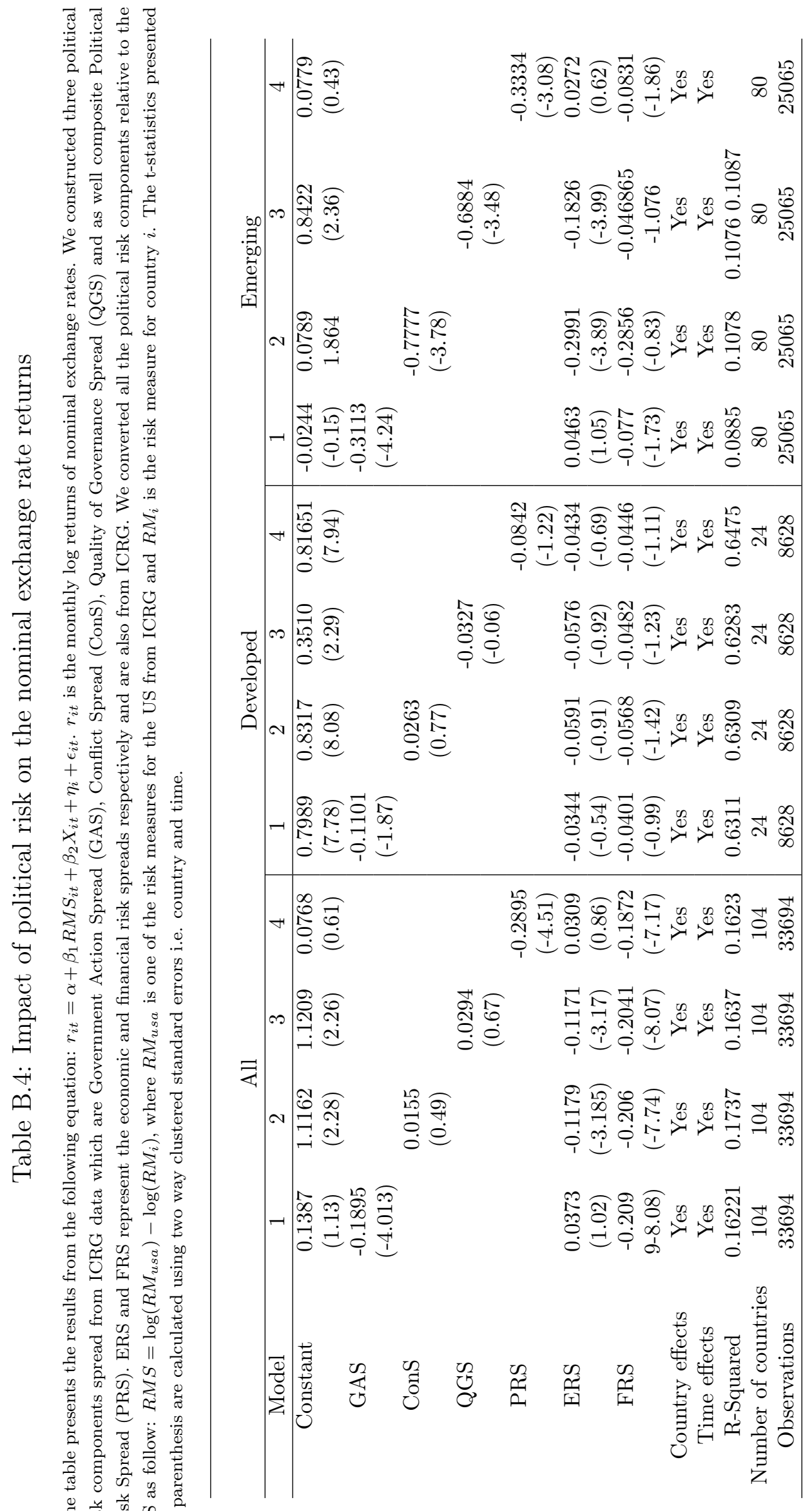




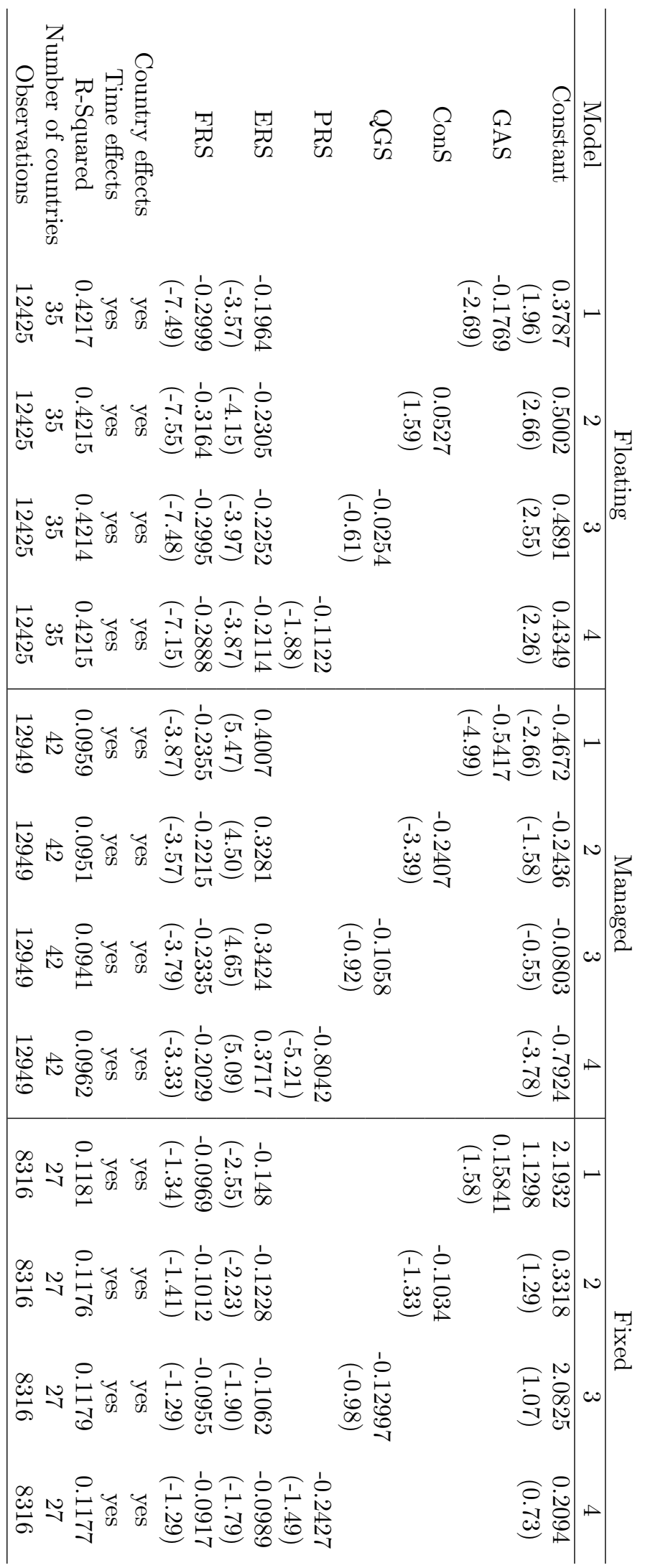

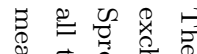

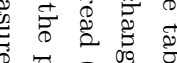

궁

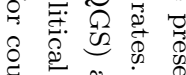

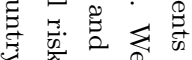

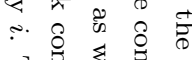

它

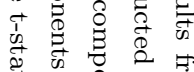

है. 曹

की

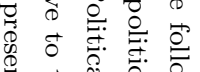

है

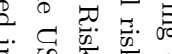

कृ

蛋

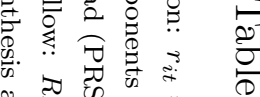

\%

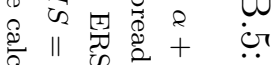

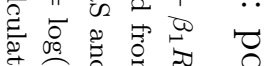

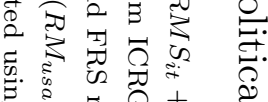

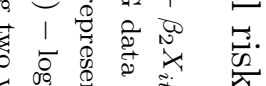

व

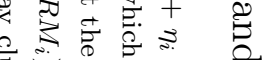

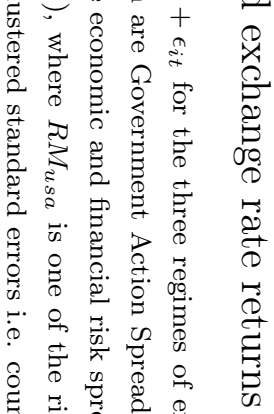

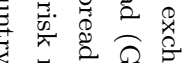

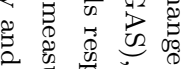

प.

象通蛋

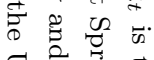

जै है है

节嘀

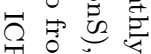

ฉ

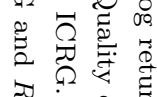

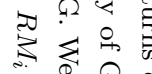

क.

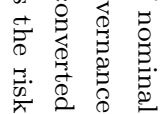




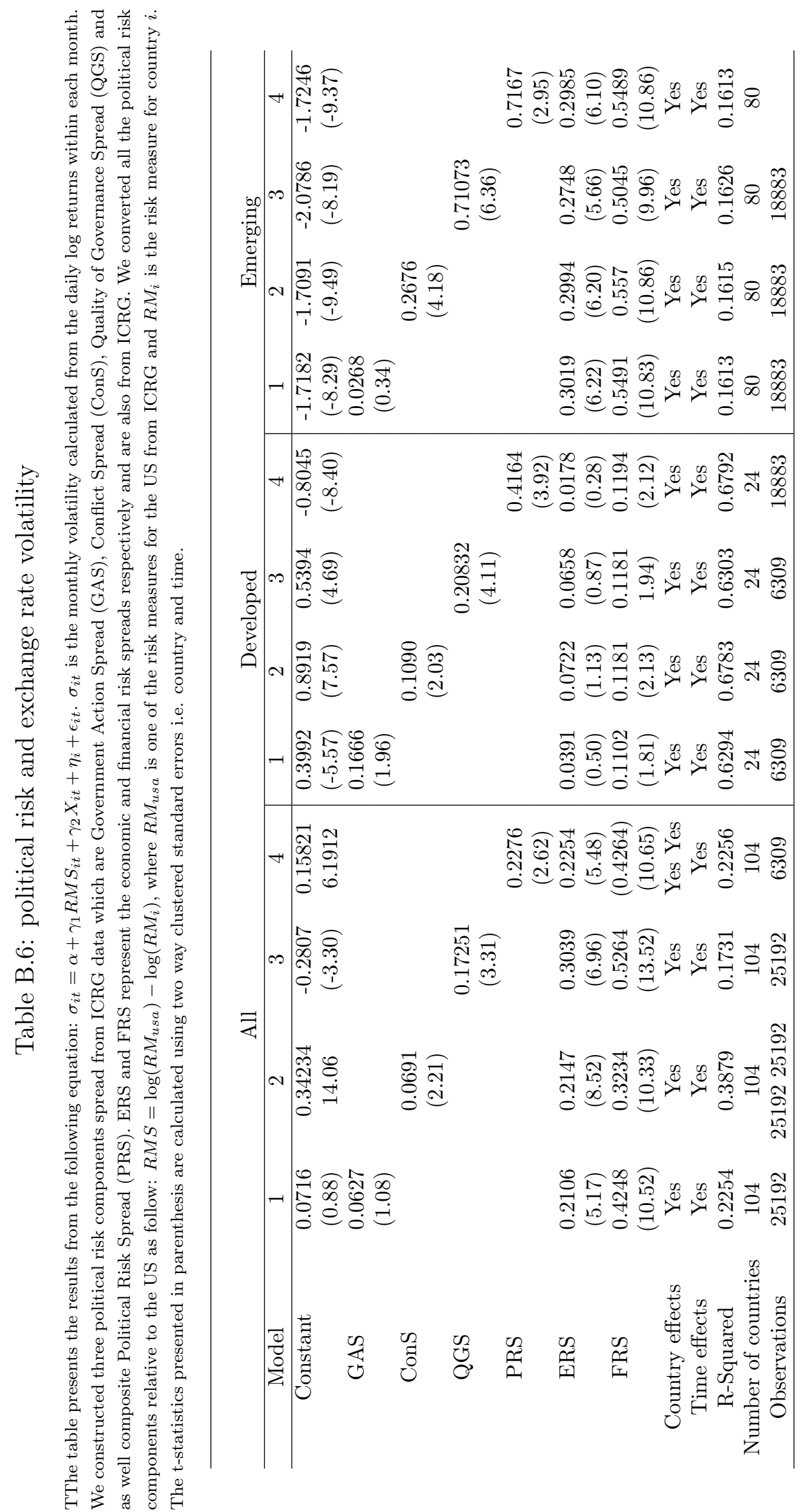




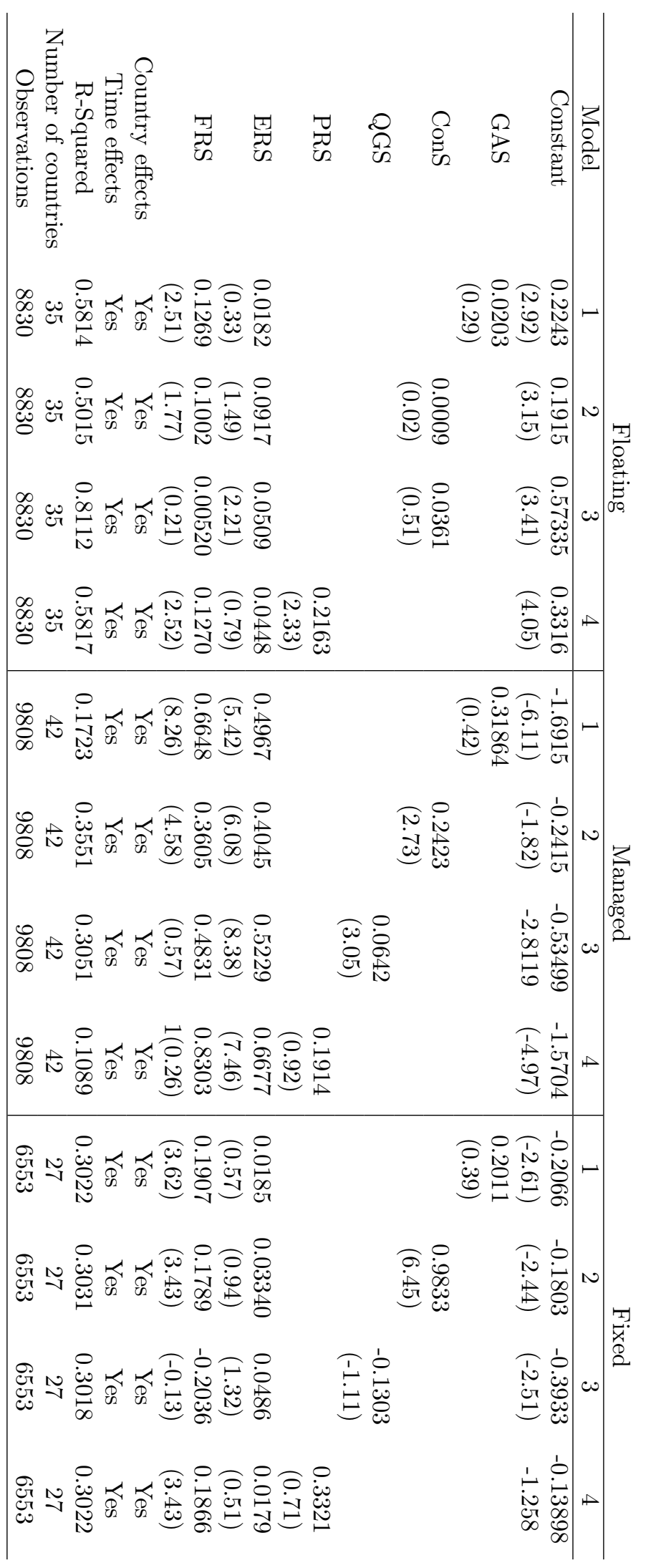

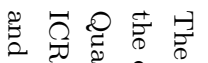
刃ำ द्व ज. 80 ०

क 可 政

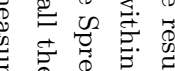

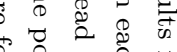
送 8 . 당 .

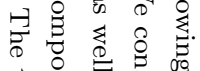

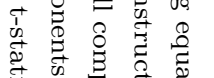

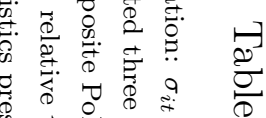

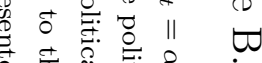

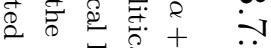

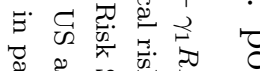

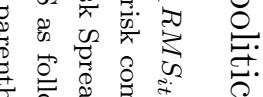

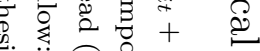

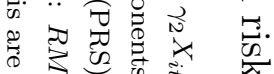
की कर

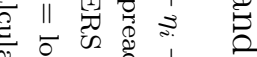

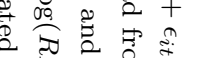

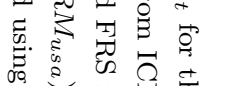
¿ 1 त्ठ

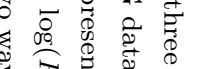

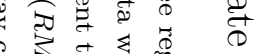

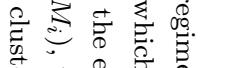

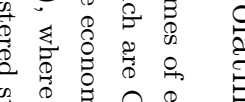

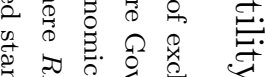
एँ है है

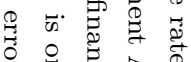
के है

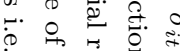

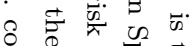

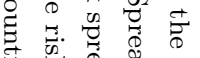

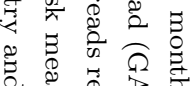

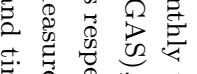
अ 象还

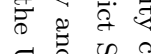

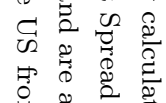
药

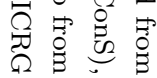




\section{Bibliography}

Aggarwal, R., Inclan, C. \& Leal, R. (1999), 'Volatility in emerging stock markets', Journal of Financial and Quantitative Analysis 34(1).

Arouri, M. E. H., Jawadi, F. \& Nguyen, D. K. (2010), The dynamics of emerging stock markets: empirical assessments and implications, Springer.

Bachman, D. (1992), 'The effect of political risk on the forward exchange bias: the case of elections', Journal of International Money and Finance 11(2), 208-219.

Baker, S. R., Bloom, N. \& Davis, S. J. (2013), 'Measuring economic policy uncertainty', Chicago Booth research paper (13-02).

Beaulieu, M., Cosset, J. \& Essaddam, N. (2006), 'Political uncertainty and stock market returns: evidence from the 1995 Quebec referendum', Canadian Journal of Economics/Revue canadienne d'économique 39(2), 621-642.

Bekaert, G. \& Harvey, C. R. (1997), 'Emerging equity market volatility', Journal of Financial economics 43(1), 29-77.

Bekaert, G., Harvey, C. R. \& Lundblad, C. (2005), 'Does financial liberalization spur growth?', Journal of Financial economics 77(1), 3-55.

Bekaert, G., Harvey, C. R., Lundblad, C. T. \& Siegel, S. (2014), 'Political risk spreads', Journal of International Business Studies 45(4), 471-493.

Belo, F., Gala, V. \& Li, J. (2011), Government spending, political cycles, and the cross-section of stock returns, Technical report, Working paper, University of Minnesota.

Berkman, H., Jacobsen, B. \& Lee, J. B. (2011), 'Time-varying rare disaster risk and stock returns', Journal of Financial Economics 101(2), 313-332.

Bernhard, W. \& Leblang, D. (2002), 'Democratic processes, political risk, and foreign exchange markets', American Journal of Political Science pp. 316333. 
Bilson, C., Brailsford, T. \& Hooper, V. (2002), 'The explanatory power of political risk in emerging markets', International Review of Financial Analysis 11(1), 1-27.

Bittlingmayer, G. (1998), 'Output, stock volatility, and political uncertainty in a natural experiment: Germany, 1880-1940', The Journal of Finance 53(6), 2243-2257.

Block, S. A. (2003), 'Political conditions and currency crises in emerging markets', Emerging Markets Review 4(3), 287-309.

Blomberg, S. B. \& Hess, G. D. (1997), 'Politics and exchange rate forecasts', Journal of International Economics 43(1), 189-205.

Boutchkova, M., Doshi, H., Durnev, A. \& Molchanov, A. (2012), 'Precarious politics and return volatility', Review of Financial Studies 24(4), 11111154 .

Breusch, T. S. \& Pagan, A. R. (1980), 'The lagrange multiplier test and its applications to model specification in econometrics', The Review of Economic Studies pp. 239-253.

Brewer, L. T. (1983), 'Political sources of risk in the international money markets: Conceptual, methodological, and interpretive refinements', Journal of International Business Studies pp. 161-164.

Brogaard, J., Dai, L., Ngo, P. T. \& Zhang, B. (2015), 'The world price of political uncertainty', Available at SSRN 2488820 .

Brogaard, J. \& Detzel, A. (2015), 'The asset-pricing implications of government economic policy uncertainty', Management Science 61(1), 3-18.

Brooks, R. D., Davidson, S. \& Faff, R. W. (1997), 'An examination of the effects of major political change on stock market volatility: the South African experience', Journal of International Financial Markets, Institutions and Money 7(3), 255-275.

Cahan, J., Malone, C. B., Powell, J. G. \& Choti, U. W. (2005), 'Stock market political cycles in a small, two-party democracy', Applied Economics Letters 12(12), 735-740.

Caldara, D. \& Iacoviello, M. (2016), 'Measuring geopolitical risk', Working Paper, Board of Governors of the Federal Reserve Board. .

Cermeño, R., Grier, R. \& Grier, K. (2010), 'Elections, exchange rates and reform in Latin America', Journal of Development Economics 92(2), 166-174. 
Chan, Y.-c., Chui, A. C. \& Kwok, C. C. (2001), 'The impact of salient political and economic news on the trading activity', Pacific-Basin Finance Journal $\mathbf{9}(3), 195-217$.

Chan, Y. \& John Wei, K. (1996), 'Political risk and stock price volatility: the case of Hong Kong', Pacific-Basin Finance Journal 4(2-3), 259-275.

Chen, D.-H., Bin, F.-S. \& Chen, C.-D. (2005), 'The impacts of political events on foreign institutional investors and stock returns: emerging market evidence from Taiwan', International Journal of Business 10(2).

Cosset, J.-C. \& De La Rianderie, B. D. (1985), 'Political risk and foreign exchange rates: An efficient-markets approach', Journal of International Business Studies pp. 21-55.

Cosset, J. \& Suret, J. (1995), 'Political risk and the benefits of international portfolio diversification', Journal of International Business Studies pp. 301-318.

Devereux, M. B. \& Lane, P. R. (2003), 'Understanding bilateral exchange rate volatility', Journal of International Economics 60(1), 109-132.

Diamonte, R., Liew, J. \& Stevens, R. (1996), 'Political risk in emerging and developed markets', Financial Analysts Journal pp. 71-76.

Dimic, N., Orlov, V. \& Piljak, V. (2015), 'The political risk factor in emerging, frontier, and developed stock markets', Finance Research Letters 15, 239245 .

Durnev, A. (2010), 'The real effects of political uncertainty: Elections and investment sensitivity to stock prices', Paris December 2010 Finance Meeting EUROFIDAI-AFFI .

Erb, C. B., Harvey, C. R. \& Viskanta, T. E. (1996), 'Political risk, economic risk, and financial risk', Financial Analysts Journal pp. 29-46.

Erb, C., Harvey, C. \& Viskanta, T. (1995), 'Country risk and global equity selection', The Journal of Portfolio Management 21(2), 74-83.

Errunza, V. R. \& Losq, E. (1987), 'How risky are emerging markets?', The Journal of Portfolio Management 14(1), 62-67.

Fama, E. F. \& French, K. R. (1993), 'Common risk factors in the returns on stocks and bonds', Journal of financial economics 33(1), 3-56.

Fama, E. F. \& French, K. R. (215), 'A five-factor asset pricing model', Journal of financial economics 116(1), 1-22. 
Filippou, I., Gozluklu, A. E. \& Taylor, M. P. (2015), 'Global political risk and currency momentum', Available at SSRN 2517400.

Fitzpatrick, M. (1983), 'The definition and assessment of political risk in international business: A review of the literature', Academy of Management Review pp. 249-254.

Fong, W. \& Koh, S. (2002), 'The political economy of volatility dynamics in the Hong Kong stock market', Asia-Pacific financial markets 9(3), 259-282.

Freeman, J. R., Hays, J. C. \& Stix, H. (2000), 'Democracy and markets: The case of exchange rates', American Journal of Political Science pp. 449-468.

Frijns, B., Tourani-Rad, A. \& Indriawan, I. (2012), 'Political crises and the stock market integration of emerging markets', Journal of Banking \& Finance 36(3), 644-653.

Ghose, T. (1988), 'How to analyse country risk', Asian Finance pp. 61-63.

Girard, E. \& Omran, M. (2007), 'What are the risks when investing in thin emerging equity markets: Evidence from the Arab world', Journal of International Financial Markets, Institutions and Money 17(1), 102-123.

Goriaev, A. \& Sonin, K. (2005), 'Is political risk company-specific? The market side of the Yukos Affair', EFA 2005 Moscow Meetings paper.

Hausman, J. A. (1978), 'Specification tests in econometrics', Econometrica: Journal of the Econometric Society pp. 1251-1271.

Hayes, N. (1998), 'Cross-border currents: Country risk revisited', Journal of Lending and Credit Risk Management 80, 61-61.

Hays, J. C., Freeman, J. R. \& Nesseth, H. (2003), 'Exchange rate volatility and democratization in emerging market countries', International Studies Quarterly 47(2), 203-228.

Herbst, A. \& Slinkman, C. (1984), 'Political-economic cycles in the US stock market', Financial Analysts Journal pp. 38-44.

Hoti, S. (2005), 'Modelling country spillover effects in country risk ratings', Emerging Markets Review 6(4), 324-345.

Hoti, S. \& McAleer, M. (2005), Modelling the riskiness in country risk ratings, Vol. 273, Elsevier.

Howell, L. D. (2001), Political Risk Assessment: Concept, Method, and Management, Political Risk Services. 
Howell, L. D. \& Chaddick, B. (1994), 'Models of political risk for foreign investment and trade: an assessment of three approaches', The Columbia Journal of World Business 29(3), 70-91.

Huang, T., Wu, F., Yu, J. \& Zhang, B. (2015a), 'International political risk and government bond pricing', Journal of Banking \& Finance 55, 393-405.

Huang, T., Wu, F., Yu, J. \& Zhang, B. (2015b), 'Political risk and dividend policy: evidence from international political crises', Journal of International Business Studies .

Hurwitz, L. (1973), 'Contemporary approaches to political stability', Comparative Politics 5(3), 449-463.

Isard, P. (1995), Exchange rate economics, Cambridge University Press.

Julio, B. \& Yook, Y. (2012), 'Political uncertainty and corporate investment cycles', The Journal of Finance 67(1), 45-83.

Kabir Hassan, M., Maroney, N., Monir El-Sady, H. \& Telfah, A. (2003), 'Country risk and stock market volatility, predictability, and diversification in the Middle East and Africa', Economic Systems 27(1), 63-82.

Kelly, B., Pástor, L. \& Veronesi, P. (2016), 'The price of political uncertainty: Theory and evidence from the option market', The Journal of Finance.

Kim, H. Y. \& Mei, J. P. (2001), 'What makes the stock market jump? an analysis of political risk on Hong Kong stock returns', Journal of International Money and Finance 20(7), 1003-1016.

Kobrin, S. J. (1979), 'Political risk: A review and reconsideration', Journal of International Business Studies pp. 67-80.

Krol, R. (2014), 'Economic policy uncertainty and exchange rate volatility', International Finance 17(2), 241-256.

Lam, S. S. \& Zhang, W. (2014), 'Does policy uncertainty matter for international equity markets?', Available at SSRN 2297133.

Leblang, D. \& Bernhard, W. (2006), 'Parliamentary politics and foreign exchange markets: the world according to GARCH', International Studies Quarterly 50(1), 69-92.

Leblang, D. \& Mukherjee, B. (2005), 'Government partisanship, elections, and the stock market: examining American and British stock returns, 19302000', American Journal of Political Science 49(4), 780-802. 
Lehkonen, H. \& Heimonen, K. (2015), Democracy, political risks and stock market performance, Vol. 59, Elsevier, pp. 77-99.

Li, J. \& Born, J. A. (2006), 'Presidential election uncertainty and common stock returns in the United States', Journal of Financial Research 29(4), 609622 .

Lin, C. \& Wang, Y. (2005), 'An analysis of political changes on Nikkei 225 stock returns and volatilities', Annals of Economics and Finance 6(1), 169.

Liu, L.-G. \& Pauwels, L. L. (2012), 'Do external political pressures affect the Renminbi exchange rate?', Journal of International Money and Finance 31(6), 1800-1818.

Lobo, B. J. \& Tufte, D. (1998), 'Exchange rate volatility: Does politics matter?', Journal of Macroeconomics 20(2), 351-365.

Lugovskyy, J. (2012), Political risk: Estimating the risk premium of political regime change, Technical report, Working paper, University of Kansas.

Malone, C., Anderson, H. \& Peng, C. (2015), 'Firm size and the political cycle premium', Managerial Finance 41(10), 1077-1095.

Mehdian, S., Nas, T. \& Perry, M. J. (2008), 'An examination of investor reaction to unexpected political and economic events in Turkey', Global Finance Journal 18(3), 337-350.

Mei, J. \& Guo, L. (2004), 'Political uncertainty, financial crisis and market volatility', European Financial Management 10(4), 639-657.

Menkhoff, L., Sarno, L., Schmeling, M. \& Schrimpf, A. (2012), 'Currency momentum strategies', Journal of Financial Economics 106(3), 660-684.

Nelson, D. (1991), 'Conditional heteroskedasticity in asset returns: a new approach', Econometrica 59(2), 347-370.

Niederhoffer, V., Gibbs, S. \& Bullock, J. (1970), 'Presidential elections and the stock market', Financial Analysts Journal pp. 111-113.

Pantzalis, C., Stangeland, D. \& Turtle, H. (2000), 'Political elections and the resolution of uncertainty: the international evidence', Journal of banking Ef finance 24(10), 1575-1604.

Pástor, L. \& Veronesi, P. (2012), 'Uncertainty about government policy and stock prices', The Journal of Finance 67(4), 1219-1264. 
Pástor, L. \& Veronesi, P. (2013), 'Political uncertainty and risk premia', Journal of Financial Economics 110(3), 520-545.

Ramcharran, H. (2003), 'Estimating the impact of risks on emerging equity market performance: further evidence on data from rating agencies', Multinational Business Review 11(3), 77-90.

Reinhart, C. M. \& Rogoff, K. S. (2002), The modern history of exchange rate arrangements: a reinterpretation, Technical report, National Bureau of Economic Research.

Robock, S. (1971), 'Political risk: Identification and assessment', Columbia Journal of World Business 6(4), 6-20.

Root, F. R. (1972), 'Analyzing political risks in international business', The multinational enterprise in transition pp. 345-365.

Salisbury, B. (1992), An analysis of political risk models, Technical report, Thunderbird mimeo.

Schnabl, G. (2008), 'Exchange rate volatility and growth in small open economies at the emu periphery', Economic Systems 32(1), 70-91.

Shanmugam, B. (1990), 'Evaluation of political risk', Bourke, P. and Shanmugam, B.,(1990) An Introduction to Bank Lending, Addison-Wesley Business Series, Sydney .

Simon, J. (1982), 'Political risk assessment: Past trends and future prospects', Columbia Journal of World Business 17(3), 62-71.

Siokis, F. \& Kapopoulos, P. (2003), 'Electoral management, political risk and exchange rate dynamics: the Greek experience', Applied Financial Economics 13(4), 279-285.

Siokis, F. \& Kapopoulos, P. (2007), 'Parties, elections and stock market volatility: evidence from a small open economy', Economics $\&$ Politics 19(1), 123-134.

Suleman, M. T. (2012), 'Stock market reaction to good and bad political news', Asian Journal of Finance and Accounting 4(1), 299-312.

Suleman, M. T. \& Daglish, T. C. (2015), 'Political uncertainty in developed and emerging markets', Available at SSRN 2647888.

Taylor, C. \& Jodice, D. (1983), 'World handbook of social and political indicators', New Haven. 
Vuchelen, J. (2003), 'Electoral systems and the effects of political events on the stock market: the Belgian case', Economics \& Politics 15(1), 85-102.

Wang, Y.-H. \& Lin, C.-T. (2009), 'The political uncertainty and stock market behavior in emerging democracy: the case of Taiwan', Quality $\&$ Quantity 43(2), 237-248. 